\title{
Urea and nickel utilization in marine cyanobacteria as evaluated by incubation, proteomic, and uptake techniques
}

\author{
By \\ Tyler Jay Goepfert \\ B.S., Cornell University, 2003 \\ M.Sc., Oldenburg University, 2010 \\ Submitted in partial fulfillment of the requirements of the degree of \\ Master of Science \\ at the \\ MASSACHUSETTS INSTITUTE OF TECHNOLOGY \\ and the \\ WOODS HOLE OCEANOGRAPHIC INSTITUTION \\ June 2013 \\ (C)2013 Tyler Jay Goepfert \\ All rights reserved.
}

The author hereby grants MIT and WHOI permission to reproduce and to publicly distribute paper and electronic copies of this thesis document in whole or in part in any medium now known or hereafter created.

Author:

Joint Program in Chemical Oceanography

Massachusetts Institute of Technology

and Woods Hole Oceanographic Institution

May 2013

Certified by:

Dr. Mak Saito

Associate Scientist, Marine Chemistry and Geochemistry

Thesis Supervisor

Accepted by:

Dr. Bernhard Peucker-Ehrenbrink

Senior Scientist, Marine Chemistry and Geochemistry

Chair, Joint Committee for Chemical Oceanography 


\section{Acknowledgements}

Thanks first to Mak Saito, my advisor and friend going on a decade now. I could not have enjoyed such success and numerous adventures around the world without your guidance and generosity, thank you Mak. My committee, Carl Lamborg, John Waterbury, and Mick Follows have been very helpful as I composed this thesis - thanks for your enthusiasm and willingness to come onboard. Dawn Moran was a welcome support throughout all field work and ashore; for incubations, microscopy, and more than I can recount, thanks. Matt McIlvin was instrumental throughout proteomic evaluations especially in running the proteomics mass spectrometers and together with Scot Birdwhistell the ICP-MS. Thanks to Anton Post who generously sequenced the Synechococcus (WH8020) genome. Joe Jennings performed the nutrient analysis from both cruises. UC Davis SIF ran the elemental analysis, thanks to Dr. Joy Matthews and Mary Anne Soriano for the rapid processing of those samples. For support at sea, my gratitude to: captain and crew of the Melville as well as Daniel Tabersky on the MV1015 cruise with chief scientist Dan Repeta and captain and crew of the Kilo Moana for the KM1128 cruise with co-chief scientists Mak Saito and Carl Lamborg. Tristan Kading and my current labmates, Kate Mackey, Nick Hawco, and David Wang all were supportive through conversations in both the field and the lab which contributed greatly to the overall success of this work. Past labmates: Anne Thompson, Abigail Noble, Erin Bertrand, Alysia Cox, and Chad Hammerschmidt; all gave inspiration to pursue science at WHOI. The Academic Programs office and my fellow chemistry cohort also have my gratitude for years of guidance and friendship. Thanks to my dear friends, Glenway, Bill, Tine, and Bea for pulling me away to "family tennis" and other necessary distractions. Of course my heartfelt gratitude is extended also to family and friends outside of the WHOI community, particularly mom, dad, Lisa, Nathan and Sandra. I love you all. 
I am grateful for funding of our lab by The Gordon and Betty Moore Foundation, the Center for Microbial Oceanography: Research and Education (C-MORE), "Metzyme" (KM1128) by NSF Division of Ocean Sciences (OCE-1031271) and "BiG RAPA" (MV1015) by NSF (DBI-0424599).

This master of science thesis has been examined by a committee from the Wood Hole Oceanographic Institution and the Massachusetts Institute of Technology:

\author{
Mak Saito \\ Associate Scientist in Marine Chemistry and Geochemistry \\ Woods Hole Oceanographic Institution \\ Advisor and Committee Chair \\ Carl Lamborg \\ Associate Scientist in Marine Chemistry and Geochemistry \\ Woods Hole Oceanographic Institution \\ John Waterbury \\ Scientist Emeritus in Biology \\ Woods Hole Oceanographic Institution \\ Michael J. Follows \\ Senior Research Scientist in Earth, Atmospheric and Planetary Science \\ Massachusetts Institute of Technology
}




\begin{abstract}
Nitrogen and trace metal biogeochemical effects on phytoplankton productivity were compared through whole water bottle incubations and proteomic evaluation of in situ harvested particulate matter from two distinct oceanographic regions: the Equatorial Pacific Upwelling and the South Pacific Gyre. Phytoplankton growth in both regions was stimulated by nitrogen additions with equivalent response from nitrate and urea. In the gyre, trace metal additions did not yield a chlorophyll response, however nickel treatments showed evidence of nickel-limited nitrogen fixation. In contrast, cell growth at the upwelling site was primarily iron-limited and iron plus urea or nitrate additions further enhanced the chlorophyll response, indicative of secondary nitrogen limitation. Nitrogen stress proteins and urea transporters from cyanobacteria in these field sites showed similar trends, with both increasing in waters containing lower dissolved inorganic nitrogen. Together with bottle incubations, the abundant urea transporters and nitrogen stress proteins indicate the importance of urea in these field sites. Representative cyanobacteria cultures (Synechococcus strain WH8020, and Prochlorococcus strain MED4) were evaluated to constrain urea uptake rates and explore the potential for compound specific uptake rates. Together, results from this study indicate that urea may represent an under-recognized component of the marine microbial nitrogen cycle.
\end{abstract}

\title{
Introduction
}

In any ecosystem where either macro or micro nutrients are limited in supply the biological productivity or species composition may be affected. In the open ocean the macronutrient nitrogen and the micronutrient iron are an especially important nutrient pair that controls primary production and species composition. Different chemical forms such as reduced/oxidized or organic/inorganic species also affect the use of these elements within ecosystem processes. The marine microbial community is influenced by, but also has feedback on nutrient inventories. Understanding interactions among nutrient resources as well as between particulate and dissolved phases improves understanding of the non-steady-state ocean and anthropogenic influences (Arrigo 2005). 
The importance of iron on a global scale and with reference to climate became apparent a few decades ago (Martin and Fitzwater 1988), but we continue to learn more about its sources, sinks, bioavailability and the implications of iron limitation or sufficiency. Iron is the metal co-factor of numerous metalloproteins involved in fundamental biochemical processes including photosynthesis and nitrogen fixation (Morel et al. 2003). The implications of iron's central role in energy supply and nitrogen acquisition are that in areas of low iron availability primary production can be limited.

Similar to iron, dissolved nickel concentrations are depleted in the surface ocean by microbes that use nickel-containing enzymes including urease and superoxide dismutase (SOD), among others (Mulrooney and Hausinger 2003). Although urease can function with manganese and cobalt (Carter et al. 2009) it is mainly recognized as a nickel containing enzyme (Watt and Ludden 1999). Urease involvement in the ornithine cycle results in a constitutive use of this enzyme (Nunn et al. 2009; Allen et al. 2011) making nickel an essential nutrient for many phytoplankton. Dupont et al. (2008) demonstrated the importance of nickel to marine Synechococcus owing to both urease and nickel-SOD (NiSOD). NiSOD is associated with nitrogen fixation as it protects nitrogenase from superoxide inhibition as shown in the non-heterocyst diazotroph, Trichodesmium by Ho (2013). Together, urease and NiSOD demonstrate the importance and utility of nickel to marine microbes. Nickel, iron and other bioactive trace metals are key to understanding global biogeochemical cycles. Efforts to map the global distributions of dissolved and particulate trace metals is progressing especially with the recent international GEOTRACES field expedition results (Bishop et al. 2012; Boyle et al. 2012; Noble et al. 
2012; Rousseau et al. 2013; Butler et al. 2013; Twining and Baines 2013; Kondo and Moffett 2013). Expanding surveys of trace metals allow more detailed investigation on the relationship between primary, secondary, and colimiting nutrients (Arrigo 2005; Moore et al. 2013).

Where multiple nutrients simultaneously impose growth limiting effects on a system there can be several modes of colimitation as described by Saito et al. (2008). Such nuanced synergistic and antagonistic effects are common among and between trace metals (Bruland et al. 1991) and nitrogen species (Price and Morel 1991). Nitrogen and iron limitations can be coupled as for example in iron enzymes used for nitrogen fixation (Saito et al. 2011a). Iron, nickel, copper, and molybdenum are extensively involved in nitrogen metabolism (Morel et al. 2003; Morel and Price 2003) though much of the ocean is limited primarily by nitrogen and iron (Moore et al. 2013). Biological response after large ocean iron fertilization was investigated during the IronEx-I and PlumEx voyages in the Equatorial Pacific (Gordon et al. 1998) and more recently in the eastern Equatorial Pacific (Landry and Constantinou 2000). More than a decade of mesoscale iron enrichment experiments have been reviewed by Boyd et al. (2007). Often during these and similar field studies, nutrient enrichment bottle incubation experiments have been performed and categorized for primary and less often for secondary nutrient limitations as well as colimitation scenarios (Moore et al. 2013). Relatively few studies exist in the central Equatorial Pacific and within the South Pacific Gyre and characterization of secondary limitation and colimitation features are rare. These study sites represent 
contrasting nutrient regimes with respect to nitrogen and phosphorus macronutrients and are also informative test sites to compare iron limitation effects.

Regional macro nutrients of relatively high concentrations (typically $>\mu \mathrm{M}$ ) stand in contrast to the trace metals and micronutrients (typically $<\mathrm{nM}$ ). The macronutrients often serve as indicators for the primary productivity potential of an oceanographic site, although trace nutrients may preclude maximum utilization of macronutrients.

Macronutrients are methodologically more accessible than many trace nutrients, resulting in the current disproportionate characterization of global macronutrient distribution as compared with trace metals for example. Chief among the macro nutrients are nitrogen and phosphorus, or more specifically nitrate $\left(\mathrm{NO}_{3}{ }^{-}\right)$and phosphate $\left(\mathrm{PO}_{4}{ }^{3-}\right)$ concentrations. In the open ocean nitrogen and phosphorus nutrients are relatively low in abundance as compared to coastal systems. The growth limiting effects of these two macro nutrients have been argued in particular because nitrogen can be biologically fixed from the abundant atmospheric dinitrogen reservoir by diazotrophs. Nitrogen fixation requires the trace metal nutrient iron, which limits production in about a third of the world ocean (Boyd et al. 2007). In practical physiological and ecological timescales from days to months nitrogen is the limiting macronutrient in most marine geographies (Moore et al. 2008).

Concentrations of inorganic nitrogen species (nitrate, nitrite, ammonium) and phosphate are routine field measurements. However dissolved organic nitrogen and phosphorus pools are being increasingly considered, particularly for their role in horizontal transport to gyres and subsequent export production (Torres-Valdés et al. 
2009). Urea is a nitrogen-rich organic molecule readily hydrolyzed to ammonia through the typically constitutive enzyme, urease (McCarthy 1972; Fan et al. 2003; Allen et al. 2011). Consequently, although urea is perhaps $10 \%$ or less of the dissolved organic nitrogen pool (Bronk 2002), it may still be a significant fraction of the easily accessible nitrogen for phytoplankton, especially in nitrate depleted oligotrophic waters where uptake rates for urea and nitrate can be of similar magnitude (Mackey et al. 2011). Even in a high nutrient low chlorophyll region urea appears to be important; for 15 depths across three stations in the Southern Ocean Antarctic zone (poleward of the polar front), the relative rate of urea uptake (molar basis urea-nitrogen to total nitrogen uptake rates) was shown to be $>20 \%$ in all except one depth (minimum 11\%, maximum $69 \%$ average 34\%, standard deviation 14\%) (Joubert et al. 2011). In more coastal areas all nitrogen species are typically higher, yet the proportion of urea uptake rate to total nitrogen uptake is typically $>20 \%$ (McCarthy 1972; Harrison et al. 1985; Joubert et al. 2011) and urea concentrations have been linked to harmful algal blooms together with increasing global production and application of urea products, especially fertilizers (Glibert et al. 2006).

Urea may be an under-recognized component of bioavailable nitrogen supply for primary production (Wafar et al. 1995) and in the microbial loop as well (Cho and Azam 1995; Alonso-Sáez et al. 2012). Sources of urea include hydrolyzed arginine, and excretion by zooplankton and other animals (Wada and Hattori 1991), with increasing anthropogenic inputs from land runoff over recent decades (Glibert et al. 2006). Subsequent horizontal transport may deliver urea to gyres as a fraction of the dissolved organic nitrogen (Torres-Valdés et al. 2009). Biological sinks of urea include the 
ubiquitous cyanobacteria Prochlorococcus which is shown to be a dominant consumer of organic nitrogen in the South Atlantic gyre (Zubkov et al. 2004) and oligotrophic and mesotrophic portions of the Arabian Sea (Zubkov and Fuchs 2003). Prochlorococcus lacks the genes for nitrate uptake and reduction, and grows poorly with nitrite, however it grows well with ammonium and urea as nitrogen sources (Moore et al. 2002b). Consequently, Prochlorococcus may be an important sink for urea and close balance of urea sources and sinks may lead to little accumulation of dissolved urea concentrations in the ocean. To date spatial coverage of urea concentrations over the globe are limited and range from below the detection limit of $0.025 \mu \mathrm{M}$ (DeManche et al. 1973), up to low micromolar $(\sim 2.5 \mu \mathrm{M})$ in the open ocean (Bronk 2002), and higher $(>5 \mu \mathrm{M})$ in coastal areas (Remsen 1971). In the open ocean, urea and ammonium concentrations are generally expected to be comparable in concentration (Wada and Hattori 1991), though few measurements are available. On a longer timescale, nitrogen species may be increasing through anthropogenic inputs for example by the Haber-Bosch process using fossil fuel to fix atmospheric dinitrogen into urea and ammonia fertilizers for agricultural application (Glibert et al. 2006; Canfield et al. 2010).

Though spatial and temporal information on the distribution of urea are limited, its role in biological systems is appreciated, with environmental uptake rates reported from 0.5-2.6 nM N L$~ L^{-1} \mathrm{~h}^{-1}$ in oceanic environments and above $300 \mathrm{nM} \mathrm{N} \mathrm{L}^{-1} \mathrm{~h}^{-1}$ in more coastal areas (Berman and Bronk 2003). Especially in diatoms, urea is of metabolic significance (Allen et al. 2011) and growth on urea is often comparable if not better than with nitrate or ammonia both for diatoms (Carpenter et al. 1972) and cyanobacteria (Zubkov and 
Fuchs 2003; Casey et al. 2007). Uptake rates for various nitrogen compounds indicate mutual interferences of oxidized and reduced nitrogen species, and urea is often shown to be the preferred nitrogen source since it can inhibit uptake of concurrent alternative nitrogen substrates (Lund 1987). In fact, urea uptake rates in the western Sargasso Sea have been estimated to be near the maximum potential (Price and Harrison 1988a) and dual stable isotope $\left({ }^{14} \mathrm{C}\right.$ - and ${ }^{15} \mathrm{~N}$-urea $)$ labeling experiments in the Arctic Ocean show that urea-carbon is respired as $\mathrm{CO}_{2}$, while most of the urea-nitrogen is incorporated by phytoplankton (Harrison et al. 1985). Culture experiments with the diatom Thalassiosira pseudonana revealed that significant portions of urea-nitrogen taken up may be released back to the environment as ammonia followed by rapid reabsorption (Price and Harrison 1988b). In both coastal and open ocean regimes urea uptake typically accounts for a third of the total nitrogen uptake (McCarthy 1972; Price and Harrison 1988a). Recent nonsaturating stable isotope tracer studies demonstrate that urea is likely to be the first nitrogen species depleted by plankton in nitrogen limited waters (Gandhi et al. 2011). Evidence of urea uptake capability can be observed in metagenomic data as cyanobacterial urea transporter genes appear frequently in the Community Cyberinfrastructure for Advanced Microbial Ecology Research and Analysis (CAMERA) global metagenomic database (http://camera.calit2.net/). Consequently ubiquitous Prochlorococcus and Synechococcus are important species to investigate with respect to the role of urea in the nitrogen cycle.

In oligotrophic waters, Prochlorococcus is a notable contributor to primary production. Organic nitrogen assimilation in the Arabian Sea by Prochlorococcus gives 
these cyanobacteria a competitive advantage (Zubkov and Fuchs 2003), and evidence from the Sargasso Sea shows cyanobacteria may even favor assimilation of labile organic molecules, particularly urea (Casey et al. 2007). Across an extensive meridional transect of the Atlantic ocean, a statistically significant correlation was upheld for Prochlorococcus abundance against urea uptake $\left(\mathrm{r}^{2}=0.83\right)$ as well as standing stocks of urea $\left(\mathrm{r}^{2}=0.78\right)$ with $\mathrm{p}<0.01$ (Painter et al. 2008). The urea uptake and Prochlorococcus abundance correlation appears to peak around the Equatorial Atlantic Upwelling (Painter et al. 2008).

Compared to Prochlorococcus, there appears to be relatively fewer published studies on the role of urea and urea uptake in Synechococcus, however Synechococcus strains grow well with urea as the sole nitrogen source (Collier et al. 1999). Genomic evidence shows that the cytoplasmic soluble nickel-containing urease is common in cyanobacteria and with low environmental urea concentrations it is suggested by Collier et al. (1999) that a high-affinity urea transport system should exist. However, urease is also noted as a constitutive enzyme and internal cycling of urea can be independent from assimilation of external urea for phytoplankton nutrition (Valladares et al. 2002; Dupont et al. 2008; Nunn et al. 2009; Allen et al. 2011), even for a diatom strain of Cyclotella when grown on nitrate in the absence of urea (Oliveira and Antia 1986). Genomic and transcriptomic tools have brought new insight into the importance of urea. Following genomic insights there is potential now to investigate nitrogen and cyanobacterial dynamics with proteomics in lab culture and in field metaproteomics. 
Proteomics considers the expressed biochemical output encoded in a particular genome (single species), while metaproteomics aims to understand proteins from a mixed community as in natural ecosystems. Having proteomic information informs not just on biological potential (genome), or expression (transcriptome), but on assembled proteins (proteome). Proteomics complements the other "omic" studies with both relative abundance (global) proteomic evaluations and targeted or quantitative assessments of particular protein(s) of interest using labeled peptide standards to calibrate for quantitation. Traditional bottle incubations as well as proteomic methods are applied to contrasting field sites in this study. The Eastern Equatorial Pacific is an iron limited ecosystem where iron addition stimulates phytoplankton and zooplankton (Landry and Constantinou 2000; Oliver et al. 2004). This iron limitation in a high nutrient low chlorophyll area (HNLC) can have especially strong implications for diatoms as demonstrated in several HNLC regions of the Pacific (Bruland et al. 2001, 2005). In contrast, the northeastern rim of the South Pacific Gyre is a downwelling site where nitrogen deficiency is pronounced. Together these two regions present extensive ecosystems where trace metals like iron and reduced nitrogen compounds such as urea can affect the regional biogeochemistry. More broadly, trace elements and alternative nitrogen sources affect plankton physiology and studies on this subject improve our ability to model biogeochemistry in a changing ocean (Follows and Dutkiewicz 2011). 


\section{Methods}

\section{Field incubations and water sampling:}

Bottle incubations were performed during two cruises in the Pacific Ocean; MV1015 was a zonal cruise through the South Pacific Gyre from Arica, Chile to Easter Island in November-December, 2010, while KM1128 was a meridional cruise from Hawaii to Samoa in October, 2011. Incubations were performed in the eastern side of the South Pacific Gyre $\left(271^{\circ} \mathrm{E},-23^{\circ} \mathrm{N}\right)$ on $\mathrm{MV} 1015$ and at the equator $\left(202^{\circ} \mathrm{E}, 0^{\circ} \mathrm{N}\right)$ during KM1128 (Figure 1). Whole seawater was collected from a SBE rosette with a CTD extension stand fitted with a SeaCAT profiler CTD SBE19plus V2 (Sea-bird Electronics, Inc.) to obtain conductivity, temperature, and depth data along with a WET labs® combination turbidity and fluorometry sensor. This CTD and water sampler was dedicated to trace metal sampling in 24 external spring niskin bottles, $8 \mathrm{~L}$ each (OceanTest Equipment, Inc.). Water was collected from the chlorophyll maximum at local time $1330 \mathrm{~h}$ in the gyre site and $0930 \mathrm{~h}$ in the Equatorial Pacific Upwelling site and used to fill triplicate biological replicates for all treatments and control samples. Ultrahigh purity nitrogen gas was plumbed to the headspace of niskin bottles at $25 \mathrm{kPa}$ to expel seawater. All handling was done in a positive pressure HEPA filtered clean bubble and all bottles and fluid handling equipment were extensively cleaned first with a minimum 2-day soak in detergent (1\% Citranox), rinsed thoroughly with Milli-Q ${ }^{\mathrm{TM}}$ water (>18 M $\Omega$ ), and at least 3-day soak in 10\% HCL (Baker Instra-analyzed), with three final rinses of $\mathrm{pH} 2$ Milli- $\mathrm{Q}^{\mathrm{TM}}$ water prior to use. Nutrient amendments were made according 
to Table 1 using metal stocks adjusted to $\mathrm{pH} 2$ with SeaStar $\mathrm{HCl}$. Nutrient additions were small volumes and did not affect the final seawater $\mathrm{pH}$. After amendments, the bottles were placed together in one deckboard incubator with flow-through surface seawater to maintain temperature near ambient sea surface temperature. Light was held at approximately $50 \%$ of incident solar radiation by blue tinted Plexiglas. After 6 and 3 days for the gyre and upwelling sites respectively, the incubations were harvested with samples taken from each bottle for: (1) chlorophyll $a$ measurements via gentle filtration $(<35 \mathrm{kPa})$ onto GFF filters and subsequent freezing and storage at $-80^{\circ} \mathrm{C}$ until extraction and analysis ashore (cold acetone $90 \%$, overnight $-20^{\circ} \mathrm{C}$ ), and (2) nutrient analysis (samples frozen and later processed ashore by Oregon State Nutrient Analysis Facility). Detection limits for nutrient analysis are as follows: phosphate, $0.01 \mu \mathrm{M}$; silicic acid, $0.41 \mu \mathrm{M}$; nitrate+nitrite $(\mathrm{N}+\mathrm{N}), 0.11 \mu \mathrm{M}$; nitrite, $0.01 \mu \mathrm{M}$; and ammonium, $0.02 \mu \mathrm{M}$. Dissolved iron was evaluated by inductively coupled plasma mass spectrometry (Woods Hole Oceanographic Institution, ICP-MS facility) following a previously established magnesium precipitation method (Saito and Schneider 2006).

\section{Particulate metal and proteome biomass collection and processing:}

Sampling for a dissolved trace metal section was conducted across the entire transect of the KM1 128 cruise which traversed the Equatorial Pacific Upwelling. Procedures used were comparable to those previously described (Bruland et al. 2005), and individual filters (acid washed $47 \mathrm{~mm}, 0.2 \mu \mathrm{m}$ Supor $^{\mathrm{TM}}$ filter membranes) were saved for particulate elemental analysis by inductively coupled plasma mass spectrometry (Woods Hole 
Oceanographic Institution, ICP-MS facility) following a 3-hour, $90^{\circ} \mathrm{C}$ heated digest in $50 \%$ nitric acid including a $1 \mathrm{ppb}$ indium internal standard. Resulting values are operationally defined as biogenic particulate elements, focusing on trace metals.

During both cruises (gyre and upwelling regions), size fractionated biomass was collected on 53, 3, and $0.2 \mu \mathrm{m}$ filters using modified large-volume McLANE® pumps fitted with either 8 or $4 \mathrm{~L} \mathrm{~m}^{-1}$ drives (note that results presented here are from the $0.2 \mu \mathrm{m}$ filter samples only). Biomass was collected from volumes on order of 100-500 L pumped in situ for a given sample depth and these filters were subsequently processed in a HEPA filtered positive pressure clean bubble. One quarter section slices allocated for proteomic assessment were preserved with RNALater (Saito et al. 2011b) and stored at $-80^{\circ} \mathrm{C}$. Once ashore, the RNALater fraction was removed and washed with 0.1 M TRIS buffer and concentrated to $200 \mu \mathrm{L}$ on a $5 \mathrm{k}$ MWCO Vivaspin filter unit centrifuged at 4,000 rpm for 1 hour. The resulting washed concentrate was reunited with its filter slice and extracted as follows: each one-quarter filer section was resuspended in $8 \mathrm{~mL}$ of SDS-lysis buffer (1\% SDS in $0.1 \mathrm{M}$ Tris $/ \mathrm{HCl}, \mathrm{pH} 7.5,10 \mathrm{mM}$ EDTA), heated to $95^{\circ} \mathrm{C}$ for $10 \mathrm{~m}$, incubated at room temperature while shaking for $1 \mathrm{~h}$, then spun $30 \mathrm{~m}$ at $4,000 \mathrm{rpm}$. The supernatant was then removed and filtered through a $5 \mu \mathrm{m}$ syringe filter and concentrated down to $300 \mu \mathrm{L}$ by Vivaspin at $4,000 \mathrm{rpm}$ for $4 \mathrm{~h}$, then washed again with SDS-lysis buffer using a Vivaspin filter for one final concentration to $300 \mu \mathrm{L}$ and subsequently precipitated for $3 \mathrm{~d}$ with $0.5 \mathrm{mM} \mathrm{HCl}$ in 50:50 MeOH:Acetone. The pellet was spun down and resuspended in Lysis buffer and protein quantified via BioRad DC Protein assay. Before targeted proteomic analysis a portion of this extract was digested by 
tube gel digest according to a previously published protocol (Lu and Zhu 2005) with minor modifications.

\section{Lab culture maintenance and preparation:}

Axenic cultures of Synechococcus (strain WH8020 isolated from oceanic water near the eastern USA at $38^{\circ} 40.7^{\prime} \mathrm{N}, 6^{\circ} 19^{\prime} \mathrm{W}$ ), and Prochlorococcus (strain MED4 isolated from the Mediterranean Sea) were used and verified clean by a marine purity test broth solution to screen for heterotrophic contamination. Maintenance cultures were grown in an incubation chamber held at $20^{\circ} \mathrm{C}$ with constant light provided at $20 \mu \mathrm{mol} \mathrm{Q} \mathrm{m} \mathrm{m}^{-2}$ for both Synechococcus and Prochlorococcus. Media for culture work was a modified SN medium (Waterbury et al. 1986) with filter-sterilized nutrient amendments made into precooled microwave-sterilized (Keller et al. 1988) seawater for final added concentrations as noted in Table 2 . The seawater base was always $25 \%$ Milli- $\mathrm{Q}^{\mathrm{TM}}$ water with the remaining $75 \%$ being oligotrophic surface seawater collected from the South Pacific Gyre (MV1015 cruise). Cultures were previously adapted through several generations to growth on urea as the sole added nitrogen source. Prior to the uptake experiment, sequential batch cultures were scaled up to $1 \mathrm{~L}$ volumes while tracking the growth characteristics in order to time the uptake experiment in the optimal exponential growth period. Growth rates were calculated as the slope for the linear portion of natural log transformed fluorescence values versus time (log-linear plots). Throughout culture work, raw fluorescence and $F_{v} / F_{m}$ were monitored with a Satlantic FIRe system (450 nm blue LED excitation source, $678 \mathrm{~nm}$ emission filter, calibrated with roseB standard and 
manually adjusted gain). Stable and optimal $\mathrm{F}_{\mathrm{v}} / \mathrm{F}_{\mathrm{m}}$ values (photosynthetic efficiency) were a proxy for culture health $\left(\mathrm{F}_{\mathrm{v}} / \mathrm{F}_{\mathrm{m}}\right.$ declines in concert with transition out of loggrowth phase) and provided assurance that cultures were in good health throughout the experiment.

At least three successive transfers were made during exponential growth prior to any experiment and experiments were started from cultures in mid-exponential growth phase as determined from fluorescence growth curves. Cells were prepared for the uptake experiments by centrifugation and decanting $(30,074 \times \mathrm{g}$ in a Beckman J2-21M centrifuge), three washes with urea-free seawater (centrifuged and decanted each time), and a concentrated resuspension was finally prepared by gentle pipetting motion with serological pipettes to homogenize the cell pellets. The homogenized cell concentrate was used to inoculate final volumes of $25 \mathrm{~mL}$ in polycarbonate centrifuge tubes with growth medium containing isotopically labeled urea for subsequent incubation at the same culture conditions described for maintenance cultures.

\section{Lab culture uptake experiments:}

Several experiments were performed, each done simultaneously with both cyanobacteria strains. First a time course uptake experiment was made with ${ }^{13} \mathrm{C},{ }^{15} \mathrm{~N}$ labled urea at $1.0 \mathrm{mM}$, sampling at 0-, 1-, 2-, 4-, 6-, 10- and 24-h time points to evaluate the characteristics of the nitrogen assimilation curve at acclimated culture conditions. Then, a short-term (4-h) urea uptake experiment was made to evaluate the anticipated Michaelis-Menten curve across a concentration range $(0.01,0.03,0.10,0.30,1.0,3.0$ 
$\mathrm{mM}$ ) in triplicate for the $1.0 \mathrm{mM}$ data and otherwise singleton. The 4-h uptake experiment was run separately with single- and double-labeled urea, enriched to 98 atom $\%{ }^{13} \mathrm{C}$ and $99 ; 98$ atom $\%{ }^{13} \mathrm{C} ;{ }^{15} \mathrm{~N}$ respectively. The double-label urea served as a nitrogen source for samples destined for elemental analysis while the single label was for cultures going toward subsequent proteomic analysis $\left({ }^{13} \mathrm{C}\right.$ would complicate downstream MS analysis). The $25 \mathrm{~mL}$ cultures were harvested in full either for elemental analysis performed by the University of California, Davis Stable Isotope Facility after filtration onto pre-combusted GFF filters $\left(8 \mathrm{~h}, 450^{\circ} \mathrm{C}\right)$, or for proteomics on centrifuge pelleted biomass (centrifugation as described for cell concentration).

Nitrogen uptake rates were calculated from initial and final particulate nitrogen concentrations and accompanying enrichment values using the following equations from Dugdale and Wilkerson (1986):

$$
\begin{aligned}
& \rho_{t}=\frac{c_{t}}{t} \times \frac{{ }^{15} N_{S}-\langle F\rangle}{15 N_{e n r}-\langle F\rangle} \\
& \rho_{0}=\frac{c_{0}}{t} \times \frac{{ }^{15} N_{S}-\langle F\rangle}{{ }^{15} N_{e n r}-{ }^{15} N_{S}}
\end{aligned}
$$

where, $c_{0}$ and $c_{t}$ are the concentration of particulate nitrogen at time zero and time t, respectively, $t$ is the duration of incubation, ${ }^{15} N_{s}$ and ${ }^{15} N_{\text {enr }}$ are the atom $\%$ of ${ }^{15} \mathrm{~N}$ in the sample and enrichment addition respectively. Since cells were washed and resuspended in labeled urea, the value of ${ }^{15} N_{\text {enr }}$ is $98 \%$. $\langle F\rangle$ is the natural abundance of ${ }^{15} \mathrm{~N}$ with a value of 0.366 atom $\%$ used here. Similar calculations for ${ }^{13} \mathrm{C}$ uptake were also made, and all uptake rates were normalized to the initial cell concentrations. Providing that the results of these equations are similar, it is advisable to take the average result of these 
equations because $\rho_{t}$ can underestimate and $\rho_{0}$ can overestimate the uptake rate. Average values are presented here and it is noted that $\rho_{0}$ generally exceeded $\rho_{t}$ by a factor of $1.6 \pm 0.08$ and $2.8 \pm 0.43$ (ave. $\pm \mathrm{std}, \mathrm{n}=12$ ) for Synechococcus and Prochlorococcus respectively.

Non-linear curve fitting determined Michaelis-Menten kinetic parameters $V_{\max }$ and $K_{m}$, according to the following equation:

$$
v=\frac{V_{\max } \times[S]}{K_{m}+[S]}
$$

Where $v$ is the urea uptake rate, $V_{\max }$ is the maximum uptake rate, $[S]$ is the substrate concentration (urea), and $K_{m}$ is the half saturation constant.

\section{Mass spectrometry sample preparation and analysis:}

For lab culture biomass, a soluble protein extraction method was used with subsequent trypsin digest by identical methods used for Crocosphaera watsonii biomass as described by Saito et al. (20011a). First-order proteomic evaluation used a Michrom ADVANCE source and Thermo LTQ ion trap mass spectrometer (method details in appended paper, section "Mass spectrometer evaluation and data analysis"). A Thermo Vantage TSQ Triple Quadrapole Mass Spectrometer was used for targeted proteomics using similar upstream LC as was described for LTQ. In brief, the LC methods were identical except for having different column length and flow rate as follows: $50 \times 0.2 \mathrm{~mm}$

on the TSQ at $4 \mu 1 \mathrm{~min}^{-1}$, and $150 \times 0.2 \mathrm{~mm}$ on the LTQ at $0.75 \mu 1 \mathrm{~min}^{-1}$. Field meta proteomics analysis used similar methods first applying global proteomics with the LTQ to discover peptides and then targeted proteomics with the TSQ and additional istopically 
labeled internal peptide standards to allow quantitative protein measurement (Saito et al., in prep; field manuscript is being prepared concurrently).

Method development for the protein biomarker and isotopic uptake assay made use of both the LTQ and TSQ. Preliminary LTQ global proteomics results from a given strain were grouped together and the relative abundance scores were summed to allow ranking of overall most abundant proteins identified. Protein or protein group assignment was partially automated through parsing from FASTA annotations and subsequent manual evaluation (e.g. grouping protein IDs associated with a single photopigment). These methods were designed to allow for a first-order overview of the most abundant proteins and to identify potential peptide sequences to monitor for stable isotope incorporation in the same peptides to be measured with the TSQ. 


\section{Results}

\section{Field incubation studies:}

The south-eastern Pacific Gyre and Equatorial Pacific Upwelling study sites present ecosystems with different physical, chemical, and biological makeup (compared in Table 3). Temperature, macro-nutrients, and chlorophyll values are all highest at the equatorial upwelling site (KM1128, Station 5) compared with the north east rim of the South Pacific Gyre (MV1015, Station 4). Initial and control sample chlorophyll levels were consistent with relatively low annual average values expected in the gyre $(\sim 0.1$ $\left.\mu \mathrm{g} / \mathrm{L}^{-1}\right)$ and relatively high values in upwelling regions $\left(\sim 0.4 \mu \mathrm{g} / \mathrm{L}^{-1}\right.$, Figure 1$)$. Gyre station results display an increase in chlorophyll for all nitrogen amended cultures (nitrate or urea), while final chlorophyll values for all other treatments remained comparable to initial $\left(\mathrm{T}_{0}\right)$ and control samples (Figure 2$)$. A more complex result was seen in the equatorial upwelling incubation station; all treatments with added iron show increased final chlorophyll levels relative to the control and an additional but smaller increase was apparent with both iron and nitrogen (nitrate or urea) together (Figure 3). Moreover, where biological replicate variability was small, pairwise comparisons show statistical significance of nickel and urea stimulation over the control sample $(\mathrm{p}<0.2$, by t-tests: one-tailed, two-sample with unequal variance after Sidak's adjustment, inset of Figure 3). Urea and nickel together show the highest average chlorophyll $a$ of the non-iron treatments, however the result was not statistically different from the control with $\mathrm{p}<0.2$. 
Nutrient data corresponding to these incubations are consistent with the geography (e.g. higher ambient nitrogen and phosphorus in the equatorial upwelling station, Figure 4 and Figure 5). In the nitrogen limited gyre, all treatments with added nitrogen drew down phosphate by $15-20 \%$ over the control and time zero phosphate concentrations (Figure 4). In nitrate to phosphate drawdown ratios (N:P drawdown, Table 4), N-drawdown accounts only for the change in nitrate plus nitrite $(\mathrm{N}+\mathrm{N})$ concentrations between the initial and final values (it is not total $\mathrm{N}$ ). In the nitrate treatments the $\mathrm{N}: \mathrm{P}$ drawdown ratio is above the Redfield value of 16 (Redfield 1934), though this elevation is not statistically significant from 16. Urea also alleviated nitrogen limitation in the gyre and stimulated a slightly greater phosphate drawdown than nitrate additions. When urea was added in the gyre, nitrate plus nitrite $(\mathrm{N}+\mathrm{N})$ increased in the final measurements and resulted in negative $\mathrm{N}+\mathrm{N}$ drawdown for those treatments (Table 4 and Figure 6). Nickel addition also yielded a negative $\mathrm{N}+\mathrm{N}$ drawdown. These results contrast with the equatorial upwelling where iron was primarily limiting growth.

All iron additions in the Equatorial Pacific incubations led to large nutrient drawdown relative to the control for biological triplicate sample averages: $67-82 \%$ of phosphate, $84-100 \%$ of silicic acid, $51-99 \%$ of $\mathrm{N}+\mathrm{N}$, and $30-86 \%$ of nitrite (Figure 5 and Table 5). Ammonium drawdown was observed in all treatments as compared to ambient starting concentrations as was also true in the gyre. Following iron limitation nitrate or urea addition further stimulated growth (Figure 3) but did not necessarily result in increased phosphate drawdown (Table 5). Nitrate addition led to N:P drawdown ratios above the Redfield ratio unlike with iron alone which resulted in N:P drawdown values below the 
Redfield ratio (Table 5). Urea additions reduced the $\mathrm{N}+\mathrm{N}$ drawdown and consequently the apparent $\mathrm{N}: \mathrm{P}$ drawdown ratio was reduced even in cultures without added iron (Figure 7Figure 8).

\section{Proteome and particulate nickel from the equatorial upwelling cruise:}

Key nitrogen and nickel proteins were quantified by proteomic analysis of samples collected across the northern transect of the Equatorial Pacific Upwelling in the upper $300 \mathrm{~m}$ of the water column. These proteins were calibrated by labeled peptides on an absolute scale and included: a nickel-containing superoxide dismutase (NiSOD), urea transporter (putative urea $\mathrm{ABC}$ transporter), and nitrogen stress protein (Figure 8, NtcA in upper panel). Overall, these specific protein concentrations were elevated in waters shallower than $100 \mathrm{~m}$ and trend towards zero by $200 \mathrm{~m}$. The urea transporter was absent at Station 5 (equatorial location of incubations), but elevated in the surface waters further north at Stations 1 and 3. Both the urea transporter proteins and nitrogen stress proteins generally decreased across the transect from north to south, while the reverse trend was seen for NiSOD which was highest at Station 5. Particulate nickel trends (Figure 8, lower panel) generally follow those of NiSOD and profiles are compared side-by-side in Figure 9.

\section{Proteome in the South Pacific Gyre:}

Targeted proteomic results are available for Station 4 of the cruise track traversing the northeastern edge of the South Pacific Gyre. Here urea transporters were measured in the 
upper water column $(<200 \mathrm{~m})$ and reached up to $0.5 \mathrm{pM}$ (Figure 10), similar to Stations 1 and 3 north of the equatorial upwelling site.

\section{Culture growth and elemental analysis for urea uptake in lab study:}

Field incubation and protein measurements are accompanied here by laboratory studies that were conducted in order to calibrate the field urea transporter abundances with urea uptake rates on laboratory monocultures. The goal is to allow estimation of potential field uptake rates in this and future studies. Results presented here are only preliminary and on-going lab and field work still remains. The lab cultures grew with rates typical of these cyanobacteria at $0.3 \mathrm{~d}^{-1}$, and $0.4 \mathrm{~d}^{-1}$ for Prochlorococcus (MED4) and Synechococcus (WH8020) respectively and were comparable in cultures across transfers in preparation for both the time course and short-term uptake experiments (Figure 11). Light intensity fluctuated around day 6 of the Prochlorococcus cultures disrupting the smooth progression in fluorescence, however $\mathrm{F}_{\mathrm{v}} / \mathrm{F}_{\mathrm{m}}$ was stable and exponential growth was observed in the proxy cultures corresponding to the uptake study (Figure 11, boxed region). The temporary light fluctuation was not considered a concern that would affect the uptake study results.

For short-term (4-h) uptake experiments the initial culture densities for Synechococcus and Prochlorococcus were $16 \times 10^{6}$ cells mL ${ }^{-1}$ and $0.8 \times 10^{6}$ cells $\mathrm{mL}^{-1}$ respectively. Initial cell densities in the time course experiment were $18 \times 10^{6}$ cells $\mathrm{mL}^{-1}$ and $2 \times 10^{6}$ cells $\mathrm{mL}^{-1}$ for Synechococcus and Prochlorococcus respectively. Cell densities 
for the parent culture, cell concentrates, and time zero experiments are summarized in Table 6.

Short-term ${ }^{15} \mathrm{~N}$ enrichment ranged from the natural abundance value of $0.366 \%$ at the lowest urea concentration and up to approximately $30 \%$ and $60 \%$ for Synechococcus and Prochlorococcus respectively (Figure 12A). Over the 24 -h period ${ }^{15} \mathrm{~N}$ enrichment proceeded in a linear trend up to $30 \%$ with Prochlorococcus more enriched in the earlier time points (Figure 12B). ${ }^{13} \mathrm{C}$ results were similar except with maximum enrichment values below $10 \%$ even for the highest urea concentrations (Figure 12C). The short-term experiment became enriched in ${ }^{13} \mathrm{C}$ and more extensively in Prochlorococcus than Synechococcus (Figure 12C). In the 24-hour time course both strains maintained ${ }^{13} \mathrm{C}$ enrichment near the $1.1 \%$ natural abundance value and Synechococcus only gradually sloped up to a maximum of about $2 \%$ by $24 \mathrm{~h}$ (Figure 12D).

Urea uptake rate saturated for Prochlorococcus cultures at a urea concentration of $1 \mathrm{mM}$, while Synechococcus did not appear to saturate over the range of concentrations tested here and attained a much lower uptake rate throughout as compared to Prochlorococcus (Figure 13A). Approximate Michaelis-Menten hyperbolic saturating shape for Prochlorococcus allowed non-linear curve fitting to determine $K_{m}$ of $0.62 \mathrm{mM}$ and $V_{\max }$ of $8.5 \mathrm{nmol} \mathrm{N}$ cell $^{-1} \mathrm{~h}^{-1}$. Though the Synechococcus data did not saturate, a similar regression yields higher values; $K_{m}$ of $45 \mathrm{mM}$ and $\mathrm{V}_{\max }$ of $15 \mathrm{nmol} \mathrm{N}$ cell ${ }^{-1} \mathrm{~h}^{-1}$ and despite uncertainty in this calculation the overall data show higher urea uptake affinity for Prochlorococcus relative to Synechococcus in the conditions described here. At $1 \mathrm{mM}$ starting urea concentration, the time course shows decreasing uptake rates in 
Prochlorococcus and steady rates for Synechococcus (Figure 13B). Higher uptake rates were observed in the short-term uptake experiments especially at higher urea concentrations, and rates in the time course were all less than the corresponding $1 \mathrm{mM}$ data from the short-term uptake study (Figure 13A,B).

Cellular carbon and nitrogen quotas remained relatively constant (Figure 13C-F), although there was an increase in cellular nitrogen quota at the highest two urea concentrations. Synechococcus had comparable cell concentrations for both experiments and this is reflected in the similarity between cell quotas of corresponding time and concentration as indicated by the dashed lines in Figure 13. Prochlorococcus had comparatively lower cell concentration in the short-term uptake experiment (Table 6) and the cellular nitrogen quota at $1 \mathrm{mM}$ urea appears greater than in the 24-h time course experiment at $4 \mathrm{~h}$. Synechococcus particulate C:N was relatively constant (ave. $4.2 \pm 0.08$ std) except for in the highest urea concentration where it dropped to 3.0. Prochlorococcus $\mathrm{C}: \mathrm{N}$ values were generally higher and more variable ranging from 4.1 to 9.5 with more constant values in the time course experiment (ave. $6.6 \pm 0.40 \mathrm{std}$ ) and a declining trend with increased urea concentrations ( 9.5 maximum, 4.1 minimum, ave. $7.1 \pm 2.4$ std). Enrichment values, cell quotas, $\mathrm{C}: \mathrm{N}$ ratios, and specific uptake rates normalized to cell concentration are summarized in Table 7. Normalizing the uptake rate to urea transporter concentration will be possible with quantitative urea transporter numbers that are forthcoming. 


\section{Proteomic analysis of uptake study cultures:}

As a method development effort greater attention was directed to the Synechococcus samples which had more proteins identified in the extracts. Extracted biomass was less than typical samples for global proteomic analysis, however the global proteome was used to determine feasibility of an isotope uptake approach by identifying only the most abundant proteins and prospective peptides for targeted proteomics. Although protein was not detectable by a standard protein quantification assay, mass spectrometric results identified proteins in all samples. Two biological samples from each culture strain were analyzed including triplicate technical replicates for one Prochlorococcus sample and singleton analysis for the other Prochlorococcus and both Synechococcus samples. Setting the protein identification threshold at $99.9 \%$ with a minimum of 1 peptide at $95 \%$ resulted in identification of 230 unique proteins (104 in Prochlorococcus and 126 in Synechococcus) including a number of anticipated pigment proteins (phycoerythrin) and nitrogen/urea-related proteins (glutamine and glutamate synthetase). Despite low protein recovery in the Prochlorococcus samples, a promising urea transporter protein was noted allowing development of an isotopically labeled peptide for future quantitative transporter concentration measurments.

Among the most abundant Synechococcus proteins identified was C-phycoerythrin class II beta chain cpaB-2 [WH8020], and a specific peptide from this protein was selected for TSQ analysis (peptide sequence and fragmentation are presented in Table 8). y-ions 7-13 were identified in the LTQ-MS results and were selected as candidates for monitoring ${ }^{15} \mathrm{~N}$ incorporation through uptake of the labeled urea nitrogen. Moreover, the 
+1 and +2 charged fragment ions elute within a narrow LC-peak (Figure 14) and the fragment ions from this peak are relatively constrained to $\mathrm{m} / \mathrm{z}$ values corresponding to y-ions expected per Table 8 .

Three samples were analyzed on the TSQ: (1) $\mathrm{T}_{0}$ (unlabeled urea), (2) low urea $\left(0.01 \mathrm{mM}{ }^{15} \mathrm{~N}\right.$ labeled urea) and (3) high urea $\left(3 \mathrm{mM}{ }^{15} \mathrm{~N}\right.$ labeled urea). The TSQ was programed to target the doubly-charged parent peptide ion from Table 8 and fragment ions with $+0,+1,+2$, and +3 mass units. Fragments were found in all cases, however there was no correlation with the labeled versus unlabeled samples. 


\section{Discussion}

\section{Field incubations:}

Limiting nutrients vary across ecosystems and affect biomass yield, growth rates, and species composition. Macro nutrients and trace elements can independently or simultaneously limit biological production depending on the ambient conditions. Among the nutrient additions performed in the nutrient poor northeastern edge of the South Pacific Gyre, bottle incubations only yielded a Chlorophyll $a$ increase after nitrogen additions (Figure 2). Chlorophyll $a$ results in the Equatorial Pacific Upwelling site were more complex than the gyre site, but urea and nitrate additions yielded similar results. That urea and nitrate stimulated comparable chlorophyll $a$ increases at these contrasting sites suggests that urea and nitrate (at equimolar nitrogen) are equally desirable nitrogen sources for phytoplankton. Microscopy or flow cytometry could reveal if these oxidized versus reduced nitrogen sources stimulated the same or different community structure in these incubations. Iron proved to be the primary limiting nutrient in the upwelling site, followed secondarily by nitrogen (Figure 3 ). These chlorophyll $a$ responses gave a first impression of limiting nutrients consistent with previous observations and modeling (Moore et al. 2002a, 2013); however, additional insight is available in the nutrient data.

Nutrient data from triplicate biological samples yields much greater capacity for insights on this matrix experiment. In particular, nitrogen drawdown measured from nitrate plus nitrite $(\mathrm{N}+\mathrm{N})$ is compared with phosphate drawdown. The resulting N:P drawdown ratio can be compared with the Redfield ratio (Redfield 1934) revised by 
Redfield himself and later by others (Takahashi 1985) yielding N:P equal to 16:1. Deviation of N:P drawdown ratios from 16 may be used to identify effects from the different nutrient treatments performed in bottle incubations from both the gyre and upwelling sites (Table 4, Table 5). These effects could be attributed to any number of individual or combined biological features including nitrogen fixation and luxury uptake of nitrogen or phosphorus.

In the South Pacific Gyre nitrate additions resulted in increased N:P drawdown ratios exceeding 16 (Table 4) suggesting an decreased phosphorus quota. In the North Pacific Subtropical Gyre a substitution strategy through the replacement of phospholipids by sulfolipids is attributed to Prochlorococcus (Van Mooy et al. 2006) ${ }^{1}$. Prochlorococcus is an abundant cyanobacterium in the South Pacific Gyre as well and sulfur substitution for phosphorus may account for the lower phosphorus quotas. The N:P drawdown values for urea treatments do not show this effect because the $\mathrm{N}+\mathrm{N}$ drawdown is negative (Table 4 , -0.26 and -0.02 for + urea and + urea $+\mathrm{Ni}$ treatments respectively), most likely a result of biological conversion of urea and subsequent leakage of nitrate/nitrite into the seawater. Drawdown ratios could not be inclusive of urea because initial and final urea concentrations were not measured; only the added amount of urea was known.

In the more productive Equatorial Pacific Upwelling site initial nitrate was greater than in the gyre $(6.99 \mu \mathrm{M}$ versus $0.56 \mu \mathrm{M})$ and treatment of iron together with nitrate in incubations yielded an N:P drawdown in excess of Redfield (16.85-19.75, Figure 7 and Table 5). Phosphate drawdown was comparable among all the iron amended treatments

\footnotetext{
${ }^{1}$ Evidence of this substitution may also be present in biogenic particulate data in the Appendix.
} 
weather additional nitrogen was supplied or not, thus the increased N:P ratio is likely the result nitrogen uptake (Table 5). Iron treatments without added nitrogen resulted in $\mathrm{N}+\mathrm{N}$ being reduced to near or below detection $(0.11 \mu \mathrm{M}$, Figure 5) and significantly lower chlorophyll values than in iron treatments with added nitrogen (Figure 3). This difference implies iron-induced nitrogen limitation and $\mathrm{N}: \mathrm{P}$ drawdown ratios of iron treatments without added nitrate were below Redfield (12.7 to 13.2) showing flexibility in the nitrogen and/or phosphate cell quota (Figure 7 and Table 5).

Trends in the nutrient data are consistent with potential influences of trace metals on the phytoplankton community through corresponding metalloenzymes. Example metalloenzymes that may influence community composition and phytoplankton productivity include nickel-enzymes: urease, hydrogenase, and superoxide dismutase. Although alkaline phosphatase is believed to be a zinc enzyme, it has never been purified from a marine microbe and verified to be exclusively a zinc enzyme. A putative cobalt alkaline phosphatase could increase access to the abundant organic phosphate reservoir. These and similar trace metal effects might exist and be reflected in data presented here.

Nickel, cobalt, and iron all effected nutrient drawdown. N:P drawdown values in the upwelling site showed decreased values for the nickel, iron, and even more so for the cobalt additions, while no effect was seen for zinc additions. Nickel is particularly interesting in the gyre results because it was the only trace metal treatment where $\mathrm{N}+\mathrm{N}$ drawdown was negative (i.e. nickel treatment resulted in addition to the dissolved $\mathrm{N}+\mathrm{N}$ pool) (Figure 6). The reduced N:P drawdown ratios in the nickel treatment from the upwelling site as well as the negative $\mathrm{N}+\mathrm{N}$ drawdown in the gyre could be explained with 
one or more known mechanisms involving nickel and nitrogen acting alone or together. Although nickel concentrations are generally quite high in the ocean it has been shown to limit or co-limit certain phytoplankton in previous field work, particularly in conjunction with urea as a reduced nitrogen source through use of nickel-urease (Dupont et al. 2010). Nickel also may have a role in nitrogen fixation through the nickel hydrogenase or nickel-superoxide dismutase (NiSOD) and has been noted to limit the non-heterocyst diazotroph, Trichodesmium (Ho 2013). In non-heterocyst diazotrophs, NiSOD would help protect nitrogenase from superoxide inhibition and thus nickel could enhance nitrogen fixation by incorporation into NiSOD. If a similar mechanism was at work in the bottle incubation, the newly fixed nitrogen would not have been accounted for in the initial nitrogen store ( $T_{0}$ in Table 5 and Figure 7 ) and by displacing a portion of the apparent nitrogen consumption would yield a lower N:P drawdown ratio. Moreover, NiSOD was observed in the same upwelling waters where this incubation was performed (Figure 8) and this metalloprotein has been shown to be important in some Synechococcus strains that cannot completely substitute alternative non-nickel SOD enzymes (Dupont et al. 2008).

Besides nickel, cobalt addition presented a pronounced decrease in N:P drawdown to 12.19 (Table 5). Cobalt is required by Prochlorococcus and has been indicated as a trace metal that can influence open ocean phytoplankton assemblage composition (Saito et al. 2005; Moore et al. 2013). However, Bertillson et al. (2003) report N:P ratios from marine particulate matter and phytoplankton culture at or below 16, while for Prochlorococcus and Synechococcus biomass, the N:P tended towards values well above 16. Given the 
particulate N:P ratios of cyanobacteria reviewed by Bertillson et al. (2003), the reduced $\mathrm{N}: \mathrm{P}$ drawdown in the upwelling site cobalt addition suggests cyanobacteria may not be responsible for this change. However in a natural assemblage community co-limitation can lead to more complex results than N:P drawdown alone implies (Arrigo 2005).

Nevertheless, in the case of iron additions to the Equitorial Pacific Upwelling incubations, evidence of diatom stimulation was pronounced.

Silicic acid is known to limit diatom growth (Martin-Jézéquel et al. 2000). Silicic acid was depleted to zero in the upwelling site and implies that diatoms were likely contributors to the stimulated production (Figure 5). Similar iron trace metal incubations performed on the same cruise at this site revealed a dramatic increase in the diatom population by microscopy (personal communications with Dawn Moran and Rene Boiteau) and $16 \mathrm{~S}$ sequencing (Ventouras 2012). These results are consistent with other investigations reporting diatom stimulation by iron in high nutrient low chlorophyll regions of the Pacific (Bruland et al. 2005). In contrast, ambient silicic acid concentrations in the gyre were below detection and consequently did not change (Figure 4).

Alongside nitrogen and iron limitations already described are several prospective coand secondary limitation features. In the gyre it appears that perhaps a secondary limitation may be restricting further phosphate and $\mathrm{N}+\mathrm{N}$ depletion. The absence of an iron response in the gyre incubations might be accounted for by the closer proximity to land except that total dissolved iron was comparable and in fact nearly $40 \%$ lower in the gyre versus the upwelling (Table 3). It would seem more likely that the low inorganic 
nitrogen $(\mathrm{N}+\mathrm{N})$ supply may lead to relative abundance in other nutrients and hence no clear trace metal effects are seen in the chlorophyll response. Alternatively, a more fully factorial experiment might allow better resolution of synergistic effects among trace metal and nitrogen treatments as were performed in the upwelling site.

In contrast to the gyre, the upwelling site presents several prospective limitation scenarios. Moreover, the higher factorial treatment groups allowed inspection of more nutrient-production couples. Iron and nitrogen dynamics are most pronounced in the upwelling site incubations. Building on the established visualizations of Saito et al. (2008), this dynamic might be visualized in a smooth multiplicative independent nutrient type limitation where iron is primarily limiting these incubations, but once supplied with iron, nitrogen can further enhance growth. More subtle effects are noted in the nutrient and chlorophyll data for treatments excluding iron.

The inset graph of Figure 3 highlights treatments without added iron. Nickel and urea colimitation was a subtle result possibly the result of the nickel containing urease enzyme (Price and Morel 1991; Dupont et al. 2010). Nickel alone and urea alone stimulated growth over the control. Biological variability was larger for combined nickel and urea and as a result, no statistically significant relationship was observed. This variation is partly on account of elevated chlorophyll content in one triplicate bottle, though the suspected outlier could not be confidently rejected (Dixon's q-test, $>90 \%$ ). The variation in some of the non-iron amended treatments may have been the result of trace iron contamination despite extensive effort to minimize such effects (see Methods). The 
potential nickel and urea colimitation though tenuous remains an interesting observation for an upwelling region where a priori nitrate is the most important nitrogen source.

Biological assimilation of urea is supported in this data. In the gyre $\mathrm{N}+\mathrm{N}$ increased slightly in the urea treatments (presumably cellular leakage via grazing and/or viral lysis), and completely displaced $\mathrm{N}+\mathrm{N}$ consumption while allowing greater phosphate drawdown as compared with the nitrate additions (Table 4). In the upwelling site the $\mathrm{N}+\mathrm{N}$ decreased in all treatments (no leakage), however the $\mathrm{N}+\mathrm{N}$ drawdown was less in urea treatments than both nitrate amended bottles and the control (Table 5). Consequently urea nitrogen appears to displace $\mathrm{N}+\mathrm{N}$ dependence and urea yields comparable results as equimolar nitrogen additions from nitrate. Moreover, urea treatments comprised the lowest N:P drawdown values in the results from the Pacific upwelling site owing to reduced $\mathrm{N}+\mathrm{N}$ dependence when urea is present (Figure 7).

Urea has generally not been considered an important nitrogen species, but this study and increasing literature references are suggesting otherwise. These incubation studies support that chlorophyll response is equivalent for urea or nitrate additions. As shown in more coastal regions, nickel and urea have individual responses reflecting potential nickel and urea co-limitation consistent with the nickel-urease biochemical mechanism (Dupont et al. 2008, 2010). Urea is accessible in such diverse biogeochemical environments as the South Pacific Gyre and Equatorial Pacific Upwelling regions investigated here and the ubiquity of urea transporters throughout the oceans suggests a very global significance of this nitrogen substrate. Urea transporters are abundant as seen in metagenomic coverage around the globe as evaluated with the Community Cyberinfrastructure for Advanced 
Microbial Ecology Research and Analysis (CAMERA) tool (http://camera.calit2.net/). The prospect of local plankton rapidly adjusting their physiology to make use of an alternative organic nitrogen species, and shift up response to urea in particular is supported both by cyanobacteria culture experiments and genomic evidence (Valladares et al. 2002). Moreover, urea need not be an abundant nitrogen species for it to play a significant role; for example it may be rapidly cycling with low leakage and high uptake by and from biota. Assessing the relationship between uptake rates and urea transporter concentration is an important long-term objective to which complementing culture uptake studies and proteomics also presented here should contribute. Metaproteomic field results already indicate the significance of urea transporters (Marchetti et al. 2012), and nitrogen and nickel related proteins have been quantitatively evaluated by this study. It is not yet determined if urea transporter concentration is proportional or inversely proportional to urea concentration and various mechanisms could support either prospect. In the field, nitrate concentration varies inversely with urea transporters (see subsequent section) which is consistent with the co-regulation of urea transporters and the nitrogen stress protein NtcA as shown by (Valladares et al. 2002). Pending results of this lab study should confirm this hypothesis. Moreover, if a relationship is obtained between urea transporter concentration and uptake rate or urea concentration, then field activities might be estimated. 


\section{Targeted field proteomics:}

The nickel urease enzyme is important to urea metabolism, however it is not particularly informative due to its constitutive nature (Valladares et al. 2002; Allen et al. 2011; generals paper in appendix). In contrast, urea transporters may be more insightful regarding urea assimilation because in some cyanobacteria a high-affinity $\mathrm{ABC}$ urea transporter is upregulated alongside the global nitrogen control transcription factor NtcA. Moreover cyanobacterial urea transporters can be dynamically adjusted on short timescales (Valladares et al. 2002) and urea ABC transporters in the open ocean are among the most prevalent Prochlorococcus proteins identified in a recent metaproteomics study by Morris et al. (2010). Dominance of cyanobacteria in the region surveyed across the upwelling transect (KM1128) provides a consistent explanation for urea transporters being regulated by nitrogen abundance with decreasing urea transporter in transit from Hawaii to the equator (Figure 8). The decreased nitrogen stress protein (NtcA) further supports this connection as described for Synechococcus over annual nutrient cycles in the Gulf of Aqaba by Post et al. (2011). All together these results emphasize the significance of urea as an active component of the nitrogen cycle.

In the expanding spatial coverage of metaproteomics presented here, there is overlap with existing particulate metal data. Consequently, metalloproteins such as NiSOD can be compared with the corresponding particulate metal concentrations and in this case a positive correlation is apparent (Figure $15, \mathrm{R}^{2}=0.72$ ). Given the nascent state of these methods, coherence between NiSOD and particulate nickel concentrations is encouraging. This correlation presumes a single nickel atom per NiSOD as characterized 
by Barondeau et al. (2004). For samples within the same $10 \mathrm{~m}$ depth range, at one nickel atom per NiSOD, the percentage of particulate nickel that is bound in NiSOD could range from 0 to $30 \%$ with an average of $5 \%$, however surface $(<100 \mathrm{~m})$ samples show an average of about $12 \%$ (Figure 15). This type of data will be improved with higher resolution sampling as is possible through continued processing of current and future sample libraries of this type. The remaining fraction of particulate nickel could be part of other metalloenzymes such as Ni-urease or Ni-hydrogenase, or chaperone proteins (Carter et al. 2009; Waldron and Robinson 2009; Waldron et al. 2009). The availability of particulate nickel data places bounds on concentrations of nickel-containing metalloproteins such as those mentioned above.

\section{Stable isotope enrichment and uptake rates in lab culture experiments:}

Transporter concentrations have been measured in the field on an absolute scale, and further lab culture studies were designed to calibrate those field measurements by measuring urea uptake with ${ }^{15} \mathrm{~N}$-labeled urea (results here) and transporter concentrations (still in development). The potential for using mass spectrometry-based ${ }^{15} \mathrm{~N}$-urea uptake was also investigated.

Following the practice of Valladares et al. (2002), biomass was collected on filters and left un-rinsed to minimize cell disruption. Consequently a small portion of enrichment could be attributed to media absorbed in the filters. However, ${ }^{15} \mathrm{~N}$ enrichment was roughly 10 times greater than ${ }^{13} \mathrm{C}$ enrichment for all treatments and time points indicating that concentration-dependent enrichment is more likely of biogenic and not 
operational origin. ${ }^{15} \mathrm{~N}$ enrichment also saturates at about $60 \%$ in the highest urea concentrations which would not occur if enrichment were merely a result of residual media operationally trapped on the filter. Consequently enrichment levels are reliable measures of biological uptake.

Although ${ }^{13} \mathrm{C}$ was also assessed, the urea-carbon is likely respired as $\mathrm{CO}_{2}$ and lost from the cell as described in the eastern Canadian Arctic (Harrison et al. 1985) and also evidenced here with the much lower ${ }^{13} \mathrm{C}$ enrichment versus ${ }^{15} \mathrm{~N}$ enrichment throughout all treatments and time points (Table 7). Consequently emphasis should be placed on interpretation of the ${ }^{15} \mathrm{~N}$ enrichment and uptake rates calculated from ${ }^{15} \mathrm{~N}$ values.

During exponential growth, uptake rates for urea-nitrogen were roughly an order of magnitude greater for Prochlorococcus than Synechococcus when normalized to initial cell-counts (Table 7). This may represent a difference in nitrogen requirements during exponential growth for Prochlorococcus, however it should be noted that cell-counts, especially for Prochlorococcus, were complicated by excessive cell clumping and fadeout for these un-stained preliminary counts. Thus cell concentrations reported in Table 6 are probably underestimated for Prochlorococcus. Normalization by cell-count was similar to normalization by bulk carbon (data not shown), consistent with visual observations of less biomass in the Prochlorococcus cultures.

The average particulate $\mathrm{C}: \mathrm{N}$ value of Prochlorococcus was $6.6 \pm 0.4$ in this study, as compared to the same MED4 strain reported at $5.7 \pm 0.7$ by Bertilsson et al. (2003). Synechococcus strains WH8012 and WH8103 isolated from the Sargasso Sea have similar C:N at 5.4 \pm 1.1 and 5.0 \pm 0.2 respectively (Bertilsson et al. 2003). The elemental 
C:N ratios of Synechococcus strain 8020 reported here was less variable than Prochlorococcus and averaged to $4.2 \pm 0.1$. Lower $\mathrm{C}: \mathrm{N}$ values reported here could be the result of luxury uptake of nitrogen in Synechococcus for which phycobiliproteins have been suggested to serve as a nitrogen storage pool (Glibert and Ray 1990). Cellular nitrogen quotas are not discussed because preliminary cell counts did not include staining and the resulting fade-out together with cell clumping resulted in underestimation of cell concentrations.

\section{Proteomic analysis of uptake study cultures:}

The proteomics evaluation of these culture studies was intended to allow future quantitative measurement of urea transporters based on istopically labeled peptide standards (pending) and to develop a mass spectrometry based ${ }^{15} \mathrm{~N}$-urea uptake method (preliminary data here). Biomass extracted for proteins was less than typically used in proteomic analysis because the effort here was to focus on the most abundant proteins. It was anticipated that only a shallow proteome was required to seek evidence of ${ }^{15} \mathrm{~N}$ incorporation into a peptide designated from a prevalent protein. Despite low protein recovery particularly in the Prochlorococcus samples, a promising urea transporter protein was noted; this is consistent with knowledge that the MED4 Prochlorococcus strain must be supplied with reduced nitrogen compounds such as ammonia and urea because it lacks both nitrate and nitrite reductase genes (Zubkov and Fuchs 2003).

Owing to the greater abundance of protein in the Synechococcus samples, effort was focused on those proteome results. In selecting a peptide to assess nitrogen assimilation 
from the ${ }^{15} \mathrm{~N}$ labeled urea there were a few important considerations. First, the selected peptide should be prevalent and from a protein which appears across all treatments and time points to be useful as a proxy for nitrogen assimilation and comparison between treatments. Second, because the signal is expected to be small for short-term uptake experiments, a prevalent, though possibly slow-turnover protein was sought (e.g. photopigment proteins). In this case a peptide from phycoerythrin was selected because it appeared in all preliminary samples by global LTQ inspection and could be isolated within a narrow LC peak where the MS fragmentation yielded y-ions predominantly from the parent peptide (Table 8 and Figure 14).

Uptake measurements using nitrogen tracers rather than carbon have the advantage that the incubation duration is less likely to be affected by diurnal variation; nitrogen is assimilated day and night, while carbon assimilation occurs essentially only during daylight hours (Dugdale and Goering 1967). However, field work by Mackey et al. (2011) identifies different ${ }^{15} \mathrm{~N}$ enrichment values for nitrate and urea in light versus dark field tracer experiments; nitrite and ammonium had lower enrichment and comparable values for light and dark treatments. Independent of diurnal effects, ${ }^{15} \mathrm{~N}$ rather than ${ }^{13} \mathrm{C}$ urea tracers should be used because as shown above the ${ }^{15} \mathrm{~N}$ is assimilated and ${ }^{13} \mathrm{C}$ respired. Moreover, in developing a ${ }^{15} \mathrm{~N}$ proteomic biomarker any ${ }^{13} \mathrm{C}$, even from natural abundance levels of ${ }^{13} \mathrm{C}$, stands to complicate analysis. With approximately three times more carbon than nitrogen in prospective peptides, the $1.1 \%$ natural abundance of ${ }^{13} \mathrm{C}$ could overwhelm any ${ }^{15} \mathrm{~N}$ incorporation from short-term uptake of ${ }^{15} \mathrm{~N}$ labeled urea. In these results it was not possible to unambiguously distinguish ${ }^{15} \mathrm{~N}$ incorporation from the 
background natural abundance ${ }^{13} \mathrm{C}$ apparent in the TSQ data, however longer incubation times, greater urea concentrations, and alternative peptides from more rapidly cycled proteins may improve the prospects of monitoring ${ }^{15} \mathrm{~N}$ incorporation by a proteomic technique.

Lab culture experiments presented here are preliminary steps towards a larger goal of determining a urea uptake to transporter ratio and this parameter may then be used in conjunction with metaproteome data to quantify urea cycling in unexpected regions such as the open-ocean sites presented here. Towards this goal cultures were grown with isotopically labeled urea and simultaneously evaluated with traditional elemental analysis alongside proteins extraction and mass spectrometer analysis of digested peptides. Uptake rates assessed by elemental analysis results yielded positive results. The proteomic uptake method is still in development at the time of this writing and cannot be properly compared with elemental results. Nevertheless, these preliminary findings represent progress towards the goal to parameterize uptake rates to transporter concentration. As inferred from field results described above, the urea transporter concentration (and uptake rates) may vary inversely with ambient nitrate concentration and perhaps urea concentration as well. 


\section{Summary, implications and future outlook:}

Field observations in contrasting regions (gyre and upwelling) showed similarities and differences in urea and trace metal utilization. Field experiment results matched expectations on the broad overview with a number of more subtle features seen only by close inspection and comparison of complementary datasets such as (1) the detailed nutrient analysis of field incubations and (2) quantitative metaproteomic results. Considering the novelty of methods and objectives described here, a reassuring outcome of this work included the correlation of nickel superoxide dismutase (NiSOD) and the particulate nickel ocean section presented here. Potential connections between other particulate metals and phosphate, sulfur, or calcium may also be explored through the particulate section (see Appendix).

Uptake experiments were conducted at elevated urea concentrations because cultures were available pre-acclimated to these conditions and it ensured that cultures would be unlikely to become nitrogen limited. After further development, investigations at saturating substrate concentrations can allow extrapolation to in situ conditions using measured or estimated half-saturation constants (McCarthy 1972). Thus, this work is a proof of concept and follow-up work should explore the potential to extrapolate to environmentally relevant conditions.

Developing proteomics-based stable isotope uptake experiments may initially require longer uptake time and larger biomass in order to increase ${ }^{15} \mathrm{~N}$ levels to optimize the methodology. Greater biomass together with screening both high and low-abundance (though perhaps more rapidly cycling) proteins may yield positive results and also allow 
quantification of urea transporters which can then be related to the uptake rates calculated for the same samples. Improving these methods opens prospects for field incubations with ${ }^{15} \mathrm{~N}$ labeled urea to investigate urea assimilation and related transporter proteins.

Multi-factorial trace metal bottle incubations yield important insight to subtle, synergistic, and antagonistic regional biogeochemical effects. Future field incubations should wherever possible include fully factorial experiments because trace metal effects can be particularly interdependent and often nutrient limited regions are limited by several nutrients simultaneously as described here. Additoinally, Arrigo (2005) notes the potential for colimitation by phosphate and iron in areas such as the oligotrophic Pacific, Atlantic, and northern Red Sea. At minimum, iron, nitrogen, and phosphate should be considered as experimental treatments for identification of nutrient limitations.

Urea proved to be a viable nitrogen source in the contrasting gyre and upwelling regions presented here. Colimitation and trace metal dependencies were characterized with prospective explanations such as (1) the nickel and urea co-dependence resulting from nickel urease and (2) the role of NiSOD in nitrogen fixation. Abundance of urea transporters in both study sites indicate that urea is an important component of the nitrogen cycle and cyanobacteria, particularly Prochlorococcus, appear to underpin this feature. These results demonstrate the importance of urea cycling in the oceans and that proteomics in field and lab cultures are a promising avenue to explore previously invisible aspects of ocean biogeochemistry. 


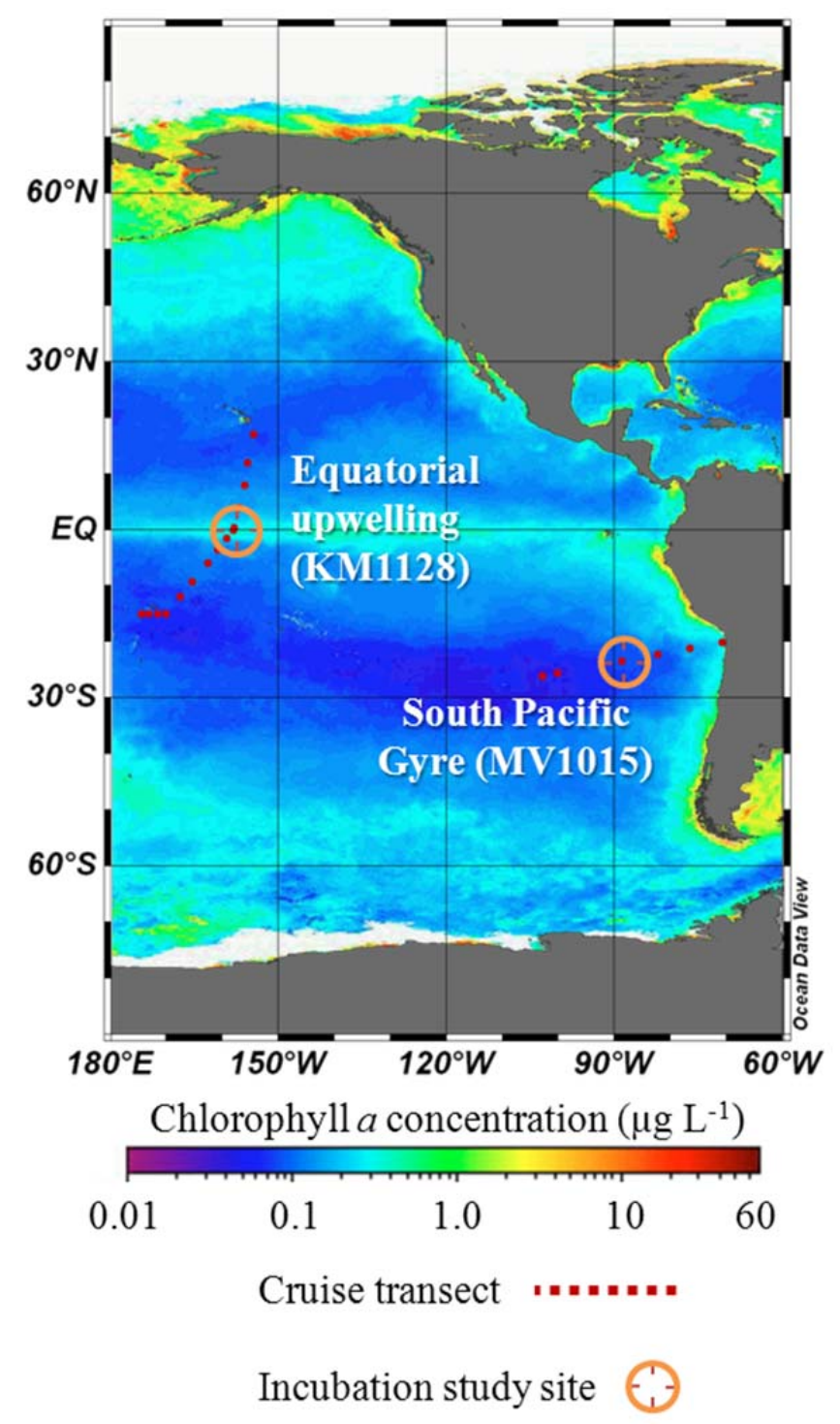

Figure 1. Global satellite image of annual average chlorophyll $a$ concentrations courtesy of NASA SeaWiFS satellite program. Cruise tracks and field incubation study sites are shown for two cruises traversing the Equatorial Pacific Upwelling (KM1128, fall 2011) and northeastern edge of the South Pacific Gyre (MV1015, fall 2010). Figure is adapted from http://earthobservatory.nasa.gov with ODV (Schlitzer 2011). 


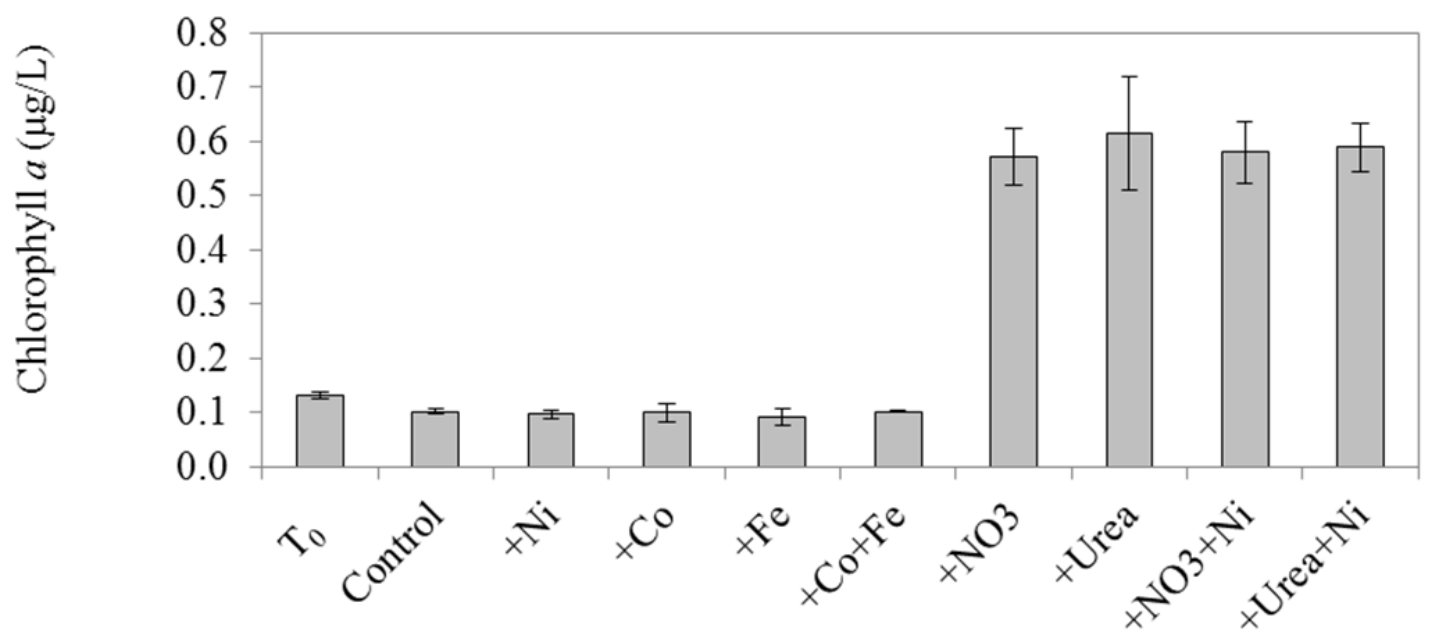

Figure 2. Chlorophyll $a$ data from 6-d bottle incubations performed in the South Pacific Gyre (MV1015 Station 4, 15m, $\left.271^{\circ} \mathrm{E},-23^{\circ} \mathrm{N}\right)$. Values are averages with error bars as standard deviation from triplicate biological replicates. Nitrogen limitation is observed, however no trace metal limitation is apparent in these results. Note that stimulation by urea alone compares with equimolar nitrogen addition by nitrate. All nitrogen treatments differ significantly from control ( $p<0.05$ by t-test; one-tailed, two-sample with unequal variance). 


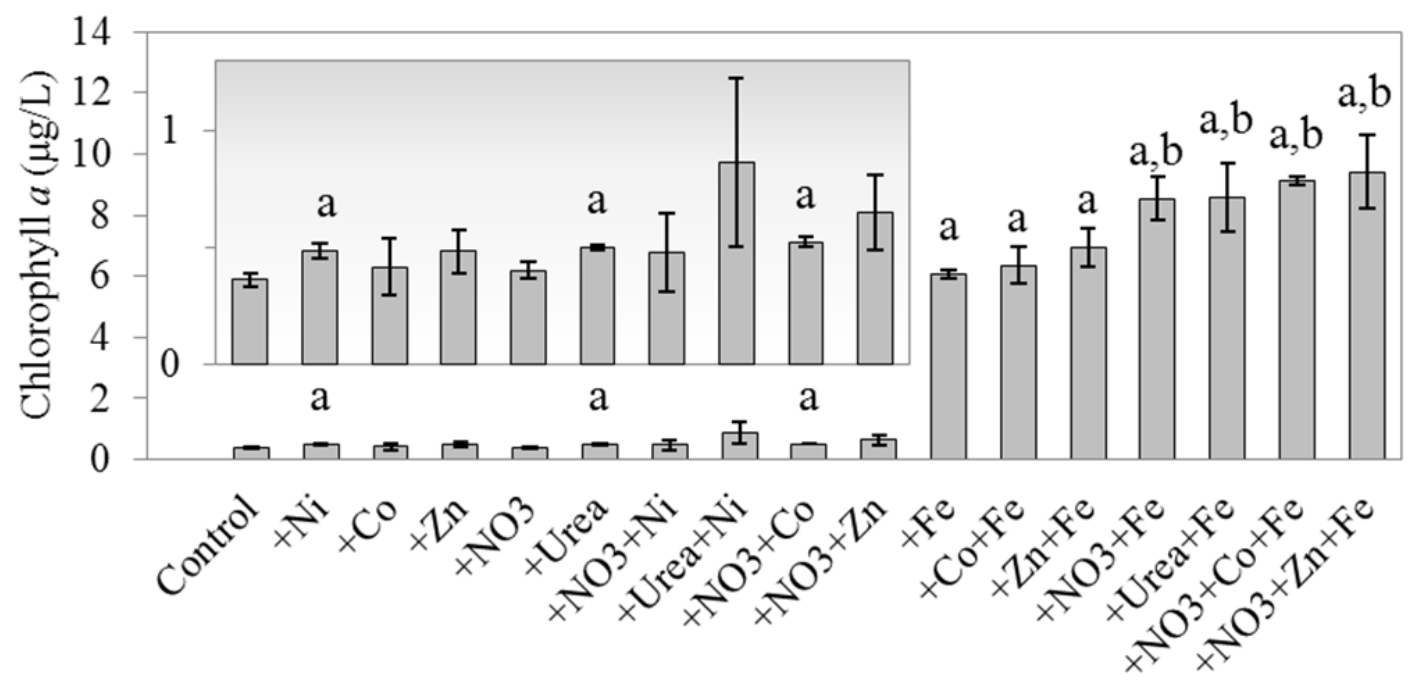

Treatment (nutrient addition)

Figure 3. Chlorophyll $a$ data from 3-d bottle incubations performed in the Equatorial Pacific Upwelling (KM1128 Station 5, 40m, 202 $\left.{ }^{\circ} \mathrm{E}, 0^{\circ} \mathrm{N}\right)$. Values are averages with error bars as standard deviation from triplicate biological replicates. Iron stimulates a response and nitrogen with iron further enhances the response (e.g. "+Fe+NO3" has higher chlorophyll than "+Fe" alone). Overlying letters indicate statistically significant results from t-tests $(p<0.2$ with Sidak adjustment, one-tailed, two-sample with unequal variance) comparing all samples with the control (a), or only the iron treatments against the + Fe-only treatment (b). 

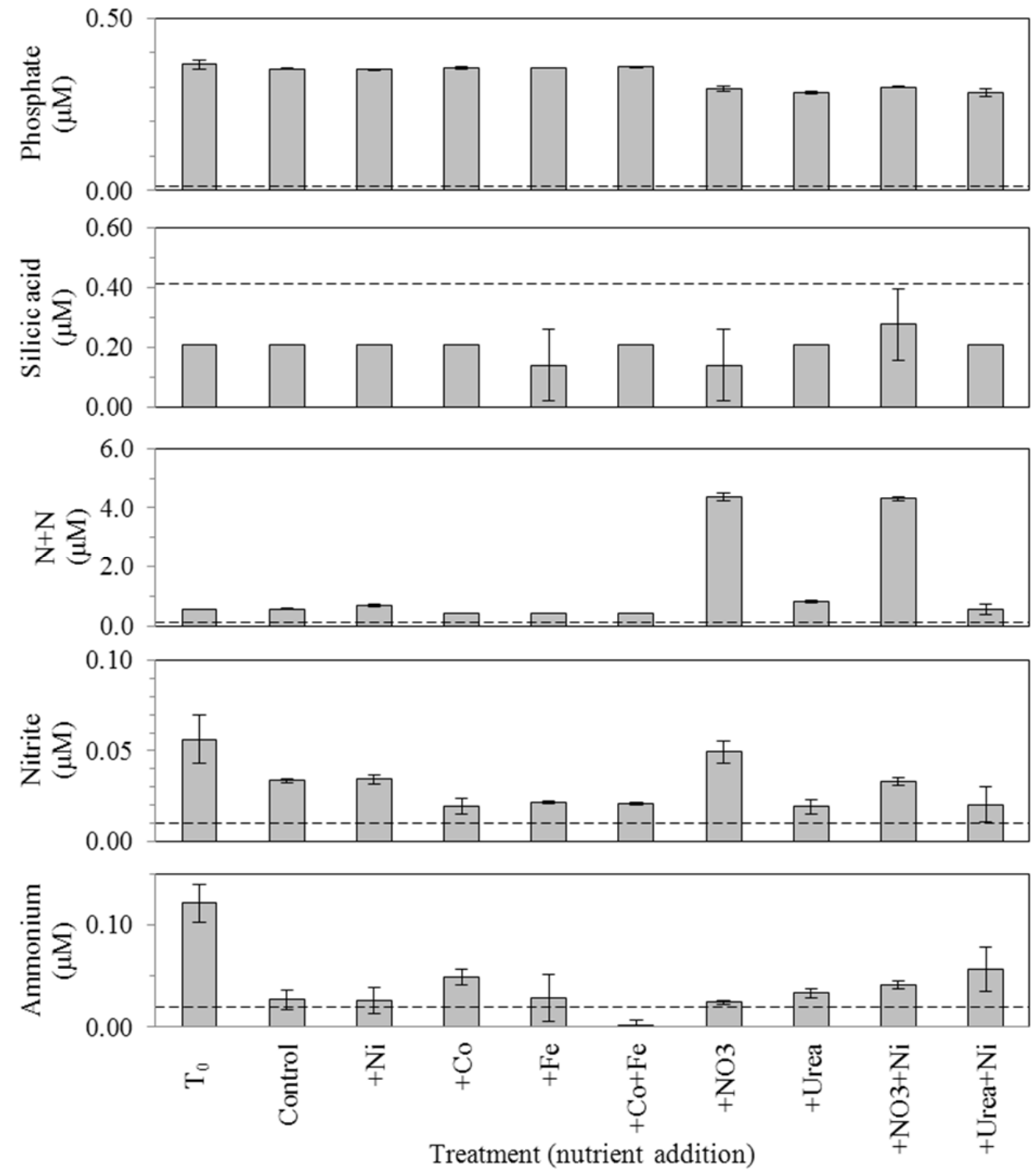

Figure 4. Nutrient data from 6-d bottle incubations performed in the South Pacific Gyre (MV1015 Station 4, 15m, $\left.271^{\circ} \mathrm{E},-23^{\circ} \mathrm{N}\right)$. Values are averages with error bars as standard deviation from triplicate biological replicates. $N+N$ is nitrate plus nitrate. Nutrient concentrations in the gyre are exceptionally low, therefore detection limits have been indicated with dashed lines; values below the detection limit are not statistically different from zero. Nitrogen stimulation is apparent in the $15-20 \%$ drawdown of phosphate as compared with the control and $T_{0}$ values. 

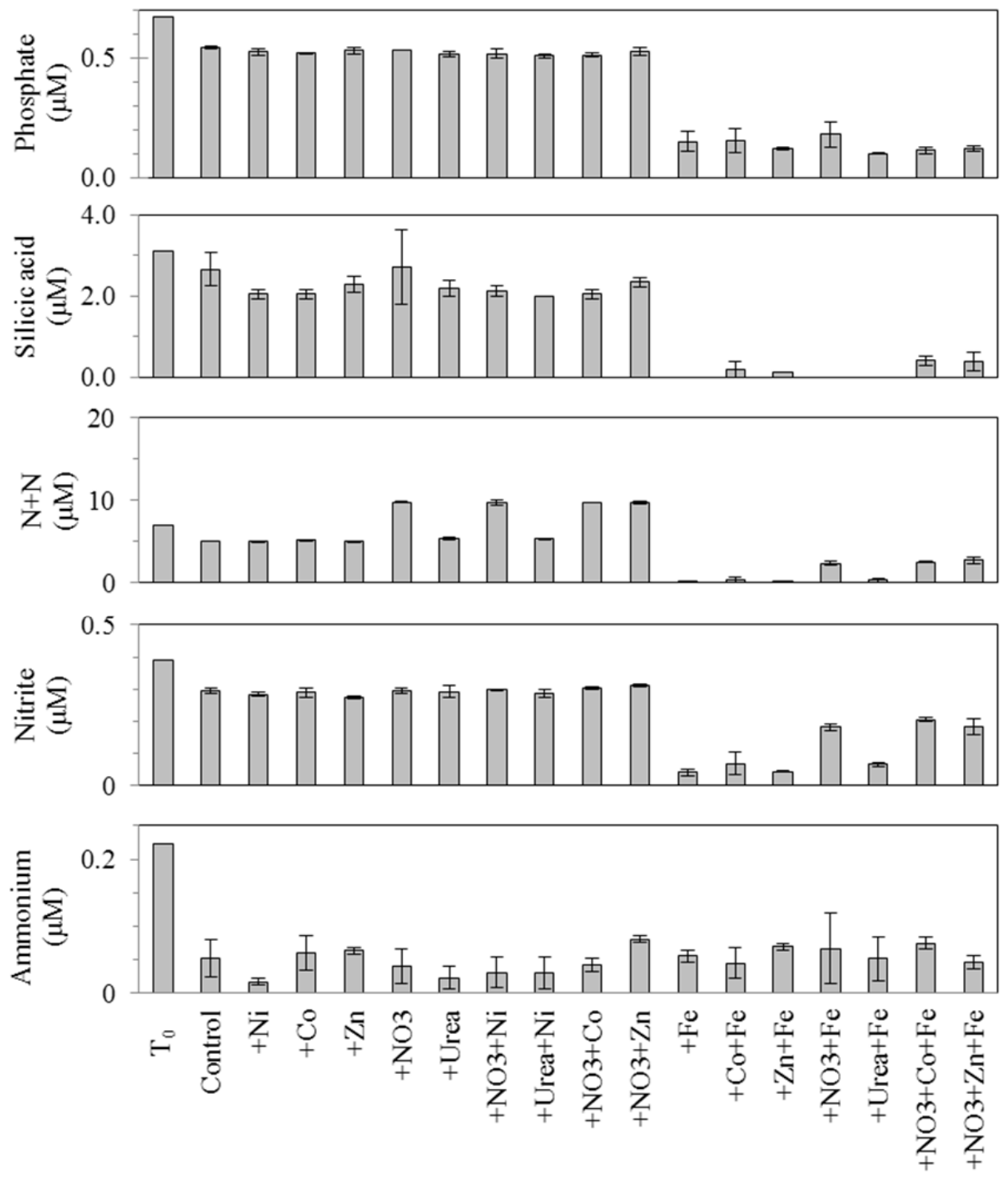

Treatment (nutrient addition)

Figure 5. Nutrient data from 3-d bottle incubations performed in the Equatorial Pacific Upwelling (KM1128 Station $\left.5,40 \mathrm{~m}, 202^{\circ} \mathrm{E}, 0^{\circ} \mathrm{N}\right)$. Values are averages with error bars as standard deviation from triplicate biological replicates (except for $\mathbf{T}_{\mathbf{0}}$ which is singleton). $\mathbf{N}+\mathbf{N}$ is nitrate plus nitrate. Iron stimulation is apparent in nutrient drawdown of phosphate, silicate, $\mathrm{N}+\mathrm{N}$, and nitrite. 


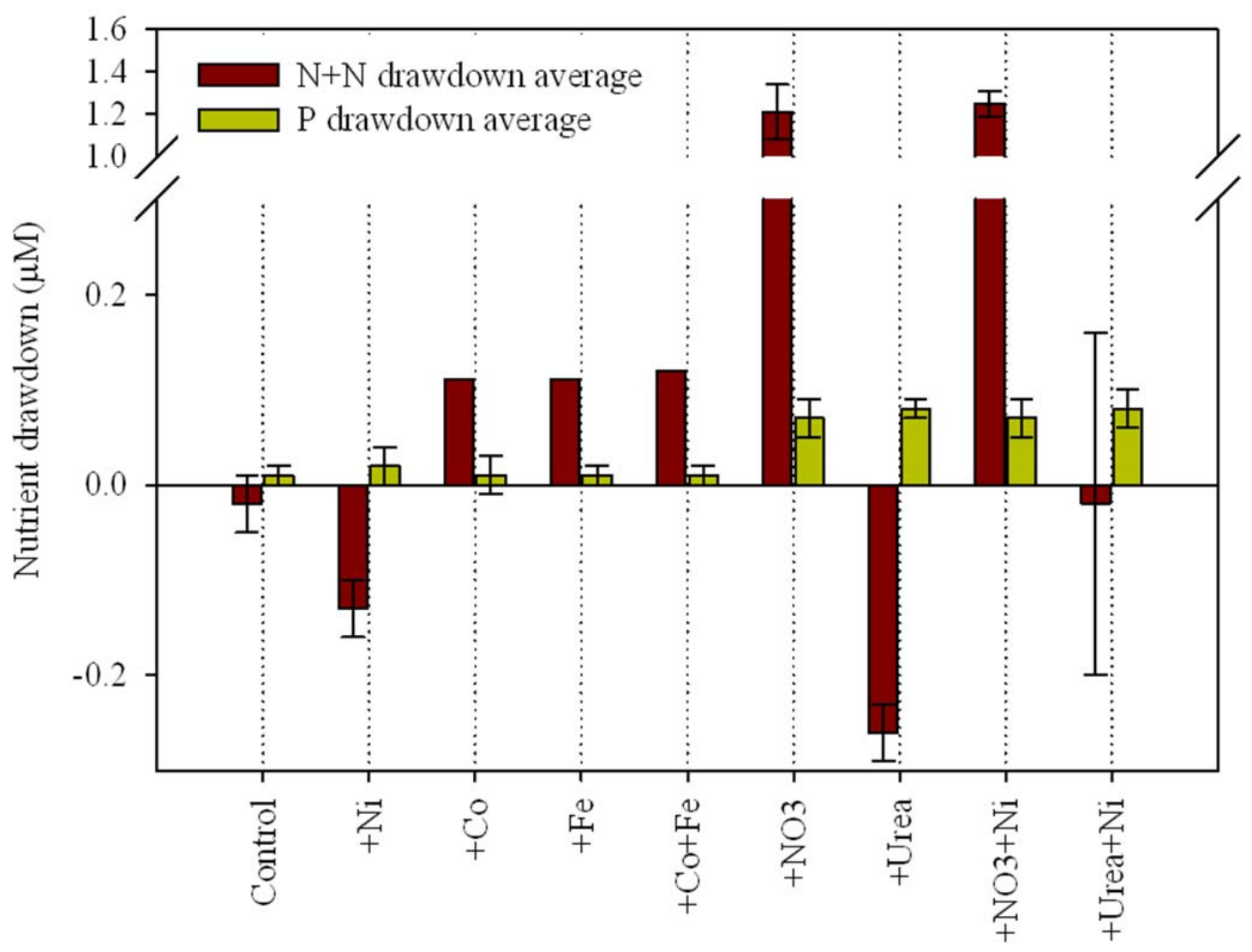

Nutrient addition

Figure 6. Drawdown values (time zero minus time final) for phosphate and inorganic nitrate plus nitrite $(\mathrm{N}+\mathrm{N})$ in the South Pacific Gyre incubation. Values are averages of biological triplicates with error bars showing standard deviation. Note that nickel is alone among the trace metal additions with a negative drawdown in nitrate. 


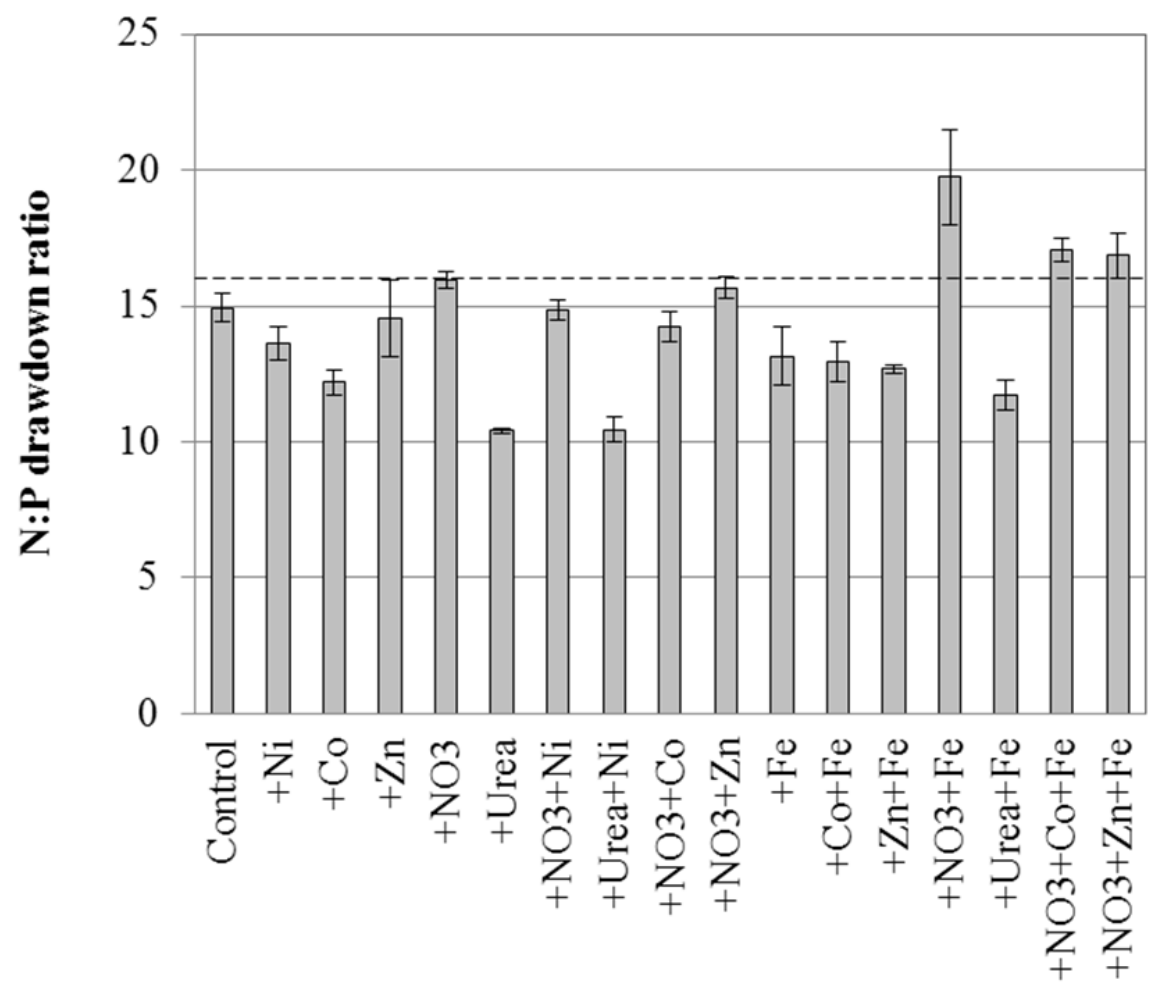

Treatment

Figure 7. N:P drawdown ratios from 3-d bottle incubations performed in the Equatorial Pacific Upwelling (KM1128 Station 5, 40m, $202^{\circ} \mathrm{E}, 0^{\circ} \mathrm{N}$ ). Dashed line indicates the Redfield N:P value of 16. Urea treatments force the N:P drawdown further below the Redfield line and the control value, as does iron addition without nitrate. Iron and nitrate additions combined result in elevated N:P drawdown ratios above both the control and Redfield values. Data are average values with error bars equal to the standard deviation of triplicate biological samples. 

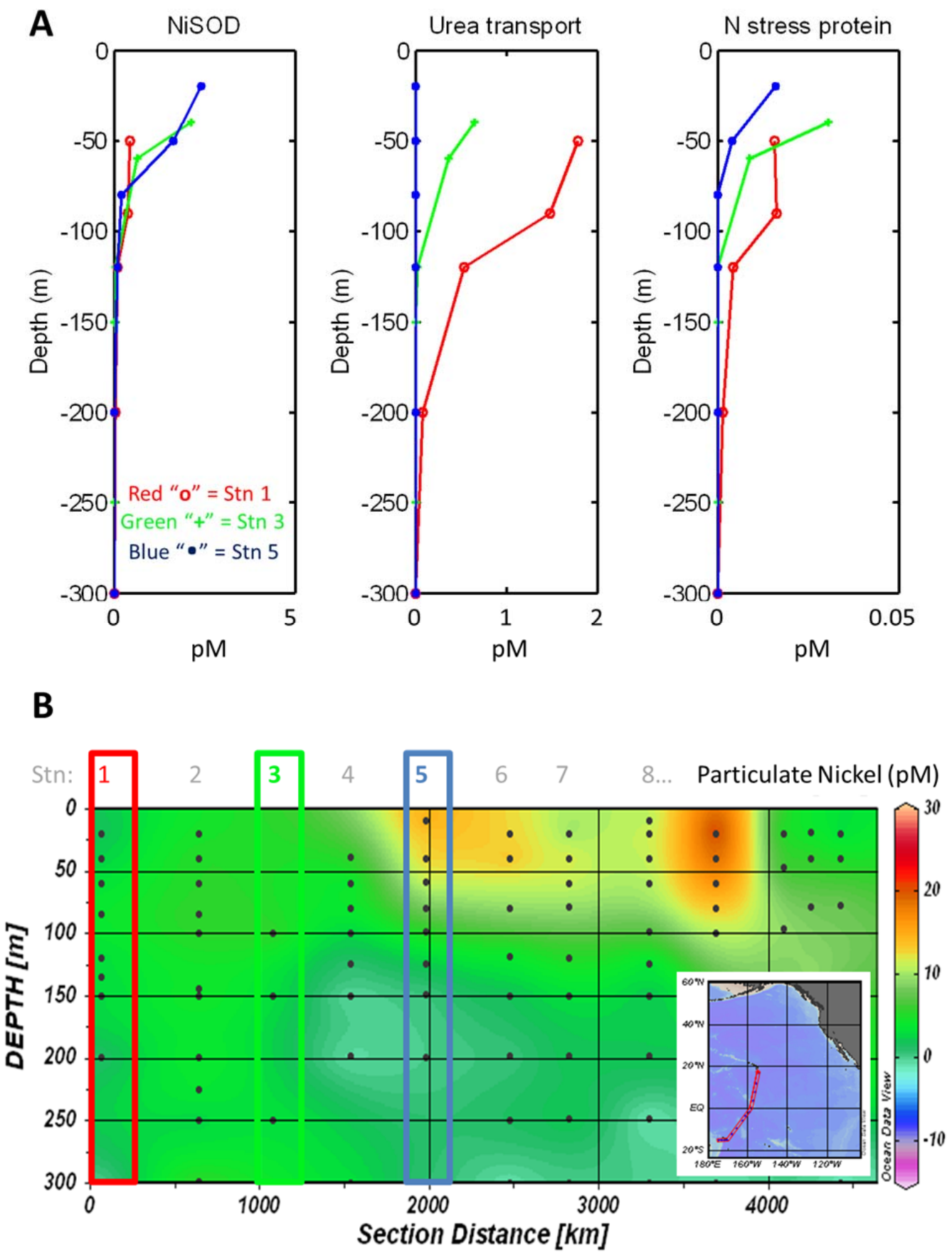

Figure 8. Quantitative proteomic depth profiles from the upwelling cruise (KM1128); red, green, and blue lines are Stations 1, 3, and 5 respectively (A). Lower plot is a section of particulate nickel (pM), showing elevated concentration in the surface waters where the incubation was conducted, figure prepared with ODV (Schlitzer 2011) (B). 

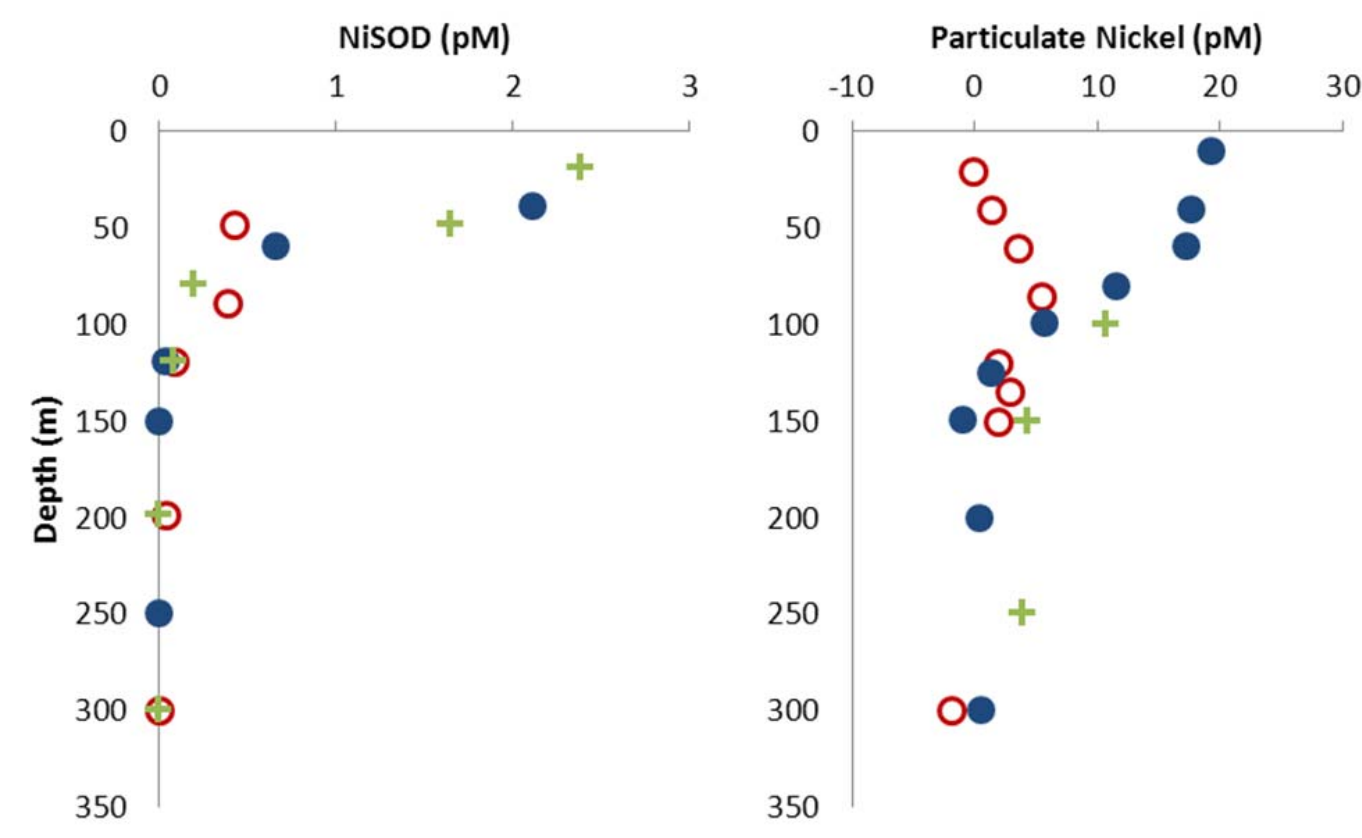

OStation $1 \quad$ Station $3 \quad+$ Station 5

Figure 9. NiSOD and particulate nickel concentration profiles at Stations 1 (red open circle), 3 (green plus), and 5 (blue closed circle). Methods for particulate metal analysis are still in development and blanks occasionally exceeded sample values resulting in several samples appearing below zero (note axis crossing at $\mathbf{- 1 0}$ for particulate nickel plot. 


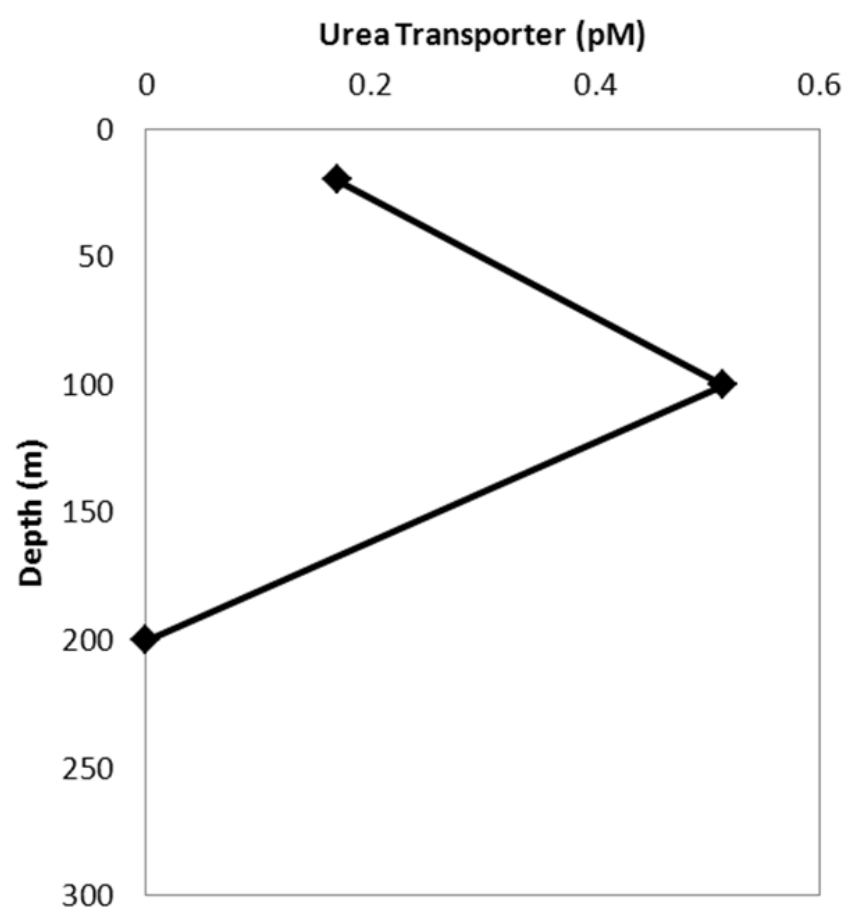

Figure 10. Quantitative urea transporter concentrations from field proteomics obtained on the gyre cruise (MV1015) at Station 4. Urea transporter concentrations are elevated in samples shallower than $100 \mathrm{~m}$ and near zero below $100 \mathrm{~m}$. 


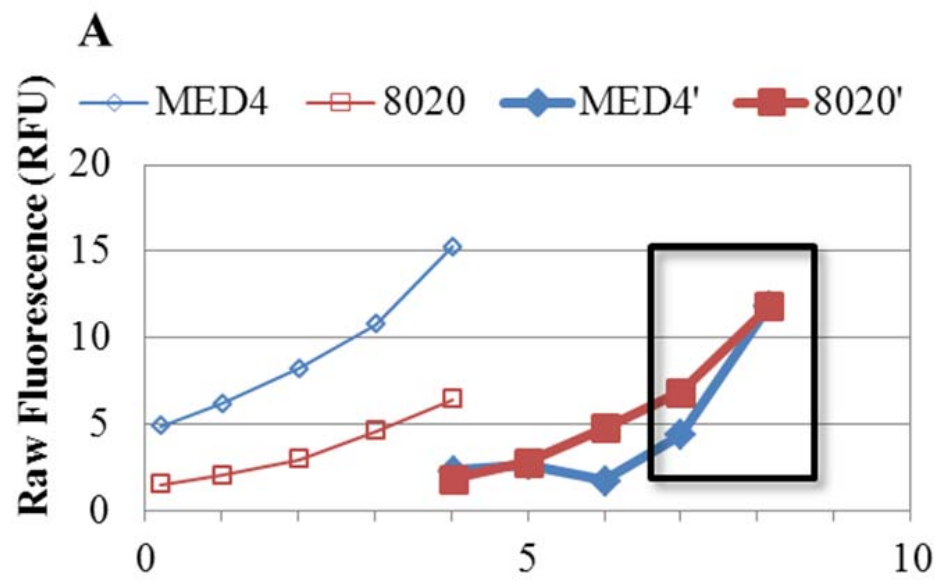

Elapsed Time (days)

\section{B}
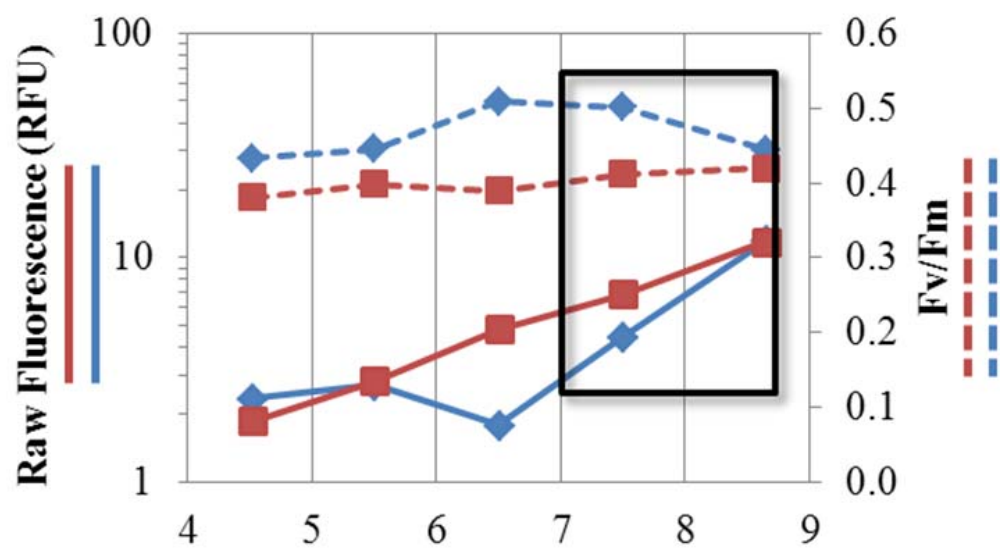

Elapsed Time (days)

Figure 11. Growth data from FIRe fluorescence time series for $1 \mathrm{~L}$ parent (open symbols) and daughter cultures (closed symbols) in preparation for the short-term uptake experiment (A). Comparison of fluorescence (solid lines) on a log-scale during exponential growth below the relatively constant $F_{v} / F_{m}$ data (dashed lines) (B). Diamonds indicate Prochlorococcus (MED4) data, while squares are for Synechococcus (WH8020) data. The boxed region highlights the window where uptake studies were conducted (roughly from day 7.5-8.5). Cultures for the time course experiment described in text behaved similarly. 

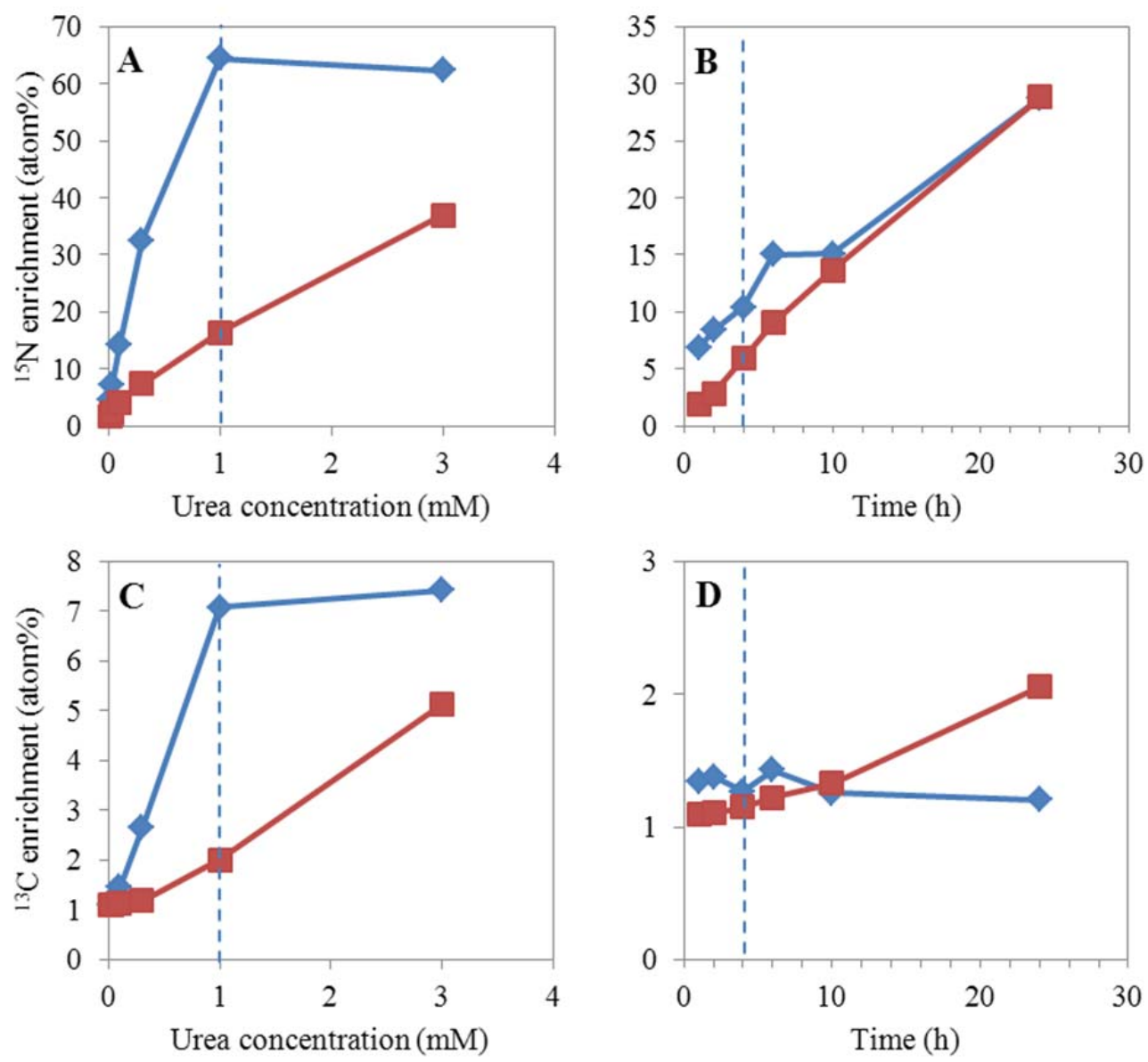

$\multimap$ Prochlorococcus (MED4)

Figure 12. Isotopic enrichment of particulate nitrogen (atom $\left.\%{ }^{15} \mathrm{~N}\right)(\mathrm{A}$ and $\mathrm{B})$ and carbon (atom $\left.\%{ }^{13} \mathrm{C}\right)(\mathrm{C}$ and D) for Prochlorococcus and Synechococcus incubations grown with isotopically labeled urea. Dashed line corresponds to comparable conditions between experiments where urea concentration and incubation duration were equal ( $1 \mathrm{mM}, 4 \mathrm{~h})$. 

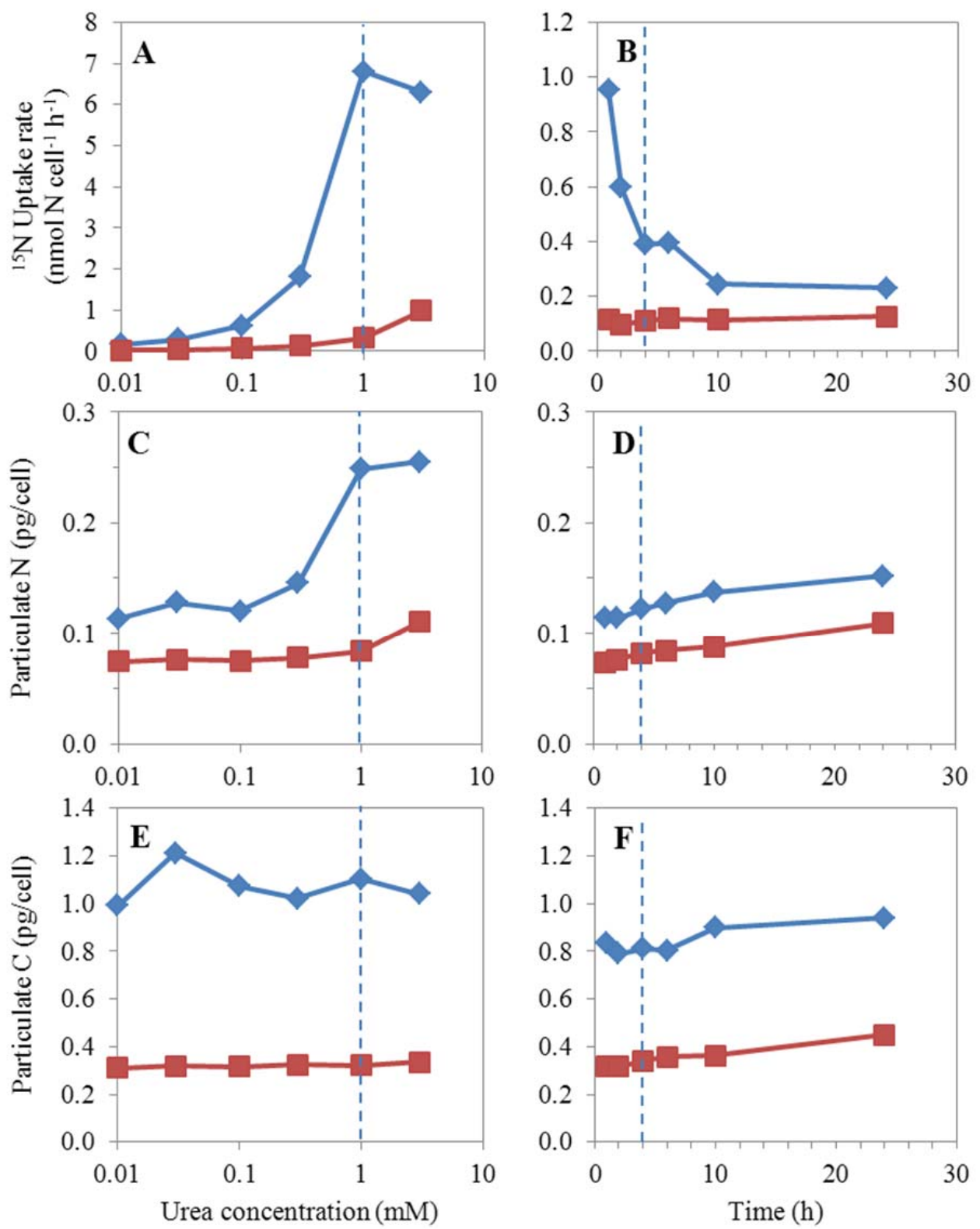

$\stackrel{- \text { Prochlorococcus (MED4) }}{\sim \text { Synechococcus (WH8020) }}$

Figure 13. Urea-N uptake rates and cellular nitrogen and carbon content for shortterm and time course uptake experiments. Dashed line corresponds to comparable conditions between experiments where urea concentration and incubation duration were equal $(1 \mathrm{mM}, 4 \mathrm{~h})$. Urea concentration axis is on log scale. Note: Trends are reliable, although the specific per-cell normalization is preliminary; as noted in the Discussion section, the cell counts are currently underestimated. 


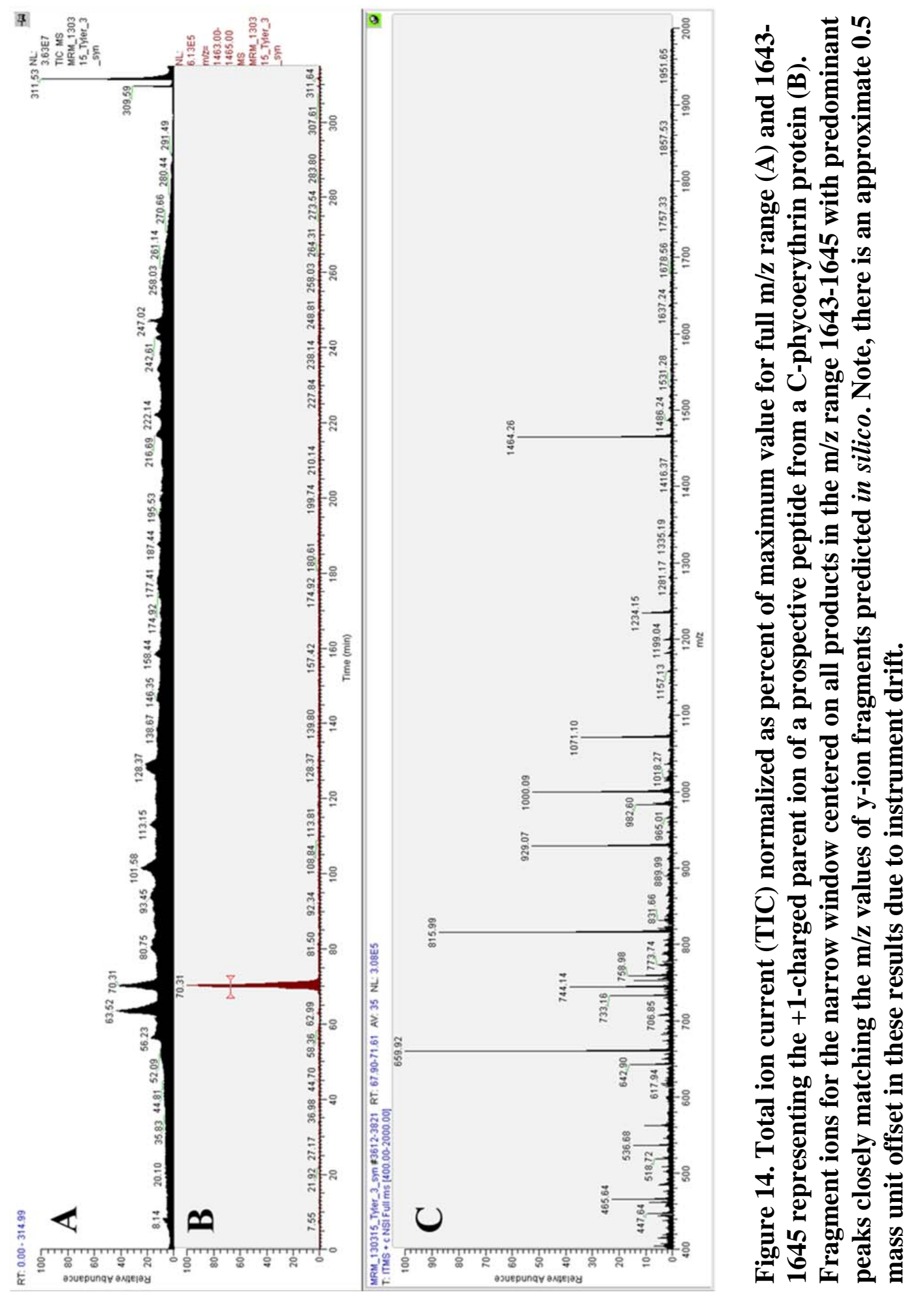




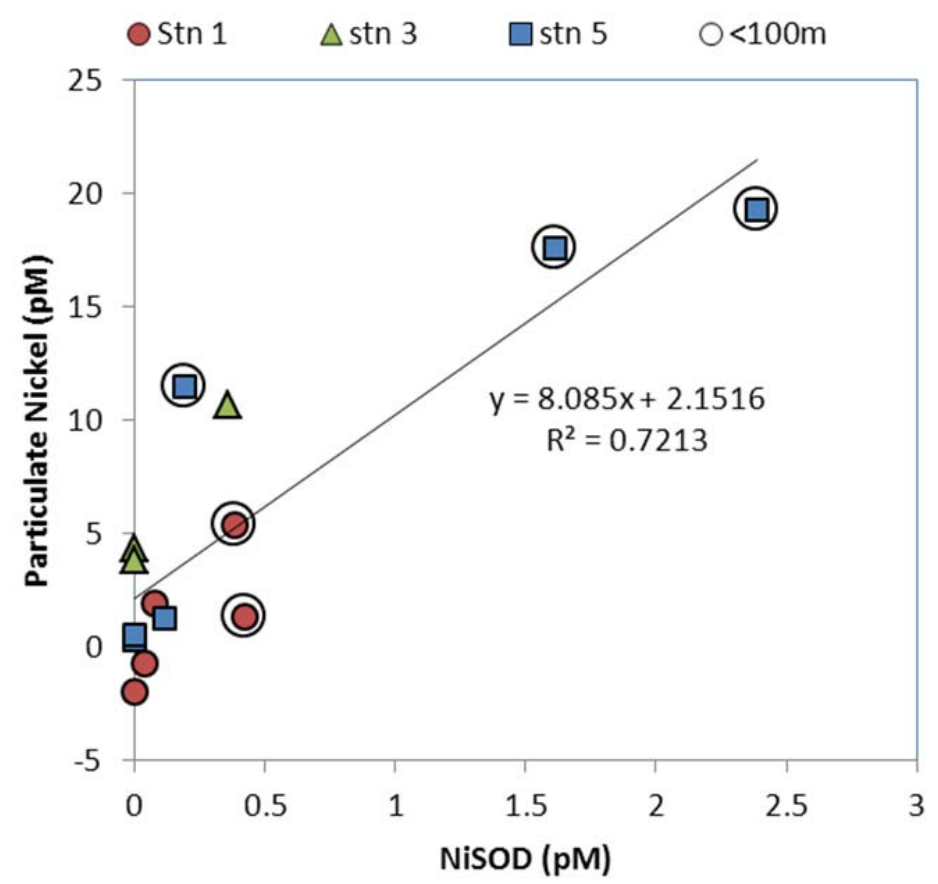

Figure 15. Particulate nickel versus NiSOD concentrations at Stations 1 (red circle), 3 (green triangle), and 5 (blue square). Comparison is limited to where sample depths were reasonably proximate. Depth mismatch for these data are all less than 9 $\mathrm{m}$ except Station 3, $100 \mathrm{~m}$ which is off by $20 \mathrm{~m}$ (low spatial resolution made interpolation impractical). Trend-line is for all data points. The particulate results are not fully blank-corrected and consequently several negative concentrations appear. 
Table 1. Field incubation experimental nutrient amendments added alone or in conjunction according to treatment description (e.g. +Fe+NO3 is a treatment with added iron and nitrate together).

\begin{tabular}{lr}
\hline Amendment & Final Concentration $(\mathrm{M})$ \\
\hline Nickel $(+\mathrm{Ni})$ & $5.0 \times 10^{-9}$ \\
Iron $(+\mathrm{Fe})$ & $1.0 \times 10^{-9}$ \\
Cobalt $(+\mathrm{Co})$ & $0.5 \times 10^{-9}$ \\
Zinc $(+\mathrm{Zn})$ & $1.0 \times 10^{-9}$ \\
Nitrate $\left(+\mathrm{NO}_{3}\right)$ & $5.0 \times 10^{-6}$ \\
Urea (+Urea) & $2.5 \times 10^{-6}$ \\
\hline
\end{tabular}

Table 2. Lab incubation experimental nutrient amendments; all constituents were provided into oligotrophic Sargasso seawater diluted with Milli-Q ${ }^{\mathrm{TM}}$ water $(25 \%)$ as described in text.

\begin{tabular}{lr}
\hline \hline Amendment & Final Concentration (M) \\
\hline EDTA & $10 \times 10^{-6}$ \\
$\mathrm{Na} 2 \mathrm{CO} 3$ & $20 \times 10^{-6}$ \\
$\mathrm{~K} 2 \mathrm{HPO} 4$ & $140 \times 10^{-6}$ \\
Urea* & $1.0 \times 10^{-3}$ \\
$\mathrm{Citric}$ Acid & $6.5 \times 10^{-6}$ \\
$\mathrm{FeCl}$ & $4 \times 10^{-6}$ \\
$\mathrm{NiCl}$ & $10.0 \times 10^{-9}$ \\
$\mathrm{MnSO}_{4}$ & $1.4 \times 10^{-6}$ \\
$\mathrm{Na}_{2} \mathrm{MoO}_{4}$ & $0.32 \times 10^{-6}$ \\
$\mathrm{ZnCl}_{2}$ & $0.15 \times 10^{-6}$ \\
$\mathrm{CoCl}_{2}$ & $0.17 \times 10^{-6}$ \\
\hline$*$ urea was provided at 1 mM for all \\
maintenance cultures and cultures used for \\
inoculation. Uptake experiment was at a \\
range of concentrations described in text.
\end{tabular}


Table 3. Field incubation station summary and comparison.

\begin{tabular}{lcc}
\hline \hline Parameter & MV1015 & KM1128 \\
& Station 4 & Station 5 \\
& South Pacific Gyre & Equatorial Pacific \\
\hline Location: Latitude, Longitude & $-23^{\circ} \mathrm{N}, 271^{\circ} \mathrm{E}$ & $0{ }^{\circ} \mathrm{N}, 202^{\circ} \mathrm{E}$ \\
Sea Surface Temperature $\left({ }^{\circ} \mathrm{C}\right)$ & 18.9 & 25.8 \\
Mixed Layer depth $(\mathrm{m})^{*}$ & 75 & 81 \\
$\mathrm{NO}_{3}{ }^{-}(\mu \mathrm{M})$ & 0.17 & 5.7 \\
$\mathrm{PO}_{4}{ }^{3-}(\mu \mathrm{M})$ & 0.4 & 0.65 \\
Dissolved N:P & 0.43 & 8.8 \\
Total dissolved iron $(\mathrm{nM})$ & 0.48 at $20 \mathrm{~m}$ & 0.75 at $40 \mathrm{~m}$ \\
Chlorophyll $a\left(\mu \mathrm{g} \cdot \mathrm{L}^{-3}\right)$ & 0.10 & 0.36 \\
Incubation water source depth $(\mathrm{m})$ & 15 & 40 \\
Incubation duration $(\mathrm{d})$ & 6 & 3 \\
\hline * Mixed layer depth determined by temperature criterion; $0.5^{\circ} \mathrm{C}$ deviation from surface \\
temperature.
\end{tabular}


Table 4. Dissolved nitrogen $(\mathrm{N})$ and phosphorus $(\mathrm{P})$ concentrations, drawdown, and N:P drawdown ratios for MV1015 gyre cruise.

\begin{tabular}{|c|c|c|c|c|c|c|c|c|c|c|}
\hline \multirow[b]{3}{*}{ Treatment * } & \multicolumn{7}{|c|}{$\mu \mathrm{M}$ Nutrient concentration $\ddagger$} & & & \multirow[b]{3}{*}{ Note $\dagger$} \\
\hline & \multirow{2}{*}{$\begin{array}{c}\text { Nitrate } \\
\text { added }\end{array}$} & \multirow{2}{*}{$\begin{array}{l}\mathrm{N}+\mathrm{N} \\
\text { ave. }\end{array}$} & \multirow{2}{*}{$\begin{array}{c}\mathrm{P} \\
\text { ave. }\end{array}$} & \multicolumn{2}{|c|}{$\mathrm{N}+\mathrm{N}$ drawdown } & \multicolumn{2}{|c|}{ P drawdown } & \multicolumn{2}{|c|}{$\mathrm{N}: \mathrm{P}$ drawdown } & \\
\hline & & & & ave. & $\pm \mathrm{std}$ & ave. & $\pm \mathrm{std}$ & ave. & $\pm \mathrm{std}$ & \\
\hline $\mathrm{T}_{0}$ & 0 & 0.56 & 0.37 & & & & & & & \\
\hline Control & 0 & 0.58 & 0.35 & -0.02 & 0.03 & 0.01 & 0.01 & & & $a, b$ \\
\hline$+\mathrm{Ni}$ & 0 & 0.69 & 0.35 & -0.13 & 0.03 & 0.02 & 0.02 & & & $\mathrm{a}$ \\
\hline$+\mathrm{Co}$ & 0 & 0.45 & 0.36 & 0.11 & 0.00 & 0.01 & 0.02 & & & $a, b$ \\
\hline$+\mathrm{Fe}$ & 0 & 0.45 & 0.36 & 0.11 & 0.00 & 0.01 & 0.01 & & & $a, b$ \\
\hline$+\mathrm{Co}+\mathrm{Fe}$ & 0 & 0.45 & 0.36 & 0.12 & 0.00 & 0.01 & 0.01 & & & $\mathrm{~b}$ \\
\hline +NO3 & 5 & 4.35 & 0.30 & 1.21 & 0.13 & 0.07 & 0.02 & 17.52 & 2.58 & $\mathrm{c}$ \\
\hline +Urea & 0 & 0.82 & 0.28 & -0.26 & 0.03 & 0.08 & 0.01 & -3.13 & 0.32 & $d$ \\
\hline$+\mathrm{NO} 3+\mathrm{Ni}$ & 5 & 4.31 & 0.30 & 1.25 & 0.06 & 0.07 & 0.02 & 19.32 & 3.86 & $\mathrm{c}$ \\
\hline +Urea+Ni & 0 & 0.58 & 0.28 & -0.02 & 0.18 & 0.08 & 0.02 & 0.11 & 2.04 & $\mathrm{~d}$ \\
\hline
\end{tabular}

* Except for $\mathrm{T}_{0}$, all data represent biological triplicate replication.

$\$$ Detection limit and level of significant difference in concentration are $0.11 \mu \mathrm{M}$ for $\mathrm{N}+\mathrm{N}$ and $0.01 \mu \mathrm{M}$ for phosphate. $\uparrow$ Notes: a, change in $\mathrm{N}+\mathrm{N}$ concentration is not statistically significant; $\mathrm{b}$, change in $\mathrm{P}$ concentration is not statistically significant; c, nitrate addition included in drawdown calculation; $\mathrm{d}$, negative $\mathrm{N}+\mathrm{N}$ drawdown implies conversion of a small portion of urea to nitrate or nitrite (statistically significant and minute for the + Urea treatment, but not significant in the + Urea+Ni treatment). 
Table 5. Dissolved nitrogen $(\mathrm{N})$ and phosphorus $(\mathrm{P})$ concentrations, drawdown, and N:P drawdown ratios for KM1128 upwelling cruise.

\begin{tabular}{|c|c|c|c|c|c|c|c|c|c|c|}
\hline \multirow[b]{3}{*}{ Treatment $*$} & \multicolumn{7}{|c|}{$\mu \mathrm{M}$ Nutrient concentration $\downarrow$} & & & \multirow[b]{3}{*}{ Note $\dagger$} \\
\hline & \multirow{2}{*}{$\begin{array}{l}\text { Nitrate } \\
\text { added }\end{array}$} & \multirow{2}{*}{$\begin{array}{l}\mathrm{N}+\mathrm{N} \\
\text { ave. }\end{array}$} & \multirow{2}{*}{$\begin{array}{c}\mathrm{P} \\
\text { ave. }\end{array}$} & \multicolumn{2}{|c|}{$\mathrm{N}+\mathrm{N}$ drawdown } & \multicolumn{2}{|c|}{$\mathrm{P}$ drawdown } & \multicolumn{2}{|c|}{$\mathrm{N}: \mathrm{P}$ drawdown } & \\
\hline & & & & ave. & $\pm \mathrm{std}$ & ave. & \pm std & ave. & $\pm \mathrm{std}$ & \\
\hline $\mathrm{T}_{0}$ & 0.0 & 6.99 & 0.67 & & & & & & & \\
\hline Control & 0.0 & 5.07 & 0.54 & 1.92 & 0.03 & 0.13 & 0.01 & 14.93 & 0.53 & \\
\hline$+\mathrm{Ni}$ & 0.0 & 5.00 & 0.52 & 1.99 & 0.09 & 0.15 & 0.01 & 13.63 & 0.62 & \\
\hline$+\mathrm{Co}$ & 0.0 & 5.16 & 0.52 & 1.83 & 0.05 & 0.15 & 0.00 & 12.19 & 0.44 & \\
\hline$+\mathrm{Zn}$ & 0.0 & 4.98 & 0.53 & 2.01 & 0.02 & 0.14 & 0.01 & 14.56 & 1.41 & \\
\hline +NO3 & 5.0 & 9.78 & 0.53 & 2.21 & 0.07 & 0.14 & 0.00 & 15.94 & 0.30 & $\mathrm{a}$ \\
\hline +Urea & 0.0 & 5.36 & 0.51 & 1.63 & 0.10 & 0.16 & 0.01 & 10.42 & 0.10 & $\mathrm{~b}$ \\
\hline$+\mathrm{NO} 3+\mathrm{Ni}$ & 5.0 & 9.71 & 0.52 & 2.28 & 0.27 & 0.15 & 0.02 & 14.84 & 0.35 & $\mathrm{a}$ \\
\hline+ Urea+Ni & 0.0 & 5.29 & 0.51 & 1.70 & 0.04 & 0.16 & 0.01 & 10.46 & 0.48 & $\mathrm{~b}$ \\
\hline$+\mathrm{NO} 3+\mathrm{Co}$ & 5.0 & 9.73 & 0.51 & 2.27 & 0.05 & 0.16 & 0.01 & 14.25 & 0.54 & $\mathrm{a}$ \\
\hline$+\mathrm{NO} 3+\mathrm{Zn}$ & 5.0 & 9.72 & 0.52 & 2.28 & 0.19 & 0.15 & 0.02 & 15.68 & 0.39 & $\mathrm{a}$ \\
\hline$+\mathrm{Fe}$ & 0.0 & 0.19 & 0.15 & 6.80 & 0.04 & 0.52 & 0.04 & 13.15 & 1.08 & \\
\hline$+\mathrm{Co}+\mathrm{Fe}$ & 0.0 & 0.33 & 0.15 & 6.66 & 0.32 & 0.52 & 0.05 & 12.95 & 0.74 & \\
\hline$+\mathrm{Zn}+\mathrm{Fe}$ & 0.0 & 0.03 & 0.12 & 6.96 & 0.01 & 0.55 & 0.01 & 12.69 & 0.15 & \\
\hline$+\mathrm{NO} 3+\mathrm{Fe}$ & 5.0 & 2.35 & 0.18 & 9.64 & 0.25 & 0.49 & 0.05 & 19.75 & 1.74 & $\mathrm{a}$ \\
\hline$+\mathrm{Urea}+\mathrm{Fe}$ & 0.0 & 0.32 & 0.10 & 6.67 & 0.29 & 0.57 & 0.00 & 11.70 & 0.55 & $\mathrm{~b}$ \\
\hline$+\mathrm{NO} 3+\mathrm{Co}+\mathrm{Fe}$ & 5.0 & 2.49 & 0.11 & 9.50 & 0.07 & 0.56 & 0.01 & 17.04 & 0.43 & $\mathrm{a}$ \\
\hline$+\mathrm{NO} 3+\mathrm{Zn}+\mathrm{Fe}$ & 5.0 & 2.74 & 0.12 & 9.25 & 0.40 & 0.55 & 0.01 & 16.85 & 0.85 & $\mathrm{a}$ \\
\hline
\end{tabular}

* Except for $\mathrm{T}_{0}$, all data represent biological triplicate replication.

$\$$ Detection limit and level of significant difference in concentration are $0.11 \mu \mathrm{M}$ for $\mathrm{N}+\mathrm{N}$ and $0.01 \mu \mathrm{M}$ for phosphate.

$\uparrow$ Notes: a, nitrate addition included in drawdown calculation; $b$, urea accounts for lower N:P drawdown because urea $\mathrm{N}$ contributes to the $\mathrm{N}$ quota reducing $\mathrm{N}+\mathrm{N}$ consumption. 
Table 6. Cell concentration for the uptake experiments with Synechococcus (WH8020), and Prochlorococcus (MED4). Parent culture was centrifuged and washed of natural abundance urea, resulting cell concentrate used to inoculate experiments with isotopically labeled urea.

\begin{tabular}{|c|c|c|c|c|}
\hline \multirow[b]{2}{*}{ Experiment } & \multirow[b]{2}{*}{$\begin{array}{l}\text { Cultured } \\
\text { organism }\end{array}$} & \multicolumn{3}{|c|}{ Cell concentration $\left(10^{6}\right.$ cell $\left.\mathrm{mL}^{-1}\right)$} \\
\hline & & $\begin{array}{l}\text { Parent } \\
\text { Culture }\end{array}$ & $\begin{array}{c}\text { Cell } \\
\text { Concentrate }\end{array}$ & Time $=0$ \\
\hline \multirow[t]{2}{*}{ 4-h uptake } & Synechococcus & 7.0 & 780 & 16 \\
\hline & Prochlorococcus & 2.0 & 39 & 1.5 \\
\hline \multirow[t]{2}{*}{ 24-h time course } & Synechococcus & 11 & 890 & 18 \\
\hline & Prochlorococcus & 2.4 & 111 & 2.2 \\
\hline
\end{tabular}


Table 7. Summary of time course (24 h) and short-term (4 h) urea uptake experiments with Synechococcus (WH8020) and Prochlorococcus (MED4).

\begin{tabular}{|c|c|c|c|c|c|c|c|c|c|}
\hline & \multicolumn{2}{|c|}{$\begin{array}{c}\text { Uptake } \\
\text { conditions }\end{array}$} & \multicolumn{2}{|c|}{ Enrichment $^{\mathrm{a}}$} & \multicolumn{2}{|c|}{$\begin{array}{c}\text { Elemental } \\
\text { quota }^{\mathrm{b}}\end{array}$} & \multirow[b]{2}{*}{$\mathrm{C}: \mathrm{N}$} & \multicolumn{2}{|c|}{ Uptake rates $^{\mathrm{c}}$} \\
\hline & $\begin{array}{c}\text { Urea } \\
(\mathrm{mM})\end{array}$ & $\begin{array}{l}\text { Duration } \\
\text { (h) }\end{array}$ & ${ }^{15} \mathrm{~N}$ & ${ }^{13} \mathrm{C}$ & $\mathrm{N}$ & C & & $\mathrm{N}$ & C \\
\hline \multirow{14}{*}{ 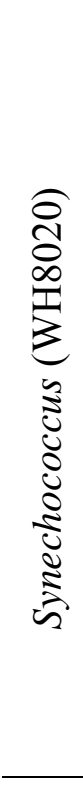 } & 1 & 0 & 0.34 & 1.08 & 0.13 & 0.54 & 4.2 & & \\
\hline & 1 & 1 & 1.89 & 1.09 & 0.07 & 0.32 & 4.3 & 0.114 & -.003 \\
\hline & 1 & 2 & 2.88 & 1.10 & 0.08 & 0.32 & 4.1 & 0.096 & 0.001 \\
\hline & 1 & 4 & 5.94 & 1.15 & 0.08 & 0.34 & 4.1 & 0.111 & 0.005 \\
\hline & 1 & 6 & 9.06 & 1.22 & 0.08 & 0.36 & 4.2 & 0.119 & 0.007 \\
\hline & 1 & 10 & 13.64 & 1.33 & 0.09 & 0.36 & 4.1 & 0.115 & 0.008 \\
\hline & 1 & 24 & 28.81 & 2.05 & 0.11 & 0.45 & 4.1 & 0.126 & 0.016 \\
\hline & 1 & 0 & 0.33 & 1.08 & 0.10 & 0.40 & 4.0 & & \\
\hline & 0.01 & 4 & 1.64 & 1.10 & 0.07 & 0.31 & 4.2 & 0.022 & 0.000 \\
\hline & 0.03 & 4 & 2.33 & 1.11 & 0.08 & 0.32 & 4.2 & 0.035 & 0.000 \\
\hline & 0.1 & 4 & 4.17 & 1.12 & 0.08 & 0.31 & 4.2 & 0.067 & 0.002 \\
\hline & 0.3 & 4 & 7.38 & 1.18 & 0.08 & 0.32 & 4.1 & 0.128 & 0.006 \\
\hline & 1 & 4 & 16.44 & 2.00 & 0.08 & 0.32 & 3.8 & 0.323 & 0.069 \\
\hline & 3 & 4 & 36.95 & 5.13 & 0.11 & 0.34 & 3.0 & 0.977 & 0.322 \\
\hline \multirow{14}{*}{ 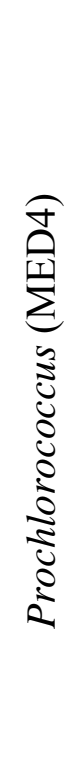 } & 1 & 0 & 0.36 & 1.08 & 0.27 & 1.15 & 4.3 & & \\
\hline & 1 & 1 & 6.84 & 1.35 & 0.11 & 0.83 & 7.3 & 0.953 & 0.121 \\
\hline & 1 & 2 & 8.40 & 1.38 & 0.11 & 0.79 & 6.9 & 0.597 & 0.066 \\
\hline & 1 & 4 & 10.43 & 1.27 & 0.12 & 0.81 & 6.6 & 0.388 & 0.020 \\
\hline & 1 & 6 & 15.03 & 1.43 & 0.13 & 0.80 & 6.3 & 0.396 & 0.026 \\
\hline & 1 & 10 & 15.12 & 1.26 & 0.14 & 0.90 & 6.5 & 0.245 & 0.008 \\
\hline & 1 & 24 & 28.79 & 1.20 & 0.15 & 0.94 & 6.2 & 0.230 & 0.002 \\
\hline & 1 & 0 & 0.35 & 1.09 & 0.21 & 0.93 & 4.4 & & \\
\hline & 0.01 & 4 & 4.48 & 1.10 & 0.11 & 0.99 & 8.7 & 0.166 & 0.000 \\
\hline & 0.03 & 4 & 7.33 & 1.20 & 0.13 & 1.21 & 9.5 & 0.296 & 0.014 \\
\hline & 0.1 & 4 & 14.32 & 1.46 & 0.12 & 1.07 & 8.9 & 0.620 & 0.047 \\
\hline & 0.3 & 4 & 32.51 & 2.64 & 0.15 & 1.02 & 7.0 & 1.801 & 0.193 \\
\hline & 1 & 4 & 64.47 & 7.08 & 0.25 & 1.10 & 4.4 & 6.804 & 0.824 \\
\hline & 3 & 4 & 62.31 & 7.43 & 0.26 & 1.04 & 4.1 & 6.298 & 0.833 \\
\hline
\end{tabular}

Notes: italicized values are the time-zero values for proceeding rows of uptake data; ${ }^{\mathrm{a}}$ atom $\% ;{ }^{\mathrm{b}} \mathrm{pg}$ cell ${ }^{-1}$, however, per-cell normalization is preliminary particularly for Prochlorococcus cells were not stained and cell clumping was prevalent; ${ }^{c}$ specific urea nitrogen or carbon uptake in nMol cell ${ }^{-1} \mathrm{~h}^{-1}$. 
Table 8. Tryptic peptide from the protein annotated " $C$-phycoerythrin class II beta chain cpaB-2 [WH8020]” with sequence: (R)ETYAALGVPTGSAAR(A) and parent mass of 1463.7. In general the $y$-ions were more readily observed. Bold italicized fonts indicate $y$-ions that were easily isolated in preliminary LTQ-MS results.

\begin{tabular}{ccccc}
\hline \hline \multicolumn{1}{c}{$\mathbf{b}$} & & & & $\mathbf{y}$ \\
\hline-- & 1 & E & 15 & --- \\
231.0975 & 2 & T & 14 & 1334.7063 \\
394.1609 & 3 & Y & $\mathbf{1 3}$ & $\mathbf{1 2 3 3 . 6 5 8 6}$ \\
465.1980 & 4 & A & $\mathbf{1 2}$ & $\mathbf{1 0 7 0 . 5 9 5 3}$ \\
536.2351 & 5 & A & $\mathbf{1 1}$ & $\mathbf{9 9 9 . 5 5 8 2}$ \\
649.3192 & 6 & L & $\mathbf{1 0}$ & $\mathbf{9 2 8 . 5 2 1 1}$ \\
706.3406 & 7 & $\mathbf{G}$ & $\mathbf{9}$ & $\mathbf{8 1 5 . 4 3 7 0}$ \\
805.4090 & 8 & $\boldsymbol{V}$ & $\mathbf{8}$ & $\mathbf{7 5 8 . 4 1 5 5}$ \\
902.4618 & 9 & $\mathbf{P}$ & $\mathbf{7}$ & $\mathbf{6 5 9 . 3 4 7 1}$ \\
1003.5095 & 10 & T & 6 & 562.2944 \\
1060.5310 & 11 & G & 5 & 461.2467 \\
1147.5630 & 12 & S & 4 & 404.2252 \\
1218.6001 & 13 & A & 3 & 317.1932 \\
1289.6372 & 14 & A & 2 & 246.1561 \\
--- & 15 & R & 1 & 175.1190 \\
\hline
\end{tabular}




\section{References}

Allen, A. E., C. L. Dupont, M. Oborník, A. Horák, A. Nunes-Nesi, J. P. McCrow, H. Zheng, D. a Johnson, H. Hu, A. R. Fernie, and C. Bowler. 2011. Evolution and metabolic significance of the urea cycle in photosynthetic diatoms. Nature 473: 2037.

Alonso-Sáez, L., A. S. Waller, D. R. Mende, K. Bakker, H. Farnelid, P. L. Yager, C. Lovejoy, J.-É. Tremblay, M. Potvin, F. Heinrich, M. Estrada, L. Riemann, P. Bork, C. Pedrós-Alió, and S. Bertilsson. 2012. Role for urea in nitrification by polar marine Archaea. Proceedings of the National Academy of Sciences of the United States of America 109: 17989-94.

Arrigo, K. 2005. Marine microorganisms and global nutrient cycles. Nature 437: 349-55.

Barondeau, D. P., C. J. Kassmann, C. K. Bruns, J. a Tainer, and E. D. Getzoff. 2004. Nickel superoxide dismutase structure and mechanism. Biochemistry 43: 8038-47.

Berman, T., and D. Bronk. 2003. Dissolved organic nitrogen: a dynamic participant in aquatic ecosystems. Aquatic Microbial Ecology 31: 279-305.

Bertilsson, S., O. Berglund, D. M. Karl, and S. W. Chisholm. 2003. Elemental composition of marine Prochlorococcus and Synechococcus: Implications for the ecological stoichiometry of the sea. Limnology and ... 48: 1721-1731.

Bishop, J. K. B., P. J. Lam, and T. J. Wood. 2012. Getting good particles: Accurate sampling of particles by large volume in-situ filtration. Limnology and Oceanography: Methods 10: 681-710.

Boyd, P. W. W., T. Jickells, C. S. Law, S. Blain, E. A. Boyle, K. O. Buesseler, K. H. Coale, J. J. Cullen, H. De Baar, M. Follows, others, H. J. W. De Baar, M. Harvey, C. Lancelot, and M. Levasseur. 2007. Mesoscale iron enrichment experiments 19932005: Synthesis and future directions. science 315: 612.

Boyle, E. a., S. John, W. Abouchami, J. F. Adkins, Y. Echegoyen-Sanz, M. Ellwood, a. R. Flegal, K. Fornace, C. Gallon, and S. Galer. 2012. GEOTRACES IC1 (BATS) contamination-prone trace element isotopes $\mathrm{Cd}, \mathrm{Fe}, \mathrm{Pb}, \mathrm{Zn}, \mathrm{Cu}$, and $\mathrm{Mo}$ intercalibration. Limnology and Oceanography: Methods 10: 653-665.

Bronk, D. 2002. Dynamics of DON, D.A. Hansell and C.A. Carlson [eds.]. Elsevier Inc. 
Bruland, K., E. Rue, and G. Smith. 2001. Iron and macronutrients in California coastal upwelling regimes: Implications for diatom blooms. Limnology and Oceanography 46: $1661-1674$.

Bruland, K. W., J. R. Donat, and D. A. Hutchins. 1991. Interactive influences of bioactive trace metals on biological production in oceanic waters. Limnology and Oceanography 36: 1555-1577.

Bruland, K. W., E. L. Rue, G. J. Smith, and G. R. DiTullio. 2005. Iron, macronutrients and diatom blooms in the Peru upwelling regime: brown and blue waters of Peru. Marine Chemistry 93: 81-103.

Butler, E. C. V., J. E. O’Sullivan, R. J. Watson, A. R. Bowie, T. a. Remenyi, and D. Lannuzel. 2013. Trace metals $\mathrm{Cd}, \mathrm{Co}, \mathrm{Cu}, \mathrm{Ni}$, and $\mathrm{Zn}$ in waters of the subantarctic and Polar Frontal Zones south of Tasmania during the "SAZ-Sense" project. Marine Chemistry 148: 63-76.

Canfield, D. E., A. N. Glazer, and P. G. Falkowski. 2010. The evolution and future of Earth's nitrogen cycle. Science (New York, N.Y.) 330: 192-6.

Carpenter, E. J., C. C. Remsen, and S. W. Watson. 1972. Utilization of urea by some marine phytoplankters. Limnology and oceanography 17: 265-269.

Carter, E. L., N. Flugga, J. L. Boer, S. B. Mulrooney, and R. P. Hausinger. 2009. Interplay of metal ions and urease. Metallomics : integrated biometal science 1: 207-21.

Casey, J. R., M. W. Lomas, J. Mandecki, and D. E. Walker. 2007. Prochlorococcus contributes to new production in the Sargasso Sea deep chlorophyll maximum. Geophysical Research Letters 34: L10604.

Cho, B., and F. Azam. 1995. Urea decomposition by bacteria in the Southern California Bight and its implications for the mesopelagic nitrogen cycle. Marine ecology progress series. Oldendorf 122: 21-26.

Collier, J. L., B. Brahamsha, and B. Palenik. 1999. The marine cyanobacterium Synechococcus sp. WH7805 requires urease (urea amiohydrolase, EC 3.5. 1.5) to utilize urea as a nitrogen source: molecular-genetic and biochemical analysis of the enzyme. Microbiology 145: 447-459.

DeManche, J. M., H. Curl, and D. D. Coughenower. 1973. An automated analysis for urea in seawater. Limnol. Oceanogr 18: 686-689. 
Dugdale, R., and J. Goering. 1967. Uptake of new and regenerated forms of nitrogen in primary productivity. Limnology and oceanography 12: 196-206.

Dugdale, R., and F. Wilkerson. 1986. The use of $15 \mathrm{~N}$ to measure nitrogen uptake in eutrophic oceans; experimental considerations. Limnology and Oceanography 3: 673-689.

Dupont, C. L., K. Barbeau, and B. Palenik. 2008. Ni uptake and limitation in marine Synechococcus strains. Applied and environmental microbiology 74: 23-31.

Dupont, C. L., K. N. Buck, B. Palenik, and K. Barbeau. 2010. Nickel utilization in phytoplankton assemblages from contrasting oceanic regimes. Deep Sea Research Part I: Oceanographic Research Papers 57: 553-566.

Fan, C., P. M. Glibert, J. Alexander, and M. W. Lomas. 2003. Characterization of urease activity in three marine phytoplankton species, Aureococcus anophagefferens, Prorocentrum minimum, and Thalassiosira weissflogii. Marine Biology 949-958.

Follows, M., and S. Dutkiewicz. 2011. Modeling diverse communities of marine microbes. Annual Review of Marine Science 3: 427-451.

Gandhi, N., S. Kumar, S. Prakash, R. Ramesh, and M. S. Sheshshayee. 2011. Measurement of marine productivity using $15 \mathrm{~N}$ and $13 \mathrm{C}$ tracers: Some methodological aspects. Journal of earth system ... 99-111.

Glibert, P. M., J. Harrison, C. Heil, and S. Seitzinger. 2006. Escalating Worldwide use of Urea - A Global Change Contributing to Coastal Eutrophication. Biogeochemistry 77: 441-463.

Glibert, P., and R. Ray. 1990. Different patterns of growth and nitrogen uptake in two clones of marine Synechococcus spp. Marine Biology 280: 273-280.

Gordon, R. M., K. S. Johnson, and K. H. Coale. 1998. The behaviour of iron and other trace elements during the IronEx-I and PlumEx experiments in the Equatorial Pacific. Deep Sea Research Part II: Topical Studies in Oceanography 45: 995-1041.

Harrison, W. G., E. J. H. Head, R. J. Conover, A. R. Longhurst, and D. D. Sameoto. 1985. The distribution and metabolism of urea in the eastern Canadian Aretie. Deep Sea Research ... 32.

Ho, T.-Y. 2013. Nickel limitation of nitrogen fixation in Trichodesmium. Limnol. Oceanogr 58: 112-120. 
Joubert, W. R., S. J. Thomalla, H. N. Waldron, M. I. Lucas, M. Boye, F. a. C. Le Moigne, F. Planchon, and S. Speich. 2011. Nitrogen uptake by phytoplankton in the Atlantic sector of the Southern Ocean during late austral summer. Biogeosciences 8: 29472959.

Keller, M., W. Bellows, and R. Guillard. 1988. Microwave treatment for sterilization of phytoplankton culture media. Journal of Experimental Marine ... 0981: 1-5.

Kondo, Y., and J. W. Moffett. 2013. Dissolved Fe(II) in the Arabian Sea oxygen minimum zone and western tropical Indian Ocean during the inter-monsoon period. Deep Sea Research Part I: Oceanographic Research Papers 73: 73-83.

Landry, M., and J. Constantinou. 2000. Biological response to iron fertilization in the eastern equatorial Pacific (IronEx II). III. Dynamics of phytoplankton growth and microzooplankton grazing. Marine Ecology ... 201: 57-72.

Lu, X., and H. Zhu. 2005. Tube-gel digestion: a novel proteomic approach for high throughput analysis of membrane proteins. Molecular \& cellular proteomics : MCP 4: $1948-58$.

Lund, B. A. 1987. Mutual interference of ammonium, nitrate, and urea on uptake of $15 \mathrm{~N}$ sources by the marine diatom Skeletonema costatum (Grev.) Cleve. Journal of Experimental Marine Biology and Ecology 113: 167-180.

Mackey, K. R. M., L. Bristow, D. R. Parks, M. a. Altabet, A. F. Post, and A. Paytan. 2011. The influence of light on nitrogen cycling and the primary nitrite maximum in a seasonally stratified sea. Progress in Oceanography 91: 545-560.

Marchetti, A., D. M. Schruth, C. a Durkin, M. S. Parker, R. B. Kodner, C. T. Berthiaume, R. Morales, A. E. Allen, and E. V. Armbrust. 2012. Comparative metatranscriptomics identifies molecular bases for the physiological responses of phytoplankton to varying iron availability. Proceedings of the National Academy of Sciences of the United States of America 109: E317-25.

Martin, J., and S. Fitzwater. 1988. Iron deficiency limits phytoplankton growth in the north-east Pacific subarctic. Nature 331: 341-343.

Martin-Jézéquel, V., M. Hildebrand, and M. A. Brzezinski. 2000. REVIEW SILICON METABOLISM IN DIATOMS: IMPLICATIONS FOR GROWTH. Journal of Phycology 36: 821-840.

McCarthy, J. 1972. The uptake of urea by natural populations of marine phytoplankton. Limnology and oceanography 17: 738-748. 
Moore, C. M., M. M. Mills, K. R. Arrigo, I. Berman-Frank, L. Bopp, B. P.W., E. D. Galbraith, R. J. Geider, C. Guieu, S. L. Jaccard, T. D. Jickells, J. La Roche, T. M. Lenton, N. M. Mahowald, E. Marañón, I. Marinov, J. K. Moore, T. Nakatsuka, A. Oschlies, M. A. Saito, T. F. Thingstad, A. Tsuda, and O. Ulloa. 2013. Regulation of marine phytoplankton by two nutrient limitation regimes. Nature Geoscience 6: 110.

Moore, J., S. Doney, D. Glover, and I. Fung. 2002a. Iron cycling and nutrient-limitation patterns in surface waters of the World Ocean. Deep Sea Research Part II: ... 49: 463-507.

Moore, L., A. Post, G. Rocap, and S. Chisholm. 2002b. Utilization of different nitrogen sources by the marine cyanobacteria Prochlorococcus and Synechococcus. Limnology and Oceanography 47: 989-996.

Moore, M. C., M. M. M. Mills, R. Langlois, A. Milne, E. P. Achterberg, J. La Roche, R. J. Geider, C. M. Moore, D.- Kiel, and J. LaRoche. 2008. Relative influence of nitrogen and phosphorus availability on phytoplankton physiology and productivity in the oligotrophic sub-tropical North Atlantic Ocean. Limnology and ... 53: 291305.

Van Mooy, B. a S., G. Rocap, H. F. Fredricks, C. T. Evans, and A. H. Devol. 2006. Sulfolipids dramatically decrease phosphorus demand by picocyanobacteria in oligotrophic marine environments. Proceedings of the National Academy of Sciences of the United States of America 103: 8607-12.

Morel, F. M. M., and N. M. Price. 2003. The biogeochemical cycles of trace metals in the oceans. Science (New York, N.Y.) 300: 944-7.

Morel, F., A. Milligan, and M. Saito. 2003. Marine bioinorganic chemistry: The role of trace metals in the oceanic cycles of major nutrients, p. 113-143. In The Oceans and Marine Geochemistry. Treatise on. Elsevier Ltd.

Morris, R. M., B. L. Nunn, C. Frazar, D. R. Goodlett, Y. S. Ting, and G. Rocap. 2010. Comparative metaproteomics reveals ocean-scale shifts in microbial nutrient utilization and energy transduction. The ISME journal 4: 673-85.

Mulrooney, S. B., and R. P. Hausinger. 2003. Nickel uptake and utilization by microorganisms. FEMS Microbiology Reviews 27: 239-261.

Noble, A. E., C. H. Lamborg, D. C. Ohnemus, P. J. Lam, T. J. Goepfert, C. I. Measures, C. H. Frame, K. L. Casciotti, G. R. DiTullio, J. Jennings, and M. a. Saito. 2012. Basin-scale inputs of cobalt, iron, and manganese from the Benguela-Angola front to the South Atlantic Ocean. Limnology and Oceanography 57: 989-1010. 
Nunn, B., J. Aker, S. Shaffer, and S. Tsai. 2009. Deciphering diatom biochemical pathways via whole-cell proteomics. Aquatic microbial 55: 241-253.

Oliveira, L., and N. J. Antia. 1986. Some observations on the urea-degrading enzyme of the diatom Cyclotella cryptica and the role of nickel in its production . Journal of Plankton Research 8 : 235-242.

Oliver, J. L., R. T. Barber, W. O. Smith, and H. W. Ducklow. 2004. The heterotrophic bacterial response during the Southern Ocean Iron Experiment ( SOFeX ). 49: 21292140 .

Painter, S. S. C., R. Sanders, H. H. N. Waldron, M. I. Lucas, and S. Torres- Valdés. 2008. Urea distribution and uptake in the Atlantic Ocean between $50^{\circ} \mathrm{N}$ and $50^{\circ} \mathrm{S}$. Marine Ecology Progress Series 368: 53-63.

Post, A., S. Penno, and K. Zandbank. 2011. Long term seasonal dynamics of Synechococcus population structure in the Gulf of Aqaba, Northern Red Sea. Frontiers in ... 2: 1-12.

Price, N., and P. Harrison. 1988a. Urea uptake by Sargasso Sea phytoplankton: saturated and in situ uptake rates. Deep Sea Research Part A. Oceanographic ... 35: 15791593.

Price, N. M., and P. J. Harrison. 1988b. Uptake of urea C and urea N by the coastal marine diatom Thalassiosira pseudonana. Limnology and oceanography 33: 528537.

Price, N. M., and F. M. M. Morel. 1991. Colimitation of phytoplankton nickel and nitrogen. Limnology 36.

Redfield, A. 1934. On the proportions of organic derivatives in sea water and their relation to the composition of plankton, p. 176-192. In R.J. Daniel [ed.], James Johnstone memorial volume. Univ. Press of Liverpool.

Remsen, C. C. 1971. The distribution of urea in coastal and oceanic waters. Limnology and Oceanography 16.

Rousseau, T. C. C., J. E. Sonke, J. Chmeleff, F. Candaudap, F. Lacan, G. Boaventura, P. Seyler, and C. Jeandel. 2013. Rare earth element analysis in natural waters by multiple isotope dilution - sector field ICP-MS. Journal of Analytical Atomic Spectrometry 28: 573.

Saito, M. A., E. M. Bertrand, S. Dutkiewicz, V. V. Bulygin, D. M. Moran, F. M. Monteiro, M. J. Follows, F. W. Valois, and J. B. Waterbury. 2011a. Iron 
conservation by reduction of metalloenzyme inventories in the marine diazotroph Crocosphaera watsonii. Proceedings of the National Academy of Sciences of the United States of America 108: 2184-9.

Saito, M. A., V. V. Bulygin, D. M. Moran, C. Taylor, and C. Scholin. 2011 b. Examination of microbial proteome preservation techniques applicable to autonomous environmental sample collection. Frontiers in microbiology 2: 215.

Saito, M. A., T. J. Goepfert, and J. T. Ritt. 2008. Some thoughts on the concept of colimitation: Three definitions and the importance of bioavailability. Limnol. Oceanogr. 53: 276-290.

Saito, M. a., and D. L. Schneider. 2006. Examination of precipitation chemistry and improvements in precision using the $\mathrm{Mg}(\mathrm{OH}) 2$ preconcentration inductively coupled plasma mass spectrometry (ICP-MS) method for high-throughput analysis of openocean Fe and Mn in seawater. Analytica Chimica Acta 565: 222-233.

Saito, M., G. Rocap, and J. Moffett. 2005. Production of cobalt binding ligands in a Synechococcus feature at the Costa Rica upwelling dome. Limnol. Oceanogr 50: 279-290.

Schlitzer, R. 2011. Ocean Data View.

Takahashi, T. 1985. Redfield ratio based on chemical data from isopycnal surfaces. Journal of Geophysical ... 90: 6907-6924.

Torres- Valdés, S., V. M. Roussenov, R. Sanders, X. P. Reynolds, R. Mather, A. Landolfi, G. A. Wolff, E. P. Achterberg, and R. G. Williams. 2009. Distribution of dissolved organic nutrients and their effect on export production over the Atlantic Ocean. Global Biogeochemical 23.

Twining, B. S., and S. B. Baines. 2013. The trace metal composition of marine phytoplankton. Annual review of marine science 5: 191-215.

Valladares, A., M. L. Montesinos, A. Herrero, and E. Flores. 2002. An ABC-type, highaffinity urea permease identified in cyanobacteria. Molecular microbiology 43: 70315.

Ventouras, L.-A. 2013. Iron and the ecology of marine microbes. Massachusetts Institute of Technology.

Wada, E., and A. Hattori. 1991. Nitrogen in the sea: forms, abundance, and rate processes, CRC Press, Inc. 
Wafar, M. V. M., P. Le Corre, and S. L'Helguen. 1995. $f$-Ratios calculated with and without urea uptake in nitrogen uptake by phytoplankton. Deep Sea Research Part I: Oceanographic Research Papers 42: 1669-1674.

Waldron, K. J., and N. J. Robinson. 2009. How do bacterial cells ensure that metalloproteins get the correct metal? Nature reviews. Microbiology 7: 25-35.

Waldron, K. J., J. C. Rutherford, D. Ford, and N. J. Robinson. 2009. Metalloproteins and metal sensing. Nature 460: 823-30.

Waterbury, J. B. J., S. W. S. Watson, F. F. W. Valois, and D. G. D. Franks. 1986. Biological and ecological characterization of the marine unicellular cyanobacterium Synechococcus. Can. Bull. Fish. Aquatic Sci. 214: 71-120.

Watt, R. K., and P. W. Ludden. 1999. Nickel-binding proteins. Cellular and molecular life sciences: CMLS 56: 604-25.

Zubkov, M., and B. Fuchs. 2003. High rate of uptake of organic nitrogen compounds by Prochlorococcus cyanobacteria as a key to their dominance in oligotrophic oceanic waters. Applied and ... 69: 1299-1304.

Zubkov, M. V, G. a Tarran, and B. M. Fuchs. 2004. Depth related amino acid uptake by Prochlorococcus cyanobacteria in the Southern Atlantic tropical gyre. FEMS microbiology ecology 50: 153-61. 


\section{Appendix}

\section{Proteomic analysis of uptake study cultures:}

About 60 and 100 unique proteins were identified in Prochorococcus and Synechococcus respectively (using two biological replicates from each). The top ten proteins detected for each culture strain in these samples are summarized in Appendix Table 1 and Appendix Table 2. Taking the most abundant protein and its average abundance score per technical replicate allows for rough comparison of bulk protein recovery; Synechococcus yields 23.8 hits vs 10.2 for Prochlorococcus. As anticipated based on visual observation of the colored protein extract and peptide digest solutions, photosystem accessory pigments (e.g. phycocyanin and phycoerythrin) dominated in the Synechococcus samples. 
Appendix Table 1. Most abundant global proteomic hits, Synechococcus.

\begin{tabular}{llcccc}
\hline & & \multicolumn{5}{c}{ Relative abundance score } \\
\cline { 3 - 6 } & Mol. & \multicolumn{3}{c}{} \\
& Wt. & Sample & Sample & & \\
Protein or protein family grouping & $(\mathrm{kDa})$ & $\# 1$ & $\# 2$ & Sum & Ave \\
\hline Phycoerythrin & 18 & 40.3 & 7.2 & 47.5 & 23.8 \\
Phycocyanin & 17 & 8.7 & 5.9 & 14.6 & 7.3 \\
Magnesium chelatase & 149 & 3.2 & 2.7 & 5.9 & 2.9 \\
Translation elongation factor & 44 & 4.0 & 1.4 & 5.3 & 2.7 \\
Putative phosphodiesterase & 15 & 3.2 & 1.8 & 5.0 & 2.5 \\
Conserved hypothetical protein & 44 & 1.6 & 2.3 & 3.8 & 1.9 \\
Ferredoxin-dependent glutamate synthase & 165 & 1.6 & 1.8 & 3.4 & 1.7 \\
Glutamine synthetase, type I glnA & 53 & 2.4 & 0.9 & 3.3 & 1.6 \\
30S ribosomal protein & 41 & 0.8 & 2.3 & 3.1 & 1.5 \\
ATP synthase & 54 & 1.6 & 1.4 & 2.9 & 1.5 \\
\hline
\end{tabular}

Appendix Table 2. Most abundant global proteomic hits, Prochlorococcus.

\begin{tabular}{llcccc}
\hline \hline & & \multicolumn{3}{c}{ Relative abundance score } \\
\cline { 3 - 6 } & Mol. & & & & \\
Protein or protein family grouping & Wt. & Sample & Sample & & \\
\hline Carboxysome shell protein & 10 & 2.8 & 17.7 & 20.5 & 10.2 \\
Ferredoxin-dependent glutamate synthase & 168 & 2.8 & 11.8 & 14.6 & 7.3 \\
Pyridoxal-dependent decarboxylase fam. & 51 & 11.2 & 2.9 & 14.1 & 7.1 \\
Phosphoribosylglycinamide synthetase & 49 & 5.6 & 5.9 & 11.5 & 5.7 \\
Translocase & 108 & 8.4 & 2.9 & 11.3 & 5.7 \\
Putative RNA methylase & 43 & 11.2 & 0.0 & 11.2 & 5.6 \\
Tyrosine binding protein & 67 & 0.0 & 8.8 & 8.8 & 4.4 \\
Hypothetical protein & 150 & 0.0 & 8.8 & 8.8 & 4.4 \\
Transcriptional-repair coupling factor & 135 & 5.6 & 2.9 & 8.5 & 4.3 \\
Putative sulfate transporter & 58 & 8.4 & 0.0 & 8.4 & 4.2 \\
\hline
\end{tabular}




\section{Particulate elements from KM1128 meridional cruise section (Hawaii to Samoa)}

Particulate biogenic elemental data (operationally defined in Methods) is still in development and the following figures are presented as preliminary figures only to complement the proteomic data presented here and reference to compare with future data. Stations detailed as in main text, Figure 8. Figures prepared with ODV (Schlitzer 2011).

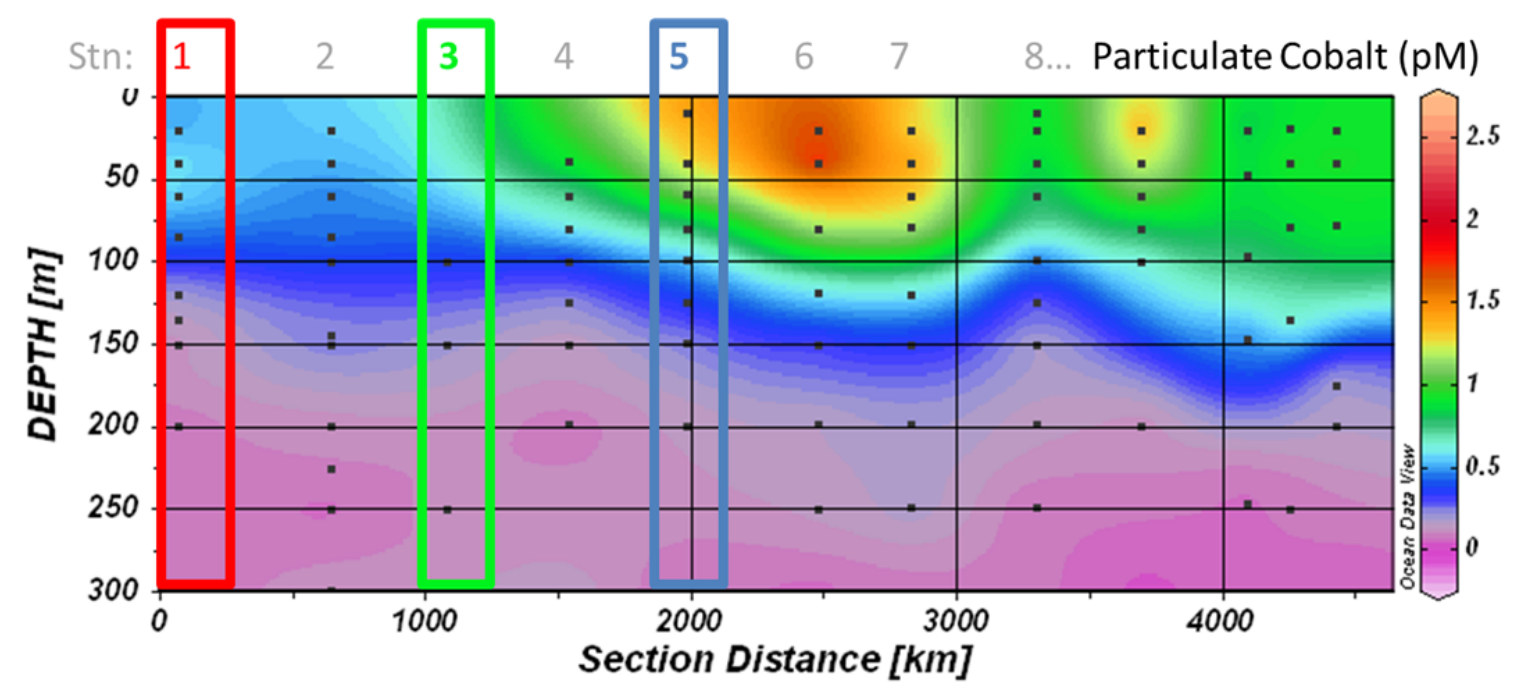

Figure A1. Preliminary particulate cobalt concentrations across the KM1128 cruise transect crossing the Equatorial Pacific Upwelling (at 2000 km in section distance).

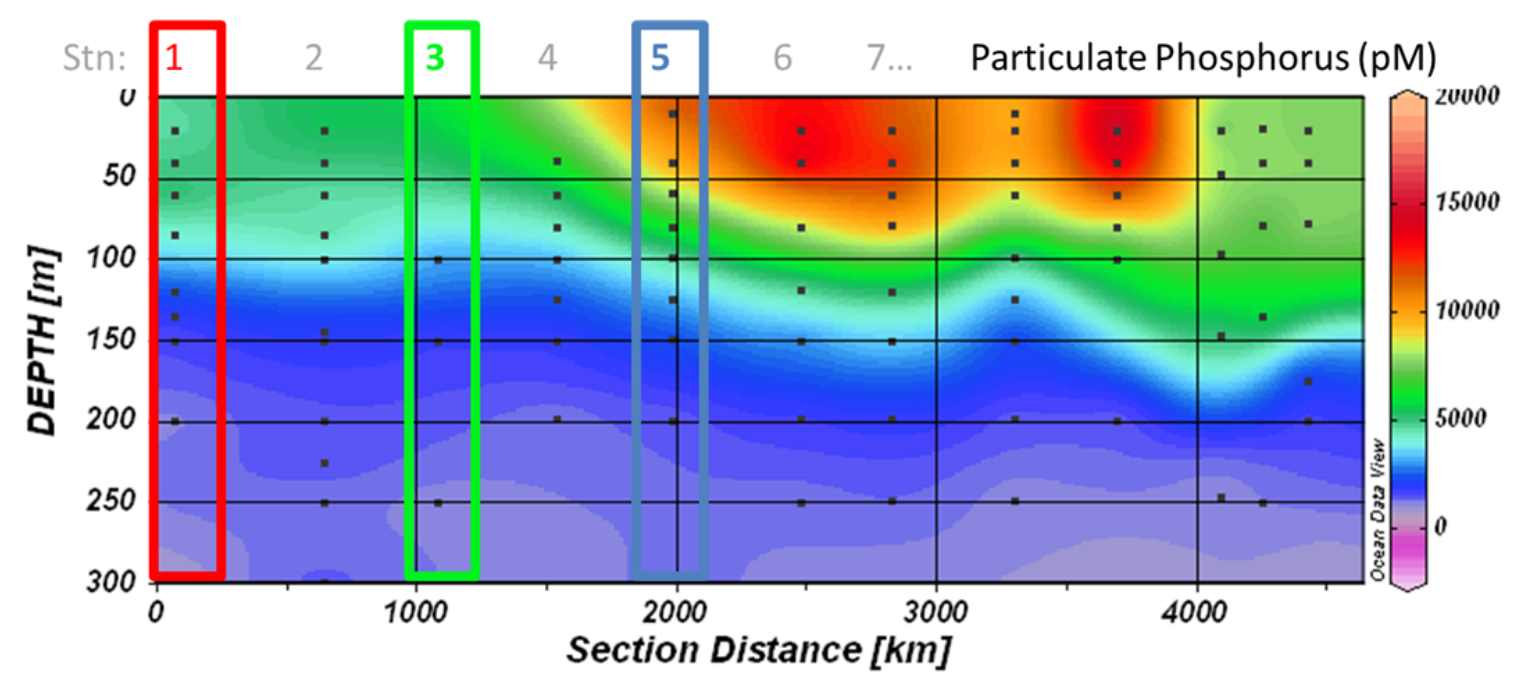

Figure A2. Preliminary particulate phosphorus concentrations across the KM1128 cruise transect crossing the Equatorial Pacific Upwelling (at $2000 \mathrm{~km}$ in section distance). 


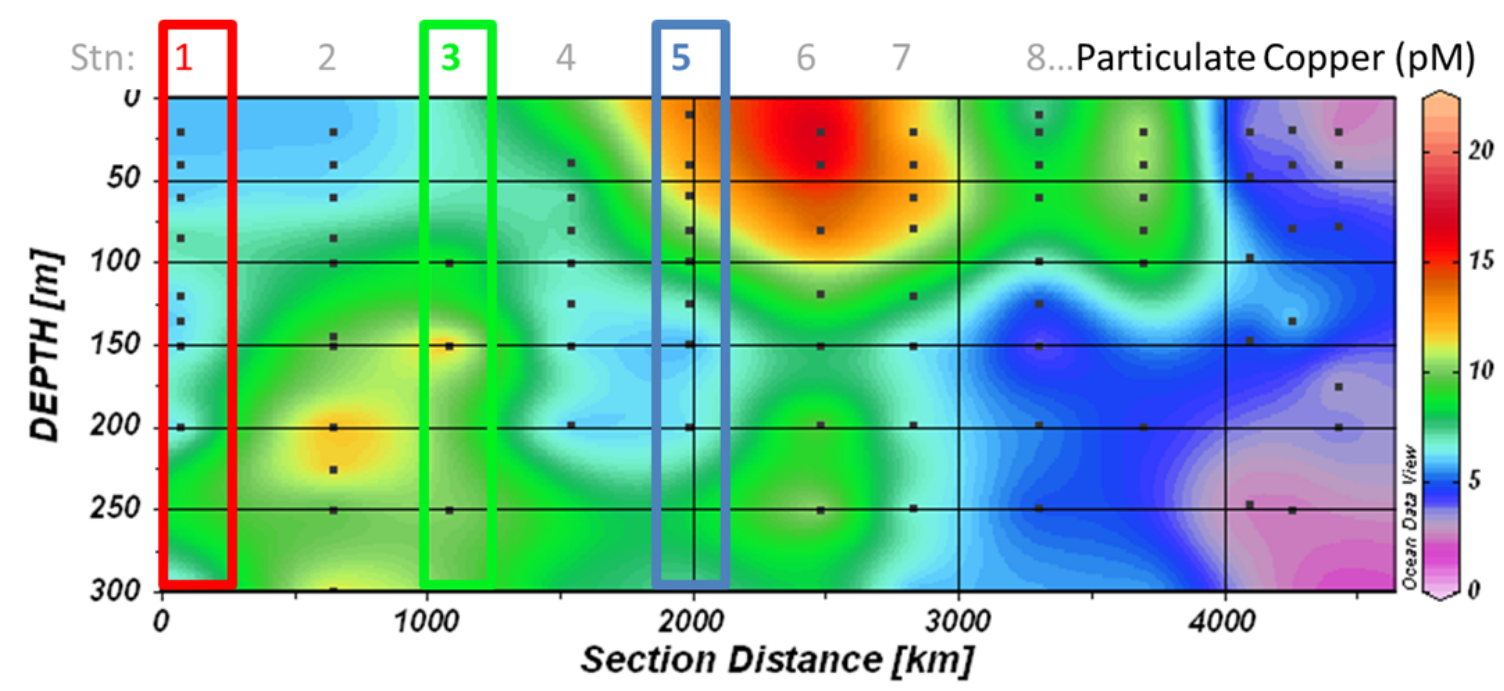

Figure A3. Preliminary particulate copper concentrations across the KM1128 cruise transect crossing the Equatorial Pacific Upwelling (at 2000 km in section distance).

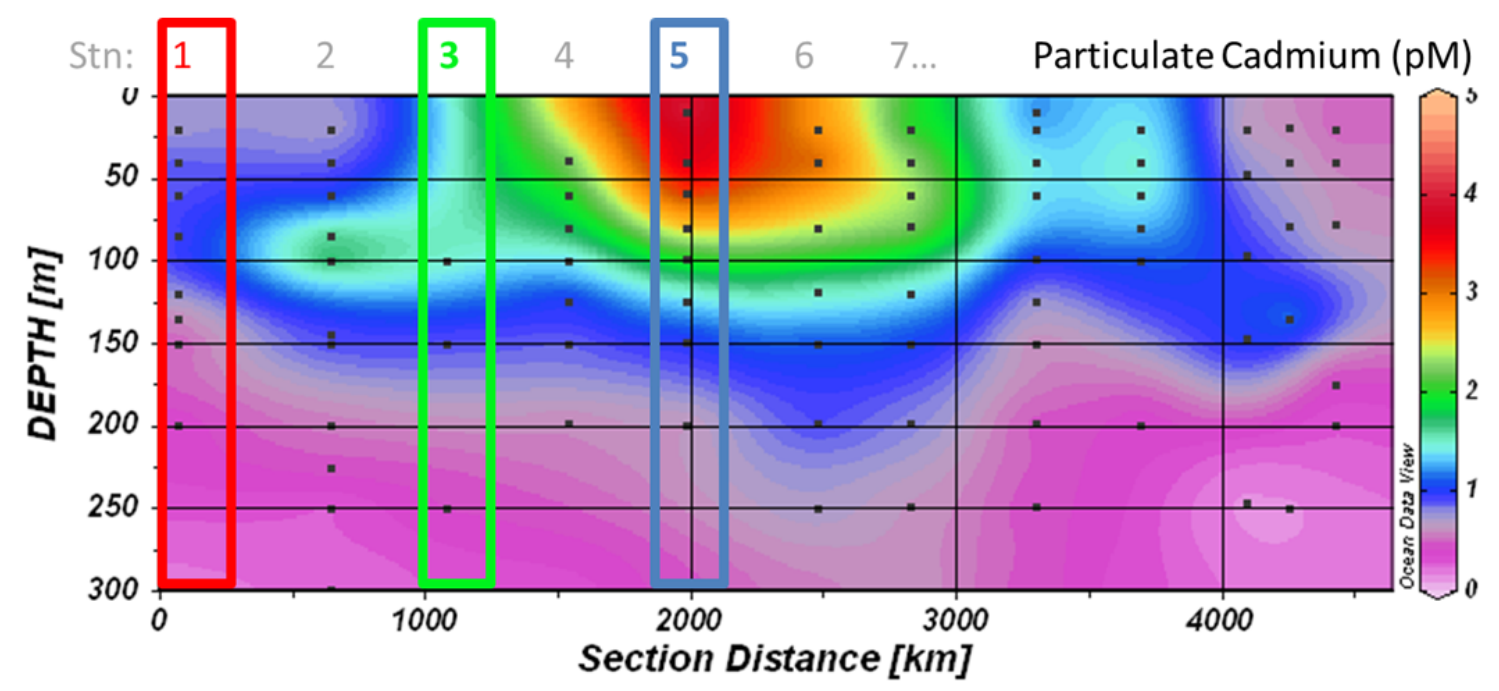

Figure A4. Preliminary particulate cadmium concentrations across the KM1128 cruise transect crossing the Equatorial Pacific Upwelling (at $2000 \mathrm{~km}$ in section distance). 


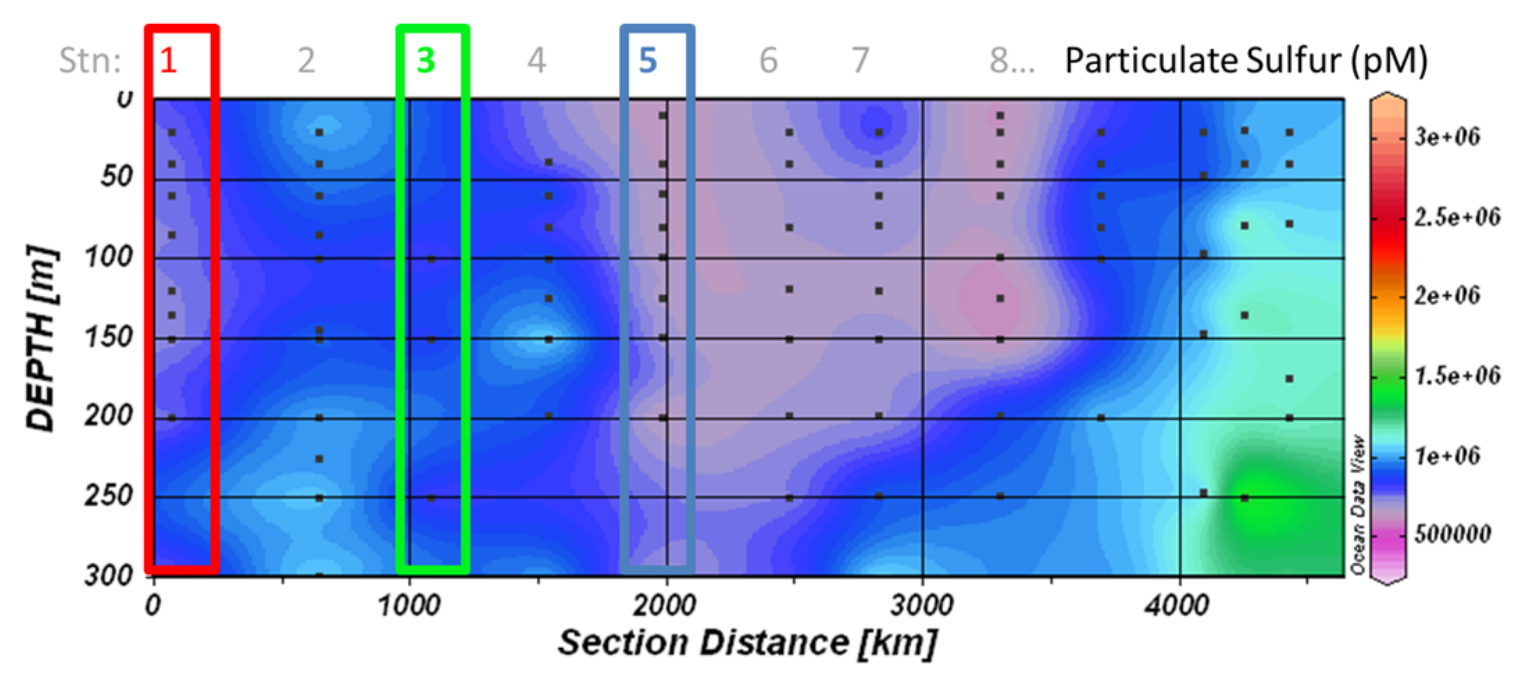

Figure A5. Preliminary particulate sulfur concentrations across the KM1128 cruise transect crossing the Equatorial Pacific Upwelling (at $2000 \mathrm{~km}$ in section distance).

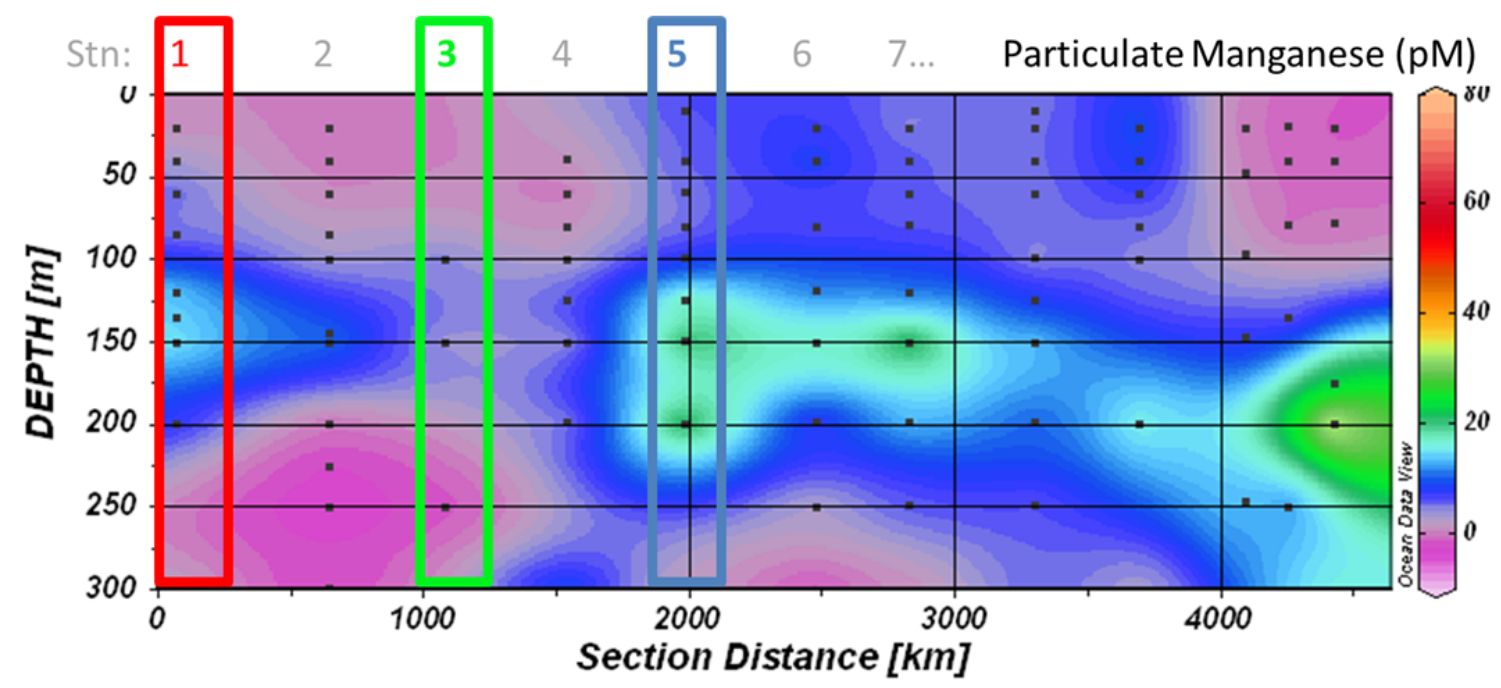

Figure A6. Preliminary particulate manganese concentrations across the KM1128 cruise transect crossing the Equatorial Pacific Upwelling (at 2000 km in section distance). Note: unresolved blank issues led to some negative values. 


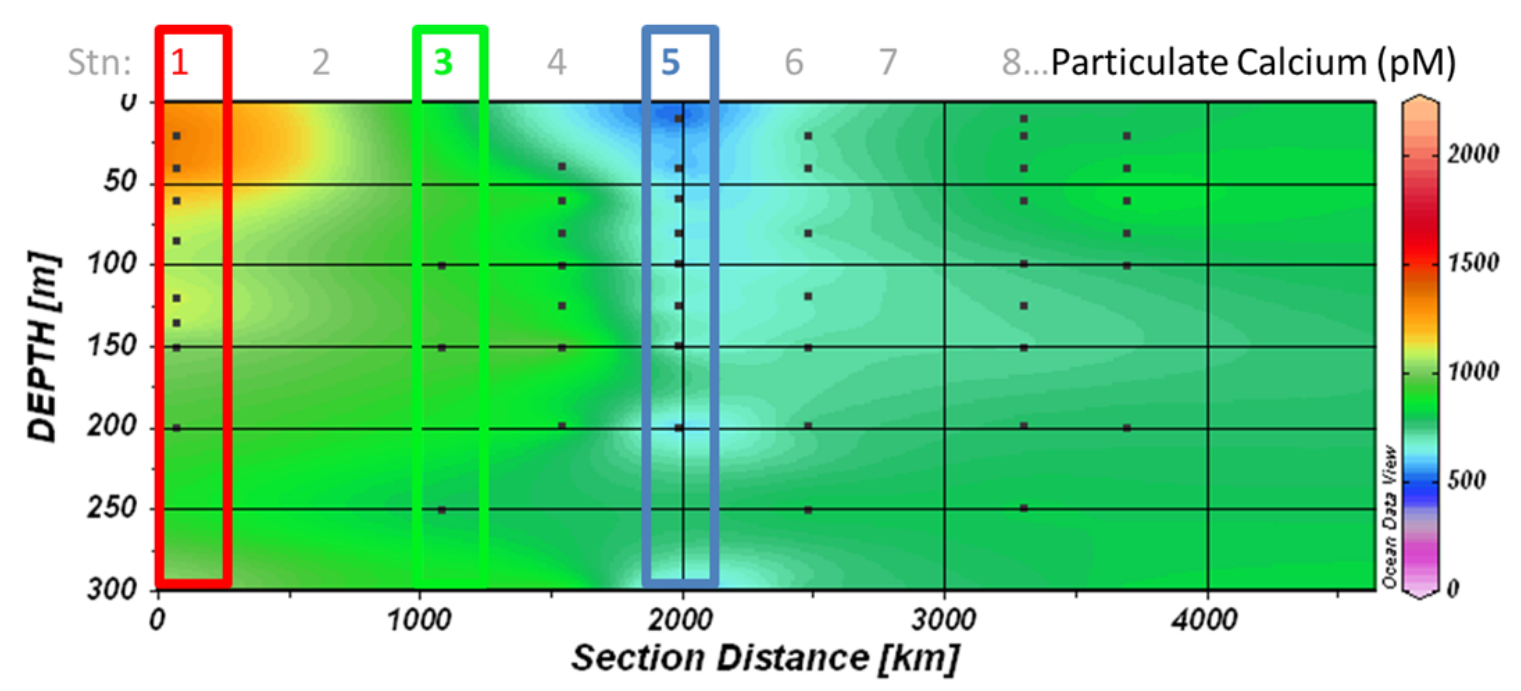

Figure A7. Preliminary particulate calcium concentrations across the KM1128 cruise transect crossing the Equatorial Pacific Upwelling (at 2000 km in section distance).

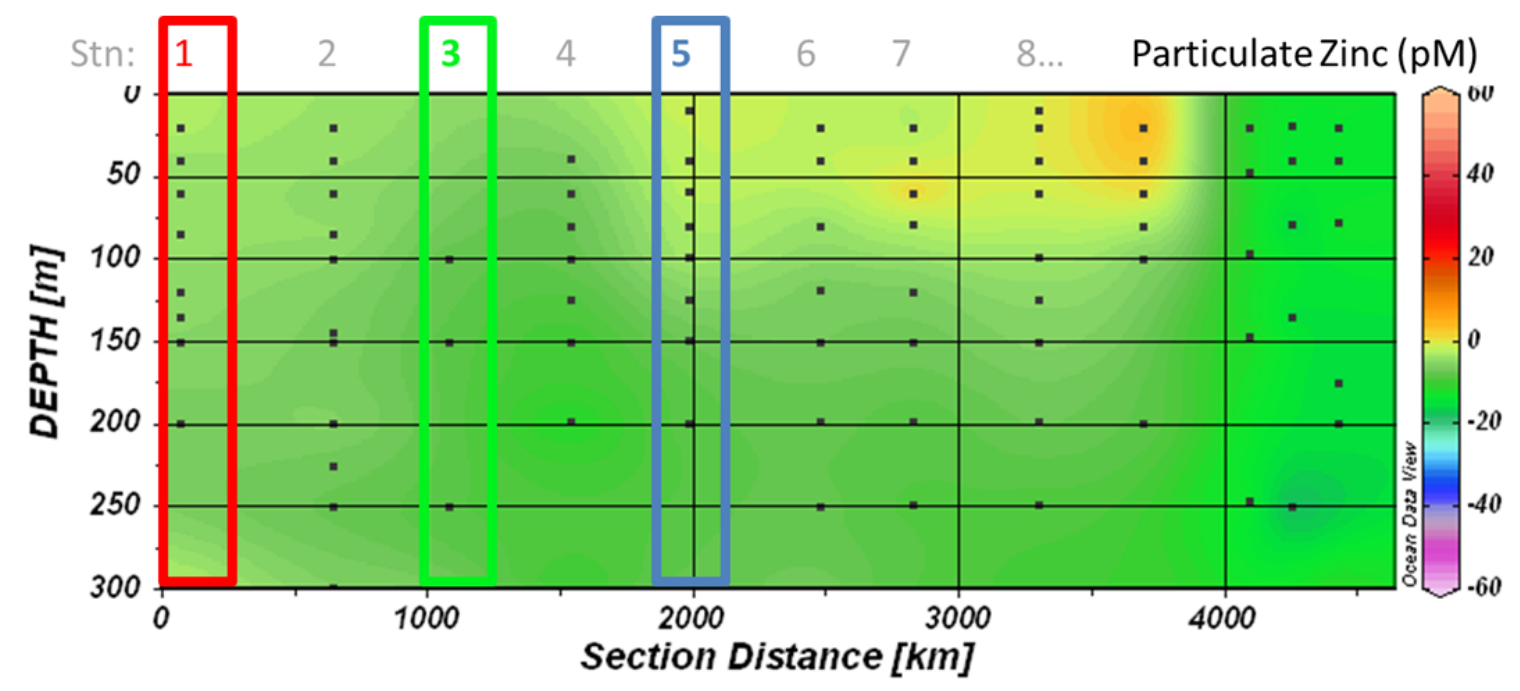

Figure A8. Preliminary particulate zinc concentrations across the KM1128 cruise transect crossing the Equatorial Pacific Upwelling (at 2000 km in section distance). Note: unresolved blank issues led to some negative values. 


\section{Generals paper:}

The following appended paper includes method details related to those used in the main paper. Diatoms were implicated in the role of silicic acid depletion in the upwelling site and consequently there is overlapping relevance to the diatom Phaeodactylum tricornutum presented in the appended generals paper. Nitrogen effects related to urea addition are also synergistic to content of the lab and field studies previously discussed. 


\title{
Proteomic insights from Phaeodactylum tricornutum grown on nitrate or urea with and without added nickel
}

Tyler Jay Goepfert

March 2012

\begin{abstract}
Global proteomics were applied to the diatom Phaeodactylum tricornutum (P.t.) grown with nitrate or urea as a nitrogen source and in the latter case with and without added nickel. When grown on urea without nickel, silica drawdown was most extensive and fatty acid methyl ester content was minimized. In contrast, biomass and nutrient characteristics from the urea cultures with added nickel approximate results from standard replete nitrate media. The proteome reveals distinct nitrogen assimilation pathways for each nitrogen source. Trace metal effects, most notably nickel-nitrogen colimitation, were observed on account of the metalloenzyme nickel urease responsible for metabolizing urea. The ubiquitous and abundant photosynthesis enzyme, RuBisCO provided further insights on carbon fixation as well as silica consumption and nickel limitation. Iron starvation induced proteins (ISIPs) were surprisingly abundant. When +nickel and -nickel treatments were compared ISIP1 was differentially expressed suggesting ISIP1 features in nickel biochemistry, urea cycling, or both. Many low-abundance differentially expressed proteins were detected and some relate to nitrogen and silica metabolism. Together these results provide insights on broader macronutrient biogeochemical cycles (carbon, nitrogen, phosphorous, silica) and the role of trace metals with emphasis on iron and nickel.
\end{abstract}

\section{Introduction and background}

Diatom biomass and associated trace element composition dominate significant oceanic regions [1]. These algae respond rapidly to nutrient inputs such as nitrogen and phosphorous, but perhaps more importantly to trace metals such as iron which is the limiting nutrient in much of the open ocean [2]. An important cultured lab species of diatom, Phaeodactylum tricornutum (P.t.), has been studied extensively and is one of the first diatoms for which we have a complete genome and tools for extensive study [3], [4]. Genomic tools prompted discoveries such as the importance of urea cycling in diatom metabolism which connects carbon and nitrogen cycling [5]. Urea is metabolized by nickel-urease, a metalloenzyme with a nickel metal cofactor [6]. Consequently, nickel is an important trace-metal that participates in the urea cycle. Nickel-nitrogen colimitation in another diatom, Thalassiosira weissflogii, has been described through urease activity and metal uptake kinetics [7]. This trace-metal colimitation is one of several varieties [8] and although subtle, it has been noted that trace metal effects underpin many lab and field observations [9].

Global proteomics is a recently developed technique characterizing the complex enzymatic, signaling compound, and cell structure/metabolite makeup across culture treatments (e.g. nutrient types) and or time (e.g. growth phase). While metaproteomics is still developing, genome-enabled proteomics is already successful in revealing biogeochemical insights [10]. Protein extracts for genome enabled proteomics in this study came from archived P.t. biomass collected in a previous M.Sc. project investigating applied aspects of microalgal biofuels [11]. The proteomic data presented here are new and highlight observations with biogeochemical implications. Interpretation of the proteome begins to explain earlier physiological observations and raises new questions as well. 


\section{Methods}

\section{Cell culture and sample collection}

Culturing and sample collection was part of a previous project which is already described in detail [11]. For clarity regarding the archive source materials the culturing methods from [11] are briefly reviewed in this section and all subsequent sections represent new and recent work since Fall 2010. Briefly, the diatom starter cultures were Phaeodactylum tricornutum (CCMP632, hereafter referred to as P.t.). P.t. was grown in a lab incubator at constant temperature and light conditions $\left(18^{\circ} \mathrm{C}, 100\right.$ $\left.\mu \mathrm{Em}^{-2} \mathrm{~s}^{-1}(\mathrm{PAR})\right)$ in $\mathrm{f} / 2$ media [12], [13]. Experiments were scaled up in several stages to a final batch culture at $80 \mathrm{~L}$ volume. Treatments were a control media with $\mathrm{f} / 2$ nutrient content (except with double the $f / 2$ phosphate concentration). $f / 2$ media uses nitrate as the nitrogen source, consequently the treatment label "nitrate" is used for the control treatment throughout this paper. One experimental condition was $\mathrm{f} / 2$ with nitrate replaced by urea at half the molar concentration of replete nitrate such that total nitrogen was maintained constant (treatment label: "urea,-Ni"). Likewise another experimental urea media was prepared with the addition of $100 \mathrm{nM}$ nickel (treatment label "urea,+Ni").

Culture growth was monitored by daily chlorophyll fluorescence. Larger volume cultures (80L) were grown in early November without artificial light in a greenhouse (Woods Hole, MA; $41^{\circ} 3305^{\prime \prime} \mathrm{N}$, $70^{\circ} 3655^{\prime \prime} \mathrm{W}, 7 \mathrm{~m}$ elevation) maintained at $\sim 12-25^{\circ} \mathrm{C}$ air temperature. Thermal mass of the $80 \mathrm{~L}$ cultures ensured narrower temperature bounds essentially constrained to $15-20^{\circ} \mathrm{C}$ (by 30 minute average digital temperature log). Once an $80 \mathrm{~L}$ culture was established a high-resolution sampling campaign was established.

A negligible volume $(\sim 50 \mathrm{~mL})$ was taken daily to track RFU over a 10-day growth curve and larger $2 \mathrm{~L}$ samples were taken on days $2,4,6,9$ and 41 such that the batch culture volume was depleted by less than $13 \%$ over the course of the entire experiment. The $2 \mathrm{~L}$ samples were divided for assessment of dryweight biomass, nutrients, lipids and proteins.

Bulk samples for protein extraction were first concentrated by centrifuge (Beckman J2-21M, rotor \#14) for 25 minutes at $9,000 \mathrm{rpm}(12,600 \mathrm{xg})$ and $10^{\circ} \mathrm{C}$. Pellets from two $250 \mathrm{~mL}$ volumes were combined in $2 \mathrm{~mL}$ microfuge vials and centrifuged at $14.5 \mathrm{krpm}$ (eppendorf MiniSpin micro-centrifuge). Supernatant was decanted and the pellet immediately stored at $-80^{\circ} \mathrm{C}$ until future processing (approximately 10 months later). All following methods pertain to new work conducted at Woods Hole Oceanographic Institution since Fall, 2010.

\section{Protein extraction and digest}

Biomass pellet archives (usually 25-50 mg dry weight basis) were thawed and re-suspended in B$\mathrm{PER}^{1}$ mix (usually $\sim 400 \mu \mathrm{L}$ ) such that the pellet volume was diluted $\sim 100-200$ fold. B-PER mix consisted of $5 \mathrm{~mL}$ B-PER, $100 \mu \mathrm{L}$ of $0.25 \mathrm{M}$ EDTA, and $25 \mu \mathrm{L}$ of $0.2 \mathrm{M}$ (in $100 \% \mathrm{MeOH}^{\text {) } \mathrm{PMSF}^{2}}$

(phenylmethanesulfonylfluoride). Preliminary mixing by vortex was followed by 10 minutes on ice and then sonication for two 4-minute cycles at a power below 15W (Branson model 450 sonifier; output control of 2.5 with $70 \%$ duty cycle) each followed by 10 minutes on ice. The last 30 seconds of the second 4-minute cycle included a boost in sonication intensity to $100 \%$ duty cycle. The disrupted biomass was centrifuged 10 minutes at $14.5 \mathrm{krpm}, 4^{\circ} \mathrm{C}$ and supernatant collected in a separate $\mathrm{MeOH}$ cleaned microfuge tube.

\footnotetext{
${ }^{1}$ Abbreviations throughout include: B-PER, Bacterial Protein Extraction Reagents(ThermoSceintific); TE, TrisEDTA buffer; TEMED, N,N,N',N'-tetramethylethylenediamine; IAA, iodoacetamide; APS, ammonium persulfate, AMBIC, ammonium bicarbonate; EtOH, ethanol; $\mathbf{M e O H}$, methanol; DTT, dithiothreitol; RT, room temperature; $\mathrm{ACN}$, acetonitrile.

${ }^{2}$ PMSF is a serine protease inhibitor commonly used in the preparation of cell lysates.
} 
Protein precipitation was induced in the B-PER supernatant by adding solvent (Acetone:MeOH, $1: 1$ ) at a volume equal to $4 x$ the volume of B-PER solution used in the previous step and the precipitate was left overnight at $-20^{\circ} \mathrm{C}$. The precipitate was next centrifuged 30 minutes at $14.5 \mathrm{krpm}$ and separated from the supernatant prior to SpeedVac drying to remove most of the solvent ( 5-10 minutes, low heat). With most of the solvent removed the pellet was reconstituted in a volume of B-PER mix (from previous day) sufficient to dissolve the pellet (typically $\sim 300 \mu \mathrm{L}$ ) and the exact volume recorded. Two $1 \mu \mathrm{L}$ aliquots of extracted protein was assessed via off-the-shelf colorimetric protein quantification assay and the remaining extract archived at $-80^{\circ} \mathrm{C}$ until digestion.

A $200 \mu \mathrm{L}$ tube-gel digest [14] was performed on $50 \mu \mathrm{g}$ of protein initially suspended in $87 \mu \mathrm{L}$ of TE buffer adding $103 \mu \mathrm{L}$ of a "pre-mix" solution containing 40\% bis-Acrylamide (Acros 29:1) and Tris $\mathrm{HCl}, \mathrm{pH}$ 7.5 at a volume ratio of $2.92: 1 \mathrm{~V}_{\text {Bis }}: \mathrm{V}_{\text {Tris. }} 1 \%$ APS $(10 \mathrm{mg} / \mathrm{mL})$ was prepared and $7 \mu \mathrm{L}$ added to the tube followed immediately by $3 \mu \mathrm{L}$ of TEMED. Brief vortexing was followed by gentle tapping to move all solution into the bottom of the tube where the TEMED and APS catalized polymerization of the acrylamide resulting in gel formation within minutes. The gel was left to completely polymerize for 1 hour at $20^{\circ} \mathrm{C}$, then fixed for 20 minutes, RT with $200 \mu \mathrm{L}$ of fixing solution composed of EtOH, acetic acid, and water (LCMS-grade) at a ratio of 11:10:1 by volume.

Next, gels were transferred to a larger $2 \mathrm{~mL}$ tube and a fresh $1.6 \mathrm{~mL}$ of fix solution were added mixing with a thermomixer at $350 \mathrm{rpm}$ at $20^{\circ} \mathrm{C}$ for 1 hour. Fixing solution was then replaced by destain solution consisting of $\mathrm{MeOH}$, acetic acid, and water (LCMS-grade) at a ratio of 11:10:1 by volume. The destaining step was left 2 hours at $350 \mathrm{rpm}, 20^{\circ} \mathrm{C}$. Gels were then diced into roughly cubic pieces $1 \mathrm{~mm}$ to a side with disposable scalpels (rinsed thoroughly with $\mathrm{MeOH}$ between samples). The gel pieces were returned to the $2 \mathrm{~mL}$ tube with $1 \mathrm{~mL}$ of $A C N$ :AMBIC, $50: 50$ by volume and mixed at $350 \mathrm{rpm}$ and $20^{\circ} \mathrm{C}$ replacing the $A C N: A M B I C$ solution after 1 hour and continuing the rinsing procedure overnight at 350rpm and $16^{\circ} \mathrm{C}$.

The following day the wash solution was replaced once more and continued on the thermomixer for 1-2 hours longer; meanwhile fresh $10 \mathrm{mM}$ DTT and 55mM IAA each in 25mM AMBIC were prepared. Wash solution was pipetted off and $0.8 \mathrm{~mL} \mathrm{ACN}$ added for dehydration, allowing 10 minutes at RT before removing this $\mathrm{ACN}$ and repeating the dehydration step twice more (discarding the $\mathrm{ACN}$ each time). Next the rinsed and gel-bound proteins were dried at low heat for 15 minutes on a SpeedVac and the thermocycler was adjusted up to $56^{\circ} \mathrm{C}$ in preparation for reduction, alkylation, and digestion steps. $0.6 \mathrm{~mL}$ DTT was added and mixed 1 hour at $350 \mathrm{rpm} 56^{\circ} \mathrm{C}$. DTT was removed carefully noting the volume absorbed by the gel (typically $\sim 250 \mu \mathrm{L}$ ). Gels were rinsed briefly by vortexing with $0.6 \mathrm{~mL} \mathrm{AMBIC}$, then replacing the $\mathrm{AMBIC}$ with $0.6 \mathrm{~mL}$ IAA they were mixed again 1 hour at $350 \mathrm{rpm}, 20^{\circ} \mathrm{C}$ in the dark (aqueous IAA is highly photosensitive). Gels were then rinsed with $1 \mathrm{~mL}$ AMBIC for 20 minutes at $350 \mathrm{rpm}, 20^{\circ} \mathrm{C}$ and another series of 3 dehydration steps performed with ACN (exactly as before) and SpeedVac for 20 minutes low heat. Finally, trypsin was added to the gel to digest the immobilized proteins. Trypsin is added according to a mass ratio trypsin:protein of 1:20 prepared in $25 \mathrm{mM}$ AMBIC at a volume equal to the volume of DTT absorbed. The trypsin rehydration was performed in an ice-bath for the first 30 minutes, then incubated at $37^{\circ} \mathrm{C}$ for 20 minutes before adding enough $\mathrm{AMBIC}$ to cover the gel (typically $\sim 150 \mu \mathrm{L}$ ), vortexing, and continuing incubation overnight while mixing at 350rpm.

Peptides of the digested protein were spun down from the gel and collected in a fresh $1.5 \mathrm{~mL}$ tube used for two repeat collections of $50 \mu \mathrm{L}$ peptide extraction buffer ( $50 \%$ Acn, $5 \%$ formic acid) incubated for 20 minutes at room temperature each time and spun for 2 minutes at $14.5 \mathrm{krpm}$ to collect. The combined volumes of extracted peptides from a given gel digest were finally spun 20 minutes at $14.5 \mathrm{krpm}$, the top $\sim 90 \%$ of the solution collected to a new microfuge tube and reduced to about $10 \mu \mathrm{L}$ by SpeedVac at low heat (to remove formic acid). This final peptide solution was archived at $-80^{\circ} \mathrm{C}$ until analysis by LC-MS for global ("shotgun") proteomics. 


\section{Mass spectrometer evaluation and data analysis}

A portion of the final peptide solution prepared in the previous digestion steps was adjusted to $0.1 \mu \mathrm{g}$ peptides per $\mu \mathrm{L}$ in a peptide solution composed of $0.1 \%$ formic acid, $2 \%$ ACN, $97.9 \%$ water (LCMSgrade). Triplicate injections of $40 \mu \mathrm{L}$ each ( $4 \mu \mathrm{g}$ peptides per run) are applied to the LC-MS. Each sample was concentrated onto a peptide cap trap and rinsed with $150 \mu \mathrm{L} 0.1 \%$ formic acid, $5 \% \mathrm{ACN}, 94.9 \%$ water before gradient elution through a reversed phase Magic $\mathrm{C} 18 \mathrm{AQ}$ column $(0.2 \times 150 \mathrm{~mm}, 3 \mu \mathrm{m}$ particle size, $200 \AA ̊$ pore size, Michrom Bioresources Inc.) on an Advance HPLC system (Michrom Bioresources Inc.) at a flow rate of $0.75 \mu \mathrm{l} / \mathrm{min}$. Reverse phase chromatography consisted of a gradient from $5 \%$ buffer A to $95 \%$ buffer B during 360 minutes, where A was $0.1 \%$ formic acid in water and B was $0.1 \%$ formic acid in ACN. A LTQ linear ion trap mass spectrometer (Thermo Scientific Inc.) was used with an ADVANCE CaptiveSpray source (Michrom Bioresources Inc.). The LTQ was set to perform MS/MS on the top 5 ions using data-dependent settings, and ions were monitored over a range of $400-2000 \mathrm{~m} / \mathrm{z}$.

Raw output data from the LC-MS was processed by BioWorks 3.3 software with subsequent evaluation by Scaffold 3 mainly to organize output and calculate Fisher's exact test scores to distinguish differentially expressed proteins with a threshold set at $p<0.01$. The proteome was cross-referenced in OpenOffice Base with the protein annotation files retrieved from the Joint Genome Institute, and the tabulated results were filtered in Cluster3.0 for at least 8 observations having spectral abundances greater than 4 with a difference between maximum and minimum of 12 . These filtered results were further processed in Cluster3.0 with a work flow to log transform, center on mean, normalize genes, and cluster (Kendall's tau with centroid linkage). Output from Cluster3.0 was prepared graphically in TreeView in the form of a heatmap with accompanying dendrogram.

\section{Results and discussion}

\section{Growth and biomass characterization overview}

To help inform the proteomic discussion two figures have been adapted from the M.Sc. thesis project noted in the introduction (Figure 1 and Figure 6). The proteome and resulting interpretations here represent new material completed subsequent to the M.Sc. project. Figure 1 is a comprehensive overview of batch culture growth curves and nutrient drawdown. Daily fluorescence values for the batch cultures followed a typical growth curve with lag, exponential, and stationary phases (Figure 1a). Fluorescence was used to track growth, determine growth rates, and establish sampling points for detailed chemical analysis. Microscopy cell counts verified that cell numbers were accurately tracked by fluorescence (Figure 1b). The urea,-Ni treatment was observed to lack the optical density (dark brown color) that was apparent in other treatments. Nevertheless, fluorescence per cell remained comparable across treatments suggesting cells were not chlorotic (data not shown).

Dissolved nutrients reflected biological uptake and incorporation in all treatments. Especially notable were phosphate and silicate drawdown. Dissolved phosphate more than halved in all treatments by mid-exponential growth phase (day 4) and the supply was virtually exhausted by stationary phase (day 9). The nitrate treatment started with phosphate at twice the concentration of the urea treatments and this excess phosphate was also completely removed (Figure 1c). Using the change in dissolved nutrients, biogenic N, P, and Si estimates are presented in Table 1 on a mole per cell basis. Where possible, Table 1 contains nutrient ratios along with reference Redfield values. The nitrate treatment had a C:P ratio approximately that of Redfield ratio suggesting luxury uptake of $\mathrm{P}$ (the result of the excess phosphate in the starting media which was twice the usual $\mathrm{f} / 2$ concentration in the nitrate treatment). In contrast, the urea treatments had C:P in excess of Redfield (implying either phosphate limitation or excessive carbon acquisition). Nitrate and nitrite appeared only in the urea treatment (Figure 1f), whereas ammonium was generally only present in the urea treatments and is likely the 
result of urea conversion to ammonium by abiotic and/or biological processes (Figure 1d). Results for these nitrogen compounds are not surprising in the context of metabolic pathways for nitrate and urea assimilation to be explored in more detail in the proteome section below.

The role of nickel in processing organic nitrogen from urea prompted an estimate of nickel utilization and determination of possible nickel limitation in the urea,-Ni treatment (Table 2). Similarly the prospect of iron limitation was evaluated and in the iron rich trace metal media it is unlikely this metal was limiting (in contrast to most oceanic regions). Nickel effects on nutrient acquisition and various biochemistries are further inspected through the lens of proteomics in the following sections.
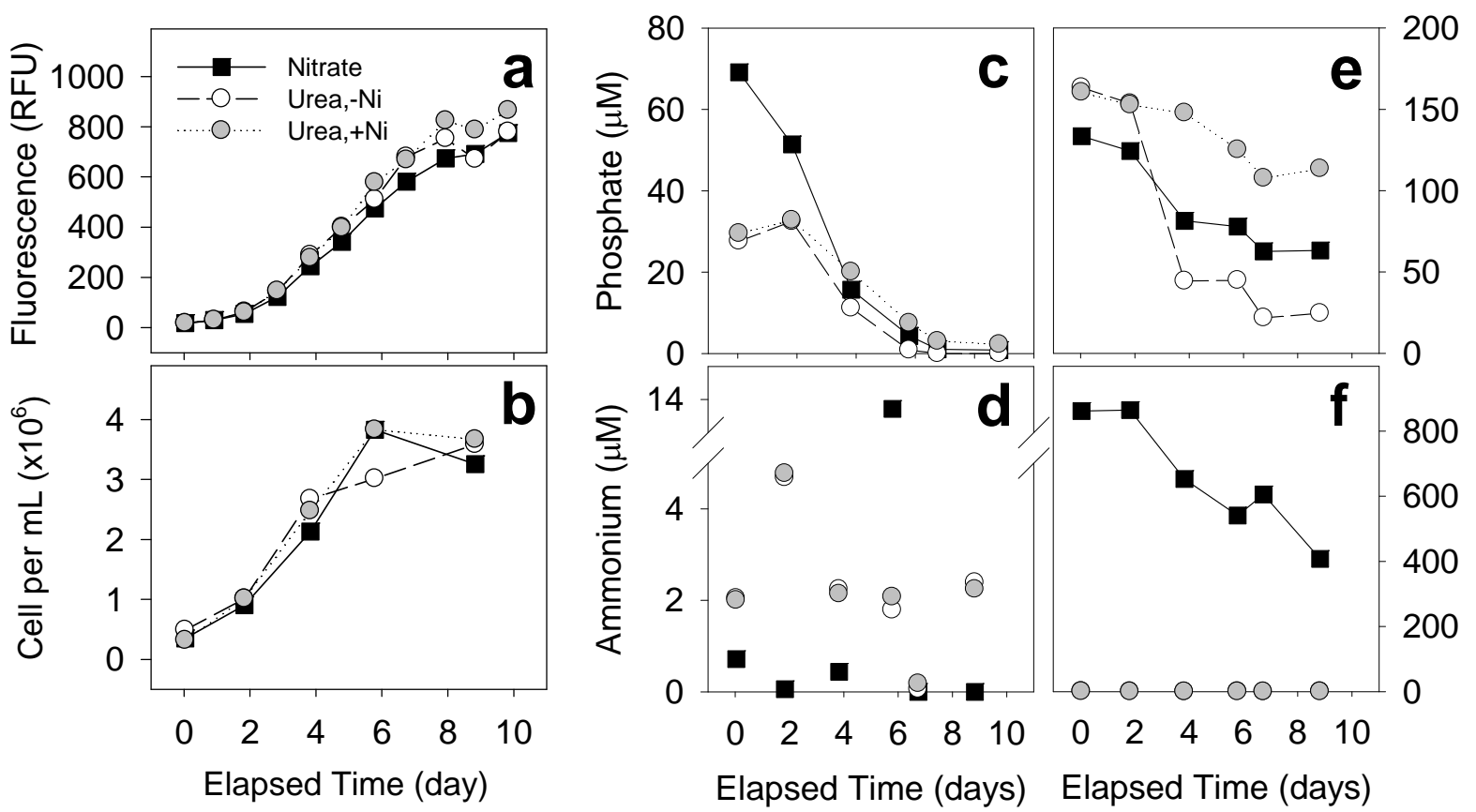

Figure 1. Batch culture growth curves $(a, b)$, and nutrient drawdown (c-f) from P.t. grown in a greenhouse at $80 \mathrm{~L}$ scale. Symbols reflect the nitrogen sources: nitrate (squares) and urea (circles), while shading in the urea treatments is grey for added nickel (+Ni) and unshaded for no added nickel (-Ni). Cell density (b) tracks florescence proxy (a). Note the influence of nickel on silica drawdown (greatest in urea,-Ni), and lower biomass yield in the urea,-Ni treatment. Nitrate+nitrite is completely absent in the urea treatments where shaded circles overlap open circles (figure adapted from [11]).

\section{Proteome}

Over 1000 unique proteins were identified across the entire experiment with greater than 600 present at each of the 5 time points where proteomic evaluation was made (days 2, 4, 6, 9, and 41). Approximately $80 \%$ of proteins were common to all treatments and were differentially expressed in many cases, while $20 \%$ of proteins appear in only one or two treatments. When present in two or more treatments (not unique) the relative abundance for each protein were evaluated by the Fisher exact test indicating differences derived from technical replicates despite singlicate biological samples. Pairwise comparisons show that method reproducibility in technical replicates was distinguishable from comparisons between time points and treatments (Figure 2). Particular proteins noted in Figure 2 will be discussed in more detail in subsequent sections. 
Technical replicates

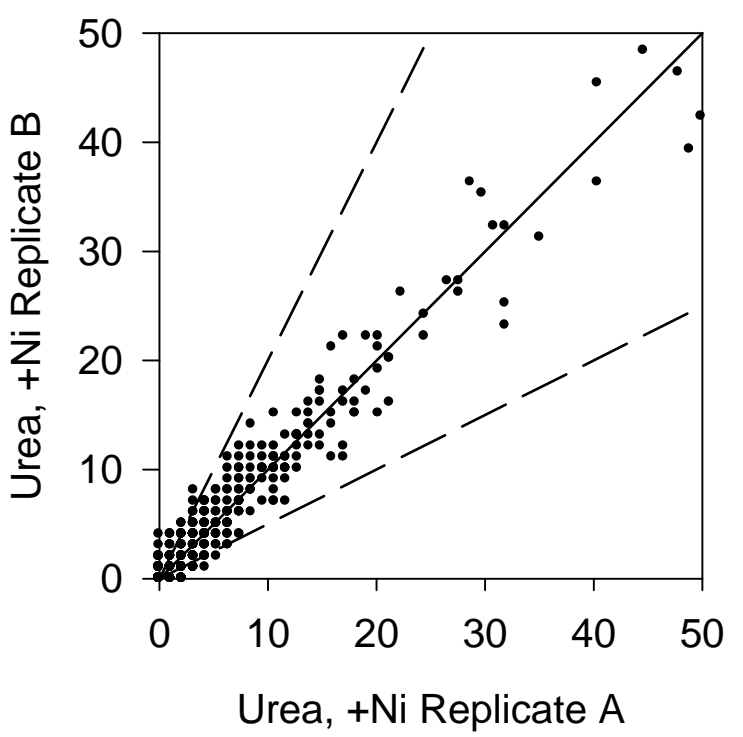

Day 9 Pairwise comparison

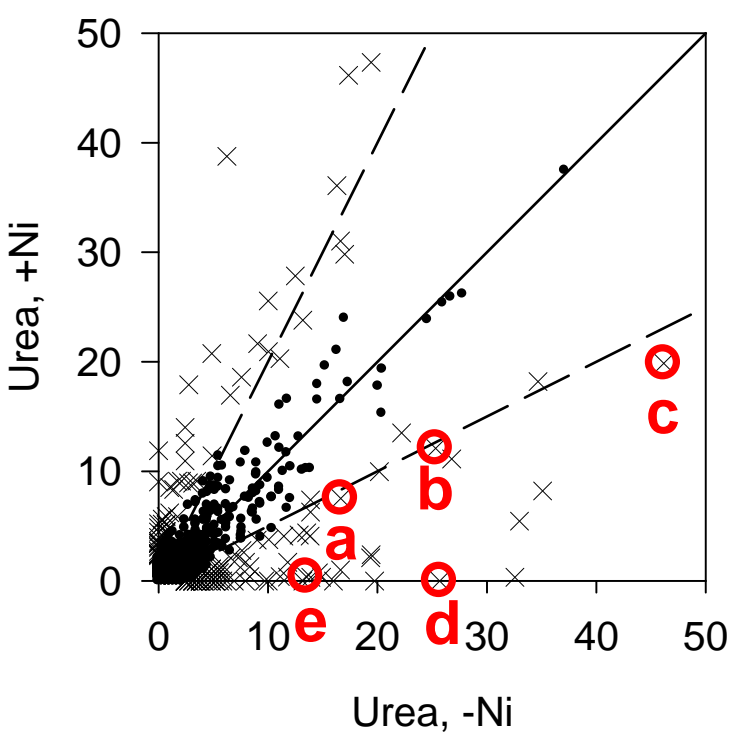

Figure 2. Relative protein abundance pairwise comparisons for: technical replicates (left panel) and a stationary time point (day 9) comparing urea treatments with and without added nickel (right panel). Lines indicate 1:1 or equal abundance (solid line) and two-fold thresholds (dashed lines). Statistical examination by Fisher's exact test designate differentially expressed results ( $p<0.01$ ) plotted as cross-hairs, while non-differentially expressed proteins are closed circles. Highlighted proteins discussed in the text are (a) adenosylhomocystine, (b) Actin (ACT1), (c) iron starvation induced protein (ISIP1), (d) carbamoyl-phosphate synthase (CPSIII), and (e) clathrin vesicle coat protein. Note that technical replicates adhere closely to the solid 1:1 line in contrast to differentially expressed proteins (crosshairs) that generally plot beyond the twofold dashed lines.

\section{Nitrogen assimilation:}

Nitrogen assimilation occured via different pathways in the media containing nitrate versus urea. Where nitrogen was present the following overall process was apparent:

$$
\text { Nitrate } \rightarrow \text { Nitrite } \rightarrow \text { Ammonium } \rightarrow \text { Protein, }
$$

with relevant enzymes being nitrate reductase (NR), nitrite reductase ( $\mathrm{NiR})$, and glutamine synthase (GSII and GSIII) depicted in Figure 4a-d. Where urea was present, after urease acted on urea, the process presumably continued at final step with ammonium making use of the alternative GSIII (Figure $4 d, e)$. If these traits hold similarly true in the field, it seems plausible that GSII could serve as an indicator of new production via nitrate, whereas absence of this enzyme (sole reliance on GSIII) might suggest regenerated production through urea or other reduced nitrogen species.

The critical role of iron in metalloenzymes amidst iron-limited growth conditions is known and leads to prospective shifts in enzyme selection in order to economize on iron [15], [16]. In more elaborate ways metalloenzymes may even routinely deconstructed and refabricated enzymes in order to separate diurnal processes and further economize for iron[10]. Nitrite reductase is an iron-rich metalloenzymes and consequently in the field if urea is available, iron stress might be reduced by prioritizing urea assimilation via urease and GSIII. In other words, given the "choice" of urea versus nitrate/nitrite assimilation in an iron-limited system, the former may be preferred since more iron would then be free for essential light harvesting pigments and other iron-intensive metalloenzymes. 

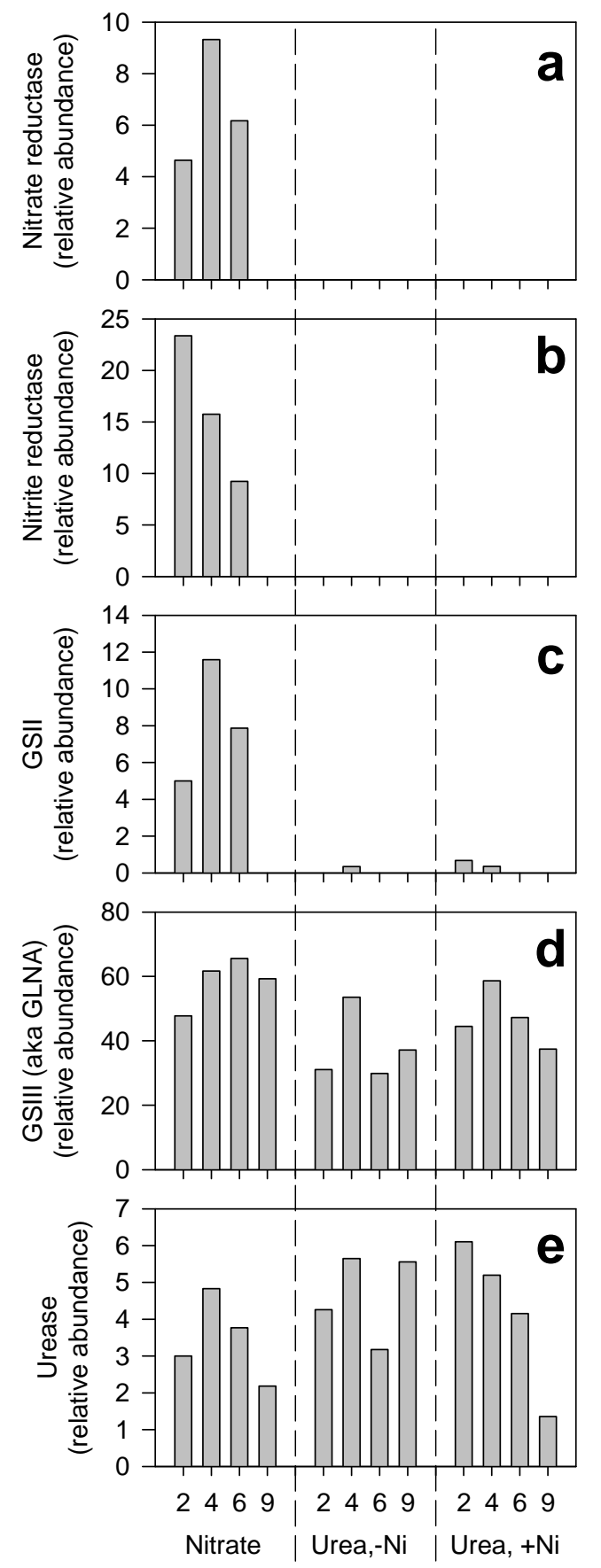

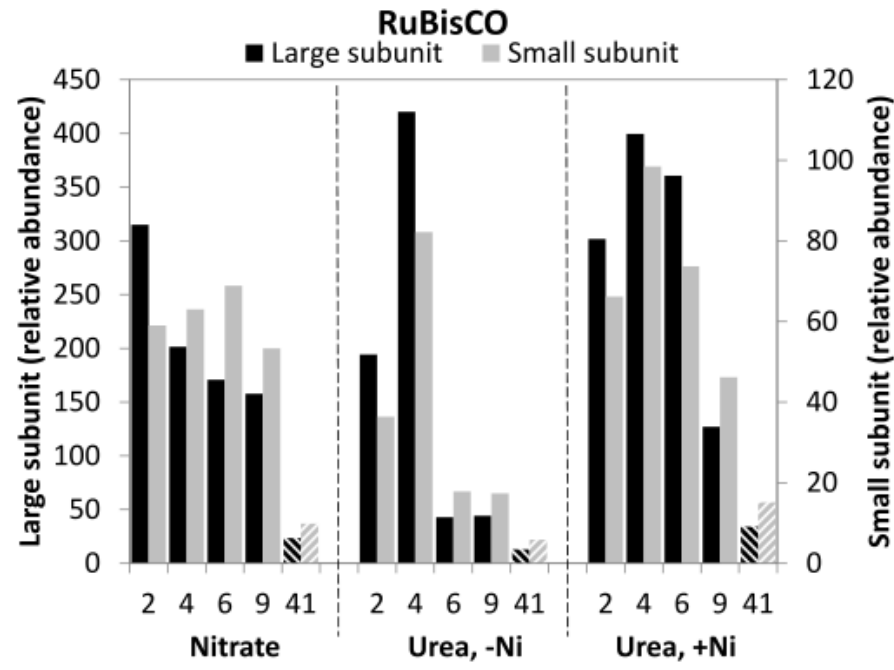

Figure 3. (Above right) RuBisCO subunit abundance with large subunit (black) and small subunits (grey). Three treatment groups and five timepoints (day number) are designated on abscissa. RuBisCO is a key enzyme in photosynthesis for carbon fixation into biomass and is perhaps the most abundant protein on earth. RuBisCO is critical for photosynthesis by P.t. and is the most bundant protein in this P.t. proteome (relative abundance in the $100 \mathrm{~s}$ compared to 10 s for most other proteins discussed here). Note the sharp decline of RuBisCO abundance in the urea,-Ni treatment at day 6 and also for all treatments by the late time point (day 41) where nutrients are depleted.

Figure 4. (Left) Relative protein abundance for several notable nitrogen assimilation enzymes over four time points (day number on abscissa), and across three treatment groups separated by the dashed lines. Reductase enzymes appear only in nitrate treatment and reduce fixed nitrogen to ammonia for assimilation into biomass (e.g. nucleic acids). Glutamine synthase has two forms (GSII and GSIII), both can produce glutamine as a precursor to nucleotide generation. Urease catalyzes conversion of urea to ammonia to be supplied to glutamine synthase. Note that GSII is less abundant and present almost exclusively in the nitrate treatment relative to GSIII which is abundant and nearly constitutive like urease. These features emphasize the potential role of the urea cycle in all treatments.

\section{Ribulose-1,5-bisphosphate carboxylase oxygenase (RuBisCO):}

The central and fundamental role of RuBisCO in carbon fixation makes it the dominant signal in the proteome and in this case variation with treatment and time were observed (Figure 3). Both the large and small subunits were elevated initially, but declined rapidly at day 6 in the urea,-Ni treatment. A late time point sample for this enzyme shows it was substantially diminished in all treatments. Interestingly, RuBisCO abundance droped precipitously at day 6 in the urea,-Ni treatment. One 
explanation could be that the culture was critically nutrient limited and subsequently halted carbon fixation. However, cell number and fluorescence continued to increase through day 9 (Figure 1a,b). An interesting alternative prospect involves the buffering potential of silica yielding a subtle but convincing connection to carbon acquisition. The role of proton buffering by silica is described by Milligan and Morel [17]. In brief, the carbon concentrating mechanism which employs the $\mathrm{pH}$ sensitive carbonic anhydrase may be effectively buffered by extensive amorphous silica yielding higher enzymatic activity and thus $\mathrm{CO}_{2}$ in the vicinity of RuBisCO consequently "pressurizing" carbon fixation at the point of RuBisCO. This proteome demonstrated Zinc-carbonic anhydrase was prevalent with generally constant or slightly increasing values during the batch culture (data not shown). Consequently, the buffering capacity of excessive silica in the urea,-Ni treatment might have led to greater efficiency of $\mathrm{CO}_{2}$ concentration around RuBisCO and reducing the need for as much of this enzyme. A combination of these explanations and still others could explain the observed decrease in RuBisCO at day 6 in the urea,Ni treatment.

\section{Iron starvation induced proteins:}

A suite of notable proteins represented in this proteome are the iron starvation induced proteins (ISIPs) (Figure 5). Although iron limitation is not expected (per Table 2), the ISIPs were not only
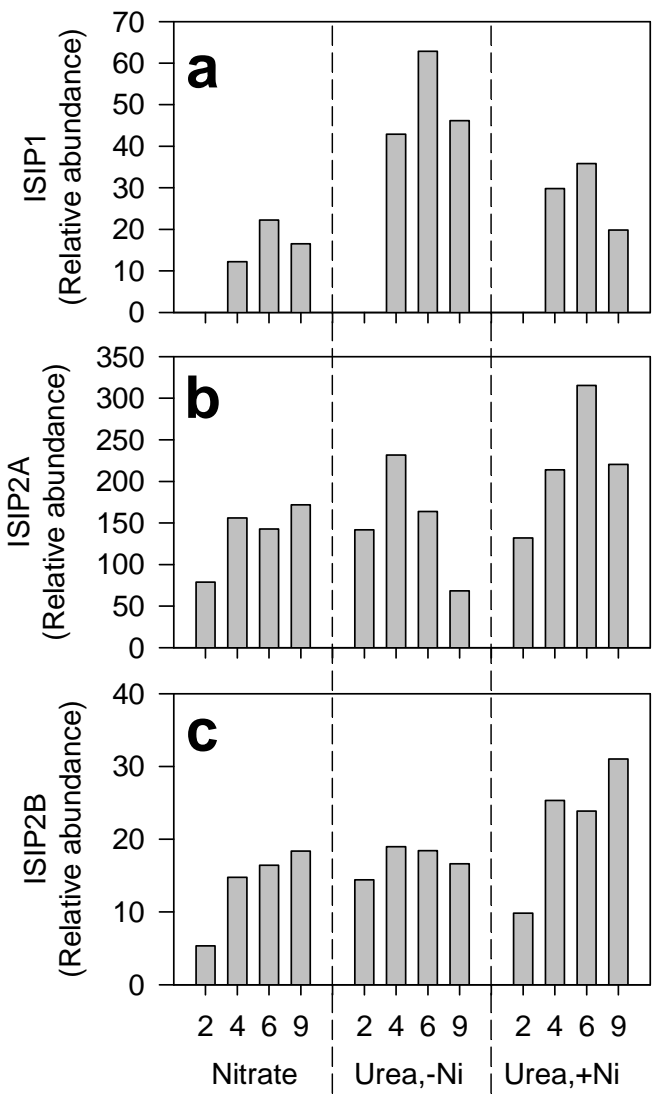
present, but in some cases compared with the outstanding RuBisCO in abundance (Figure 5b). Unlike the relatively constitutive presence of ISIP2A and ISIP2B in this proteome, ISIP1 was roughly two-fold more abundant in the Urea,-Ni treatment (Figure $2 \mathrm{c}$ and Figure 5a). This result hints that ISIP1 may not strictly relate to iron, for example it may be a divalent cation transporter deployed here to access more nickel under nickel-limited conditions. Protein structure information may eventually address questions as to the biochemical role of ISIP1. The abundance of iron starvation induced proteins (ISIPs) is surprising considering the iron rich media and absence of predicted iron limitation (Table 2). Field metatranscirptome studies have emphasized the importance of these ISIPs in evaluating iron limitation but at the same time note the significance of urea cycle proteins in the iron response [18]. It might warrant consideration then that ISIP1 may have roles in metals other than iron, or perhaps relates to the urea cycle or polyamine synthesis and thus silica deposition. Consequently when transcriptomic results for ISIP1 normalized to actin diagnose iron starvation, the positive correlation might be mere serendipity if actin increases with diatoms that typically appear promptly after an iron pulse [2].

Figure 5. Three iron starvation induced proteins (ISIP), namely (a) ISIP1, (b) ISIP2A, (c) ISIP2B. Treatments and time point (day) are denoted on the abscissa. Note, ISIP1 is relatively higher in the urea,-Ni treatment and appears only after day 2 while the other ISIPs tend towards a more constitutive nature. 


\section{Nutrient and FAME correlations:}

Silica limitation has been implicated for inducing triacylglycerol synthesis and is consequently a lipid accumulation "trigger" in some diatoms[19], however as P.t. has no obligate silica requirement this mechanism may not apply here. In fact, the most silica depletion occurred in the urea,-Ni treatment which had the lowest FAME productivity (compare Figure 1e and Figure 6). It was considered that this could be an artifact of elevated mineral silicate contributing to the dry weight. Thus an ash-free dry weight normalization strategy becomes advisable. Ash free dry weight for biomass collected on triplicate glass fiber filters after muffle furnace combustion $\left(500^{\circ} \mathrm{C}\right.$ overnight, data not shown) were rather inconclusive as within the experimental error all treatments are comparable and if anything the ash-free dry weight trend would strengthen the observed FAME trends in Figure 6.

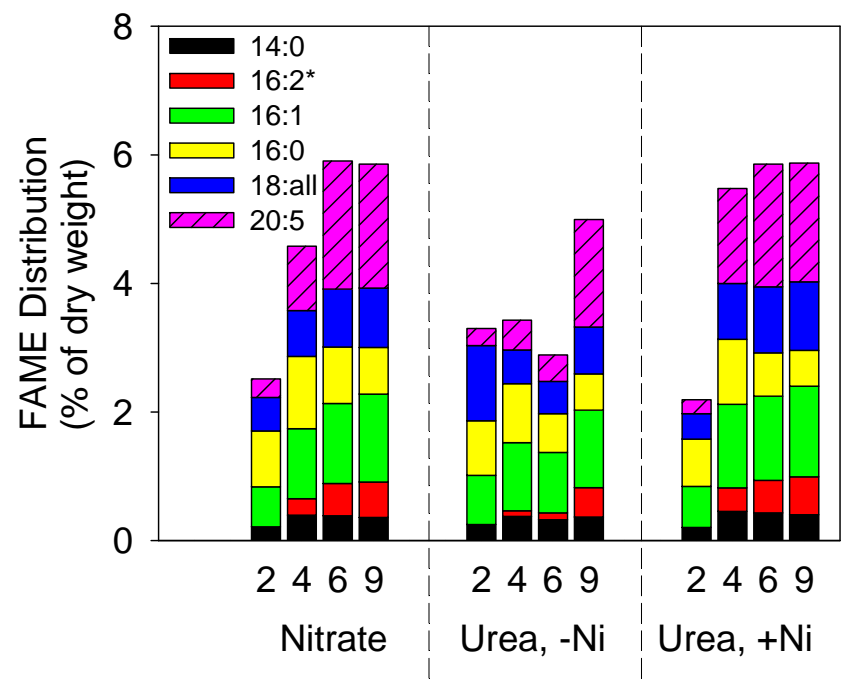

Figure 6. (Above left) Fatty acid methyl ester (FAME) data for three treatment groups over 4 timepoints designated by day-number on abscissa. Each cumulative bar graph depicts the profile of FAMEs according to the convention of carbon-length:double-bond number (e.g. 20:5 is an unsaturated alkane composed of a 20-carbon chain with 5 double bonds). The hatched component emphasizes the omega-3 fatty acid "Eicosapentaenoic acid" (EPA) which generally increased with time, and is the dominant FAME at stationary phase in all cultures (figure adapted from [11]).

Figure 7. (Above right) Relative protein abundance for (a) phosphatase linked to lipid biosynthesis, (b) phosphoglucomutase associated with glycolysis, and (c) alkaline phosphatase-like protein (AP). Three treatment groups, and four time points designated by day-number on abscissa. Note the trend correlation of pyrophosphatase with FAME data of Figure 6. Also note how the alkaline phosphatase-like protein tracks downward along with dissolved $\mathbf{P}$ in all treatments.

Nutrient and FAME data trends were often echoed in the proteome. One representative example is inorganic pyrophosphatase which is critical in lipid synthesis. Pyrophosphatase appeared disproportionately between treatments and the lowest abundance occured in the urea,-Ni culture (Figure 7a). Conversely, catabolic activity was evidenced by enhanced phosphoglucomutase abundance (Figure 7b), where phosphoglucomutase participates in glycolysis/glucogenesis. More globally these effects are portrayed by the broad cross-cutting down regulation pattern after day 4 in the lower two branches of the heat map for the urea,-Ni treatment (Figure 8) where most of the protein annotations were for photosystem and ribosomal units (suggests anabolic pathways were generally shut down). Finally, a nutrient trend echoed in the proteome is typified by an alkaline phosphatise-like (AP-like) protein. Phosphate depletion occurred along with a downregulation of the AP-like protein (Figure 7c). 


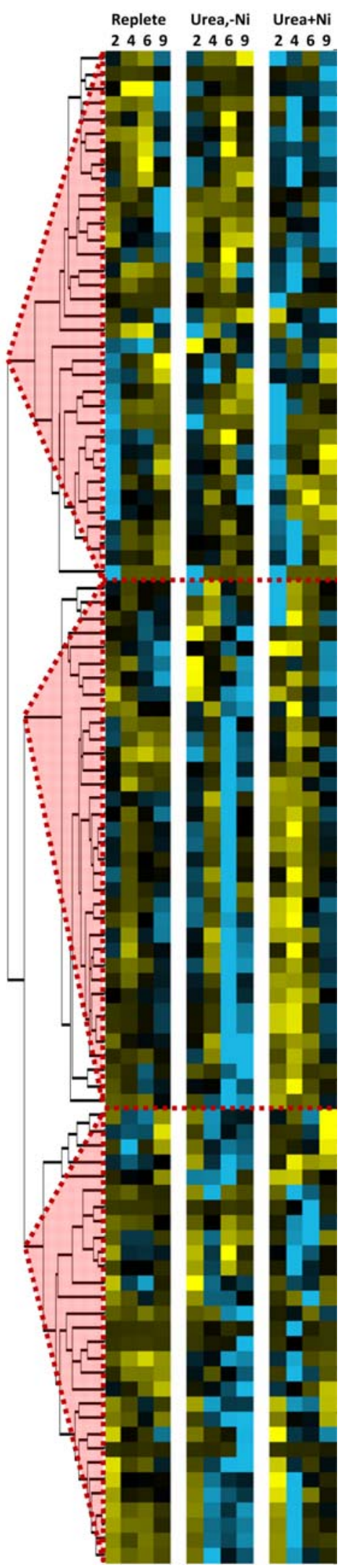

Scatter plots and heatmaps such as Figure 2 and Figure 8 are useful tools that facilitate interpretation of the enormous datasets that can come from global proteomics. Noting differentially expressed protein patterns yields insightful interpretation such as the underlying biochemistries, but can also help identify subtle or overlooked processes. Some outstanding examples in this process were described above as relate to nitrogen and carbon acquisition. A few brief and more subtle examples follow, where each could be expanded in its own right.

Adenosylhomocysteinase:

Adenosylhomocysteinase is in the cysteine and methionine metabolism pathway and is strongly expressed in the urea,-Ni treatment (Figure 2a). Cysteine being an important residue for many metal ion binding proteins could point to efforts to overcome nickel limitation through cysteine-rich high-afinity cation transporters. This protein is also annotated to be highly expressed under nitrogen limitation which is consistent with the interpretation of a nickelnitrogen colimitation effect imposed on the urea,-Ni treatment. Carbamoyl-phosphate synthase:

The presence of carbamoyl-phosphate synthase (CPSIII) reflects the first committed step of the urea cycle. Through downstream products such as proline and glutamine, CPSIII also has a critical effect on cell wall formation. The differential expression of CPSIII noted in the urea,-Ni treatment (Figure $2 \mathrm{~d}$ ) is a good starting point for investigation of the extensive silica drawdown seen in that treatment.

\section{Silica metabolism}

The importance of silica in diatoms and the extensive variation in silica depletion noted in Figure 1e warrant an expanded discussion. P.t. has several unique cell shapes ("morphotypes") that have been described and related to silica and lipids as early as 1958 [20].

Moreover, $P$.t. is a unique diatom having no absolute silica requirement depending on the morphotype, thus it is important to consider the dominant morphotype in this study. An extensive review covers 10 dominant culture accessions including the accession of this study (Pt1 aka CCMP 632) [21].

Figure 8. Global heat map for three treatments (nitrate; urea,-Ni; and urea,+Ni) and four time points (days $2,4,6,9$ ) designated at the top. Warm (yellow) and cool (blue) color scheme denotes increased and decreased abundance respectively relative to the average for a given protein (horizontal row). Proteins that cluster near each other generally show similar patterns within treatments and/or time. Approximately 100 differentially expressed proteins cluster into three general groups in the dendrogram (branching structure at left, highlighted with shaded triangles). Note the up-regulated proteins where nickel was omitted (in the top branches nitrate, and urea,-Ni treatments) as well as the broad cross-cutting down-regulation pattern at day 6 of the urea,-Ni treatment (middle branches). 
Silica was drawn down in all treatments, but to differing extent depending on the treatment. The urea,-Ni treatment had the most extensive silica drawdown (Figure 1e) as reflected in the biogenic silica per cell (Figure 9). The small and rare ovular ("ovoid") P.t. morphotype from this P.t. strain may explain this result on account of its distinguishing silica demand [22]. Ovoid cells of this P.t. strain rarely exceed more than $5 \%$ of the total cell number[21], yet in the urea,-Ni treatment ovoid cells exceeded $10 \%$ by day 6 (microscopy data not shown). Silica deposition and frustule formation is a complex process involving specialized scaffolding proteins that coordinate detailed and high-fidelity nanofabrication [3], [23]. Though complex, the topic is important to consider because in the field, dense frustules support sinking particulate matter fluxes that can export carbon from the surface ocean and consequently participate in the climate regulating global carbon cycle.

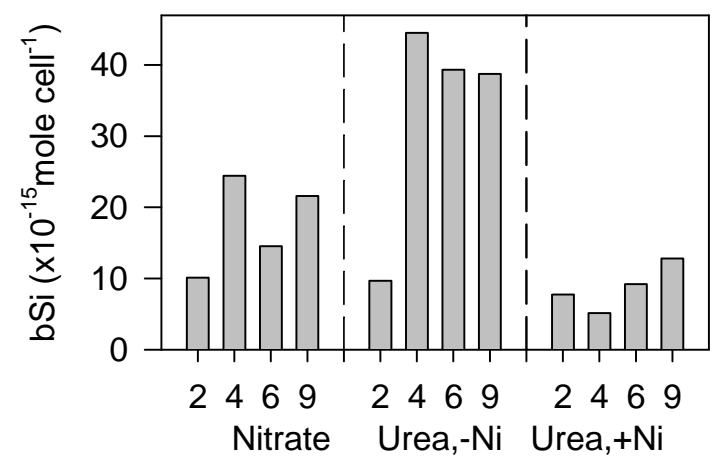

Figure 9. Estimated biogenic silica per cell (bSi) as derived from dissolved silica depletion divided by cell density. Treatment groups and day number along the abscissa. Note that bSi is generally elevated in the urea,-Ni treatment.

Proteome results related to silica deposition include low-abundance differentially expressed proteins, namely actin and related proteins (ACT1), and clathrin, a vesicle coat protein (Figure $2 \mathrm{~b}, \mathrm{e}$ ). It has been shown that a substantial correlation exists between silica structure and actin [24]. Actin in this proteome is highest in the urea,-Ni treatment (Figure $2 \mathrm{~b}$ ) and corresponds to elevated silica incorporation (Figure 9). It may be speculated that clathrin vesicle coat protein may relate to cyst formation to wait through nutrient depleted conditions until upwelling or lateral advection of fresh nutrients. Alternatively, clathrin vesicles might harbor gas vesicles to regulate buoyancy counteracting the weight imparted by silica deposition in frustules. Together these proteome results begin to explain the observed silica drawdown as well as the morphotype transition to increased silica-rich ovoid cells.

\section{Basic environmental context}

Considering diatoms are rapid-responders to fresh nutrients, it is important to understand their silica physiology and potential to cycle organic nitrogen via the ornithine urea cycle. It is evident here that organic nitrogen from urea is an effective nitrogen source when nickel supply is sufficient. The importance of iron in carbon, nitrogen, and silica field dynamics has been studied [25], and perhaps nickel too features in these dynamics. In this paper, no detailed evaluation of bioavailable nickel has been performed, but results here reiterate the importance and potential role of nickel in nitrogen limitation via urease as previously noted [7]. The nitrate focused new production dogma [26], [27] has already been challenged by recent nitrogen cycle discoveries such as anaerobic ammonia oxidation and importance of nitrogen fixation [28]. From the earliest studies, urea and other organic nitrogen assimilation was considered only a concomitant and almost negligible factor. The dearth of field measurements for urea were lamented even 50 years ago[27]. Although the importance of urea is increasingly recognized analytical limitations continue to plague the effort to study urea uptake in the field[29]. Nevertheless, from an energetic perspective urea may represent a more favorable nitrogen source than nitrate which requires iron-intensive reductases to metabolize. The scarcity of iron, and the possibly large reservoir of urea suggest that regenerated production might be more significant than previously considered. Interestingly recent nitrogen cycle updates make no mention of urea [28], [30]. While the role urea for marine Archaea may be nonexistent [31], urea transporters are a prevalent feature in the metagenomic database, mainly from cyanobacteria (CAMERA microbial ecology portal; accessed online, 30 March 2012). The revised global nitrogen cycle [32] may benefit from considering colimitation effects and clarification of the urea cycle in the field. 


\section{Summary and conclusions}

Urea replacing nitrogen as a nitrogen source for the diatom P.t. was successfully evaluated through detailed physiological and proteomic analysis. Nickel proved to be an important facilitator of urea assimilation. In prospective application of algal mediated waste water treatment and biomass production strategies, trace metals such as nickel should not be disregarded.

The proteome revealed the metabolic pathway for the different nitrogen substrates and hints that certain proteins such as glutamine synthase (GSII) may serve as indicators of the nitrogen source for diatom blooms and may be worth continued evaluation. Additionally, a surprisingly high number of iron starvation inducible proteins were observed. Considering the complex interaction of nitrogen cycle genes and silica frustule formation, caution is advised when using ISIP genes as iron starvation proxies in the field.

Further investigation on the role of iron, nickel, nitrate, and urea synergistic effects may help clarify the broader nitrogen cycle in terms of limits to new and regenerated production. Proteomic lab studies and field measurements have the potential to inform such an endeavor.

\section{Tables}

Table 1. Estimates of biogenic elemental composition for $N, P$, and Si along with pertinent elemental ratios to compare with Redfield ratio values. Estimates are based on amount (moles) of nutrient depleted from solution divided by the cell density at that time point (cell density in Table 2).

\begin{tabular}{|c|c|c|c|c|c|c|c|c|c|}
\hline \multirow{2}{*}{$\begin{array}{l}\text { Time } \\
\text { Days }\end{array}$} & \multicolumn{3}{|c|}{$\mathrm{N}+\mathrm{N}$ incorporation/cell (moles) } & \multicolumn{3}{|c|}{ PO4 incorporation/cell (moles) } & \multicolumn{3}{|c|}{ Si incorporation/cell (moles) } \\
\hline & Nitrate & Urea, -Ni & Urea, $+\mathrm{Ni}$ & Nitrate & Urea, -Ni & Urea, $+\mathrm{Ni}$ & Nitrate & Urea, -Ni & Urea, $+\mathrm{Ni}$ \\
\hline 2 & NA & NA & NA & $2.0 \mathrm{E}-14$ & $-4.8 \mathrm{E}-15$ & $-3.2 \mathrm{E}-15$ & $1.0 \mathrm{E}-14$ & 9.7E-15 & $7.7 \mathrm{E}-15$ \\
\hline 4 & $9.8 \mathrm{E}-14$ & NA & NA & $2.5 \mathrm{E}-14$ & $6.2 \mathrm{E}-15$ & $3.8 \mathrm{E}-15$ & $2.4 \mathrm{E}-14$ & $4.5 \mathrm{E}-14$ & $5.1 \mathrm{E}-15$ \\
\hline 6 & $8.4 \mathrm{E}-14$ & NA & NA & $1.7 \mathrm{E}-14$ & $8.9 \mathrm{E}-15$ & $5.8 \mathrm{E}-15$ & $1.5 \mathrm{E}-14$ & $3.9 \mathrm{E}-14$ & $9.2 \mathrm{E}-15$ \\
\hline 9 & $1.4 \mathrm{E}-13$ & NA & NA & $2.1 \mathrm{E}-14$ & 7.7E-15 & $7.5 \mathrm{E}-15$ & $2.2 \mathrm{E}-14$ & $3.9 \mathrm{E}-14$ & $1.3 \mathrm{E}-14$ \\
\hline Time & $\mathrm{C} / \mathrm{N}$ & N, Redfield & 6.6 & $C / P$ & Redfield = & 106 & $\mathrm{~N} / \mathrm{P}$ ratio & & \\
\hline Days & Nitrate & Urea, -Ni & Urea, $+\mathrm{Ni}$ & Nitrate & Urea, -Ni & Urea, $+\mathrm{Ni}$ & Nitrate & & \\
\hline 2 & NA & NA & NA & 64 & NA & NA & NA & & \\
\hline 4 & 13 & NA & NA & 50 & 202 & 325 & 3.9 & & \\
\hline 6 & 15 & NA & NA & 74 & 141 & 216 & 5.0 & & \\
\hline 9 & 9 & NA & NA & 60 & 162 & 167 & 6.6 & & \\
\hline
\end{tabular}

Table 2. Daily cell concentrations and theoretical trace-metal $(\mathrm{M})$ utilization for three culture treatments. Utilization estimated from a typical $15 \mathrm{pgC} \mathrm{cell}^{-1}$ estimated from [33] and verified by [34] assuming typical cell volume of 130 $\mu^{3}$. Metal (M) quota ratios defined as $\mathrm{mol} \mathrm{M} / \mathrm{mol} \mathrm{C}$ are taken from diatom specific equatorial pacific field measurements given in [1]; $\mathrm{Ni} / \mathrm{C}=3.7 \times 10^{-6}, \mathrm{Fe} / \mathrm{C}=12.3 \times 10^{-6}$. Bold and shaded cells denote suspected $\mathrm{Ni}$-limitation assuming $20 \times 10^{-9} \mathrm{M}$ total $\mathrm{Ni}$ and conservatively estimating $50 \%$ bioavailability. Note that predicted limitation around day 4 is consistent with many observations in the physiological data and proteome.

\begin{tabular}{|c|c|c|c|c|c|c|c|c|c|}
\hline \multirow{2}{*}{\begin{tabular}{|l} 
Time \\
Days
\end{tabular}} & \multicolumn{3}{|c|}{ Cell $/ \mathrm{mL}$} & \multicolumn{3}{|c|}{ Theoretical Ni utilization (mole/L) } & \multicolumn{3}{|c|}{ Theoretical Fe utilization (mole/L) } \\
\hline & Nitrate & Urea, -Ni & Urea, $+\mathrm{Ni}$ & Nitrate & Urea, -Ni & Urea, $+\mathrm{Ni}$ & Nitrate & Urea, -Ni & Urea, $+\mathrm{Ni}$ \\
\hline 0 & $3.5 \mathrm{E}+5$ & $4.9 \mathrm{E}+5$ & $3.2 \mathrm{E}+5$ & $1.6 \mathrm{E}-9$ & $2.3 \mathrm{E}-9$ & $1.5 \mathrm{E}-9$ & $2.9 \mathrm{E}-9$ & $4.1 \mathrm{E}-9$ & $2.7 \mathrm{E}-9$ \\
\hline 2 & $9.0 \mathrm{E}+5$ & $1.0 \mathrm{E}+6$ & $1.0 \mathrm{E}+6$ & $4.2 \mathrm{E}-9$ & 4.7E-9 & $4.7 \mathrm{E}-9$ & $7.6 \mathrm{E}-9$ & $8.4 \mathrm{E}-9$ & $8.4 \mathrm{E}-9$ \\
\hline 4 & $2.1 \mathrm{E}+6$ & $2.7 \mathrm{E}+6$ & $2.5 \mathrm{E}+6$ & $9.9 \mathrm{E}-9$ & $1.2 \mathrm{E}-8$ & $1.1 \mathrm{E}-8$ & $1.8 \mathrm{E}-8$ & $2.2 \mathrm{E}-8$ & $2.1 \mathrm{E}-8$ \\
\hline 6 & $3.8 \mathrm{E}+6$ & $3.0 \mathrm{E}+6$ & $3.8 \mathrm{E}+6$ & $1.8 \mathrm{E}-8$ & $1.4 \mathrm{E}-8$ & $1.8 \mathrm{E}-8$ & $3.2 \mathrm{E}-8$ & $2.5 \mathrm{E}-8$ & $3.2 \mathrm{E}-8$ \\
\hline 9 & $3.3 \mathrm{E}+6$ & $3.6 \mathrm{E}+6$ & $3.7 \mathrm{E}+6$ & $1.5 \mathrm{E}-8$ & 1.7E-8 & $1.7 \mathrm{E}-8$ & $2.7 \mathrm{E}-8$ & $3.0 \mathrm{E}-8$ & $3.1 \mathrm{E}-8$ \\
\hline 41 & $9.4 \mathrm{E}+6$ & $2.7 \mathrm{E}+6$ & $3.2 \mathrm{E}+6$ & $4.3 \mathrm{E}-8$ & $1.2 \mathrm{E}-8$ & $1.5 \mathrm{E}-8$ & $7.8 \mathrm{E}-8$ & $2.2 \mathrm{E}-8$ & $2.7 \mathrm{E}-8$ \\
\hline
\end{tabular}




\section{References}

[1] B. S. Twining, S. B. Baines, J. B. Bozard, S. Vogt, E. a. Walker, and D. M. Nelson, "Metal quotas of plankton in the equatorial Pacific Ocean," Deep Sea Research Part II: Topical Studies in Oceanography, vol. 58, no. 3-4, pp. 325-341, Feb. 2011.

[2] P. W. W. Boyd et al., "Mesoscale iron enrichment experiments 1993-2005: Synthesis and future directions," science, vol. 315, no. 5812, p. 612, 2007.

[3] M. Siaut et al., "Molecular toolbox for studying diatom biology in Phaeodactylum tricornutum.," Gene, vol. 406, no. 1-2, pp. 23-35, Dec. 2007.

[4] C. Bowler et al., "The Phaeodactylum genome reveals the evolutionary history of diatom genomes.," Nature, vol. 456, no. 7219, pp. 239-44, Nov. 2008.

[5] A. E. Allen et al., "Evolution and metabolic significance of the urea cycle in photosynthetic diatoms.," Nature, vol. 473, no. 7346, pp. 203-7, May 2011.

[6] R. K. Watt and P. W. Ludden, "Nickel-binding proteins.," Cellular and molecular life sciences : CMLS, vol. 56, no. 7-8, pp. 604-25, Nov. 1999.

[7] N. M. Price and F. M. M. Morel, "Colimitation of phytoplankton nickel and nitrogen," Limnology, vol. 36, no. September, 1991.

[8] M. A. Saito, T. J. Goepfert, and J. T. Ritt, "Some thoughts on the concept of colimitation : Three definitions and the importance of bioavailability," Limnol. Oceanogr., vol. 53, no. 1, pp. 276-290, 2008.

[9] K. W. Bruland, J. R. Donat, and D. A. Hutchins, "Interactive influences of bioactive trace metals on biological production in oceanic waters," Limnology and Oceanography, vol. 36, no. 8, pp. 1555-1577, 1991.

[10] M. A. Saito et al., "Iron conservation by reduction of metalloenzyme inventories in the marine diazotroph Crocosphaera watsonii.," Proceedings of the National Academy of Sciences of the United States of America, vol. 108, no. 6, pp. 2184-9, Feb. 2011.

[11] T. J. Goepfert, "Microalgal Biofuels: Isochrysis sp. and Phaeodactylum tricornutum lipid characterization and physiology studies," Oldenburg University, 2010.

[12] R. R. L. Guillard and J. H. Ryther, "Studies of marine planktonic diatoms: I. cyclotella nana hustedt, and Detonula confervacea (cleve) gran.," Canadian journal of microbiology, vol. 8, no. 2, pp. 229-239, 1962. 
[13] R. R. L. Guillard, "Culture of phytoplankton for feeding marine invertebrates," in Culture of Marine Invertebrate Animals, vol. 0, no. 0, W. L. Smith and M. H. Chanley, Eds. Plenum Press, 1975, pp. 26-60.

[14] X. Lu and H. Zhu, "Tube-gel digestion: a novel proteomic approach for high throughput analysis of membrane proteins.," Molecular \& cellular proteomics : MCP, vol. 4, no. 12, pp. 1948-58, Dec. 2005.

[15] J. Raven, "The iron and molybdenum use efficiencies of plant growth with different energy, carbon and nitrogen sources," New Phytologist, vol. 109, no. 3, pp. 279-287, 1988.

[16] J. Raven, "Functional evolution of photochemical energy transformations in oxygenproducing organisms," Functional Plant Biology, pp. 505-515, 2009.

[17] A. J. Milligan and F. M. M. Morel, "A proton buffering role for silica in diatoms.," Science (New York, N.Y.), vol. 297, no. 5588, pp. 1848-50, Sep. 2002.

[18] A. Marchetti et al., "Comparative metatranscriptomics identifies molecular bases for the physiological responses of phytoplankton to varying iron availability.," Proceedings of the National Academy of Sciences of the United States of America, vol. 109, no. 6, pp. E31725, Feb. 2012.

[19] R. M. Hildebrand, S. Smith, J. Traller, T. Schroeder, T. Frymann, "The Development of Diatoms for Biofuels Production," in The Molecular Life of Diatoms, 2011, p. 36.

[20] J. C. Lewin, R. A. Lewin, and D. E. Philpott, "Observations on Phaeodactylum tricornutum," Journal of General, vol. 18, no. 2, pp. 418-426, 1958.

[21] A. D. Martino, A. Meichenin, J. Shi, K. Pan, and C. Bowler, "Genetic and phenotypic characterization of Phaeodactylum tricornutum (Bacillariophyceae) accessions," Journal of Phycology, vol. 43, no. 5, pp. 992-1009, Oct. 2007.

[22] G. Francius, B. Tesson, E. Dague, V. Martin-Jézéquel, and Y. F. Dufrêne, "Nanostructure and nanomechanics of live Phaeodactylum tricornutum morphotypes.," Environmental microbiology, vol. 10, no. 5, pp. 1344-56, May 2008.

[23] N. Kröger and N. Poulsen, "Diatoms-from cell wall biogenesis to nanotechnology.," Annual review of genetics, vol. 42, pp. 83-107, Jan. 2008.

[24] B. Tesson, R. Shreshta, and M. Hildebrand, "Top Down Control Over Diatoms Cell Wall Morphogenesis: The Role Of The Cytoskeleton," in The Molecular Life of Diatoms, 2011, p. 54. 
[25] G. F. Firme, "Spatial and temporal variability in phytoplankton iron limitation along the California coast and consequences for $\mathrm{Si}, \mathrm{N}$, and C biogeochemistry," Global Biogeochemical Cycles, vol. 17, no. 1, pp. 1-13, 2003.

[26] R. W. Eppley and B. J. Peterson, "Particulate organic matter flux and planktonic new production in the deep ocean," Nature, vol. 282, no. 5740, pp. 677-680, 1979.

[27] R. Dugdale and J. Goering, "Uptake of new and regenerated forms of nitrogen in primary productivity," Limnology and oceanography, vol. 12, no. 2, pp. 196-206, 1967.

[28] J. A. Brandes, A. H. Devol, and C. Deutsch, "New developments in the marine nitrogen cycle.," Chemical reviews, vol. 107, no. 2, pp. 577-89, Feb. 2007.

[29] F. Lipschultz, "A time-series assessment of the nitrogen cycle at BATS," Deep Sea Research Part II: Topical Studies in Oceanography, vol. 48, no. 8-9, pp. 1897-1924, Jan. 2001.

[30] M. G. Klotz and L. Y. Stein, "Nitrifier genomics and evolution of the nitrogen cycle.," FEMS microbiology letters, vol. 278, no. 2, pp. 146-56, Jan. 2008.

[31] C. B. Walker et al., "Nitrosopumilus maritimus genome reveals unique mechanisms for nitrification and autotrophy in globally distributed marine crenarchaea.," Proceedings of the National Academy of Sciences of the United States of America, vol. 107, no. 19, pp. 8818-23, May 2010.

[32] J. P. Zehr and R. M. Kudela, "Nitrogen Cycle of the Open Ocean: From Genes to Ecosystems," Annual Review of Marine Science, vol. 3, no. 1, pp. 197-225, Jan. 2011.

[33] R. R. Strathmann, "Estimating the organic carbon content of phytoplankton from cell volume or plasma volume," Limnology and oceanography, vol. 12, no. 3, pp. 411-418, 1967.

[34] S. Menden-Deuer and E. J. Lessard, "Carbon to volume relationships for dinoflagellates, diatoms, and other protist plankton," Limnology and Oceanography, vol. 45, no. 3, pp. 569-579, 2000. 